\title{
INVESTIGATE THE IMPACT OF A LOW U-VALUE FRAMING CONDITION AND AN INSULATED CURB CONDITION AT CANTILEVERD CONCRETE BALCONY SLABS IN HIGH-RISE MURBS
}

\author{
By \\ Chafik Murad \\ Bachelor Degree of Civil Engineering \\ University of Damascus, SYRIA, 1987
}

\author{
A Major Research Paper \\ presented to Ryerson University \\ in partial fulfillment of the \\ requirements for the degree of \\ Master of Building Science \\ in the Program of \\ Building Science
}

Toronto, Ontario, Canada, 2015

(C) (Chafik Murad) 2015 


\section{AUTHOR'S DECLARATION}

I hereby declare that I am the sole author of this MRP. This is a true copy of the MRP, including any required final revisions.

I authorize Ryerson University to lend this MRP to other institutions or individuals for the purpose of scholarly research.

I further authorize Ryerson University to reproduce this MRP by photocopying or by

other means, in total or in part, at the request of other institutions or individuals for the purpose of scholarly research.

I understand that my MRP may be made electronically available to the public. 


\begin{abstract}
Cantilevered concrete balcony slabs are being investigated in high-rise (MURBs) to control thermal bridging in terms of energy efficiency and thermal comfort where the use of a proprietary thermal break was the prime application as a solution to improving energy efficiency.

This MRP investigated the thermal performance of using a lower U-value framed glazing condition and an insulated curb condition and developed assemblies in scenarios that were simulated in THERM, and focused on the technical performance of thermal comfort benefit of insulated curb condition of $12.7 \mathrm{~mm}$ thick EPS.

Concrete surface temperatures were significantly increased in values from $4.8{ }^{\circ} \mathrm{C}$ to 9.6 ${ }^{\circ} \mathrm{C}$ and from $6.2{ }^{\circ} \mathrm{C}$ to $10.0{ }^{\circ} \mathrm{C}$ above balcony slab and from $6.7^{\circ} \mathrm{C}$ to $10.8^{\circ} \mathrm{C}$ below slab when an insulated curb condition was used in conventional scenarios and in a lower U-value framed condition scenario with no proprietary thermal break added.

U-values are reduced $10 \%$ to $18 \%$ for the upper surface of balcony slab and $4 \%$ reduction of the overall U-values when an insulated curb condition is incorporated.
\end{abstract}




\section{AKNOWLEDGEMENT}

I would like to express my sincere gratitude for my supervisor Professor Hitesh Doshi for his contribution and the guidance he has provided in its successful completion. Thanks also go to Dr. Ramani Ramakrishnan for his input and critical review of this project.

I would also like to thank Dr. Hua Ge for her guidance and support. Her knowledge and involvement in this field have been essential in this topic's development.

Special thanks to Ms. Melissa Morlidge and Mr. Mohammad Hussein for being available when needed and my sincere appreciation to my brother and friend Mr. Peter Irwin for his dedicated support.

Sincere thanks for my peers Mr. Sam Abdalla and Mr. Al Stevenson for their support and indulgence.

Lastly, I dedicate this MRP to my beloved wife, Hamsa, who has been greatest supporter of all; giving me strength and courage to carry on with this research study and to my adorable boys Noor and Yousef who have grown up so fast during the last 4 years since I enrolled in this Building Science Program. 


\section{Table of Contents}

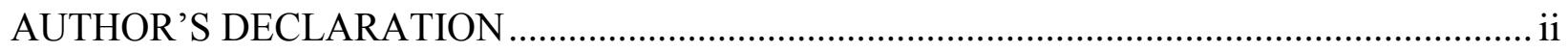

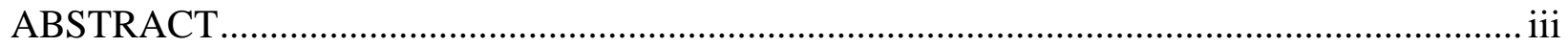

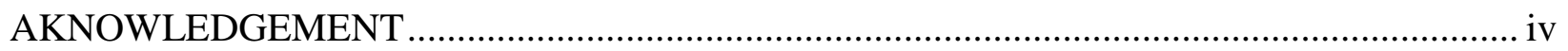

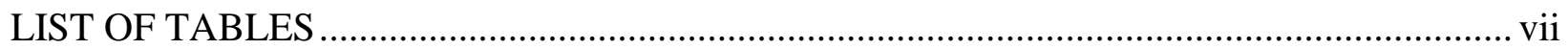

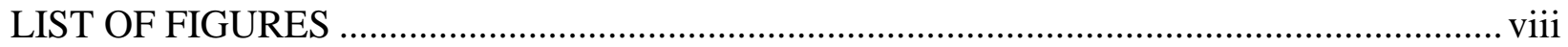

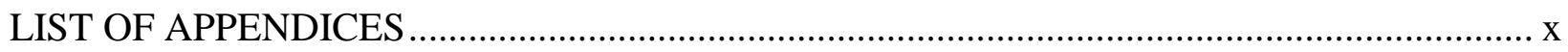

1.0 INTODUCTION

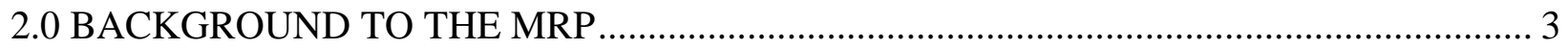

2.1 Issues Related to Concrete Balcony Slab Thermal Bridges .................................................. 4

2.2 Addressing Thermal Bridging at Cantilevered Concrete Balcony Slabs .............................. 7

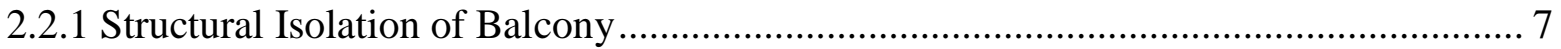

2.2.2 Isolation by Perforation of Slab at Wall Location ...................................................... 10

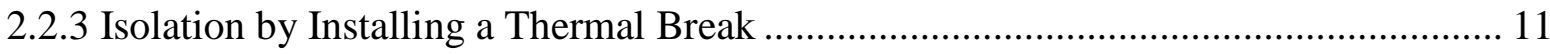

2.2.4 Concluding Remarks on Dealing with Thermal Bridges........................................... 12

2.3 Thermal Bridges and Their Treatment in Analysis .................................................... 13

2.4 Thermal Breaks in Concrete Balcony Thermal Bridges Condition ................................... 15

2.4.1 2D Heat Transfer Study: Impact of Balcony Thermal Bridges on the overall Thermal

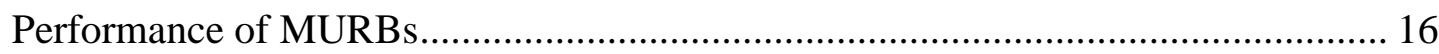

2.4.2 3D Heat Transfer Study: Thermal and whole building Energy Performance of Thermal Break Technology for Concrete Balconies in High-Rise MURBs ............................. 19

2.4.3 3D Heat Transfer Study: The Importance of Slab Edge \& Balcony Thermal Bridges 23

2.4.4 ASHRAE Research Project (RP 1365) .............................................................. 26

2.5 Comparative Analysis of Findings from Key Studies: .................................................... 28

2.5.1 Thermal Transmittance U-values: ............................................................................. 30

2.5.2 Interior Concrete Surface Temperatures: .................................................................. 32

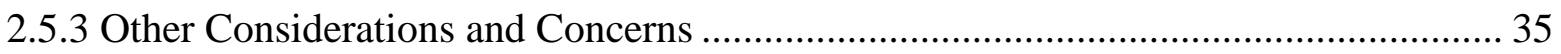

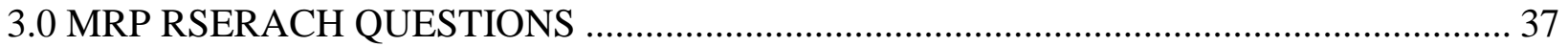

4.0 ANALYSIS AND SIMULATION MODELS ................................................................... 41

4.1 Description of Proposed Construction Assembly ………………………………………...... 42

4.2 Description of Variables.................................................................................................. 45 
4.2.1 Description of KAWNEER Glazing System .................................................... 45

4.2.2 Description of the Insulated Curb Condition Solution ......................................... 48

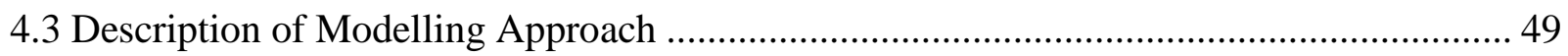

3.3.1 Developing Models for 2D THERM Simulation .............................................. 54

4.3.2 Assumption and Boundary Conditions ................................................................ 55

4.3.3 2D THERM Scenario's Simulation Limitations ....................................................... 56

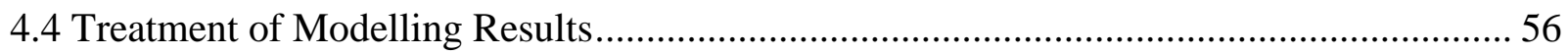

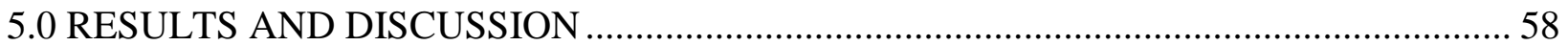

5.1 Interior Surface Temperature Modeling Results ........................................................ 59

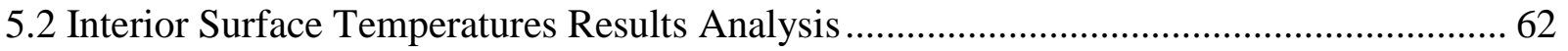

5.3 Condensation Resistance Results Analysis .................................................................. 63

5.4 Interior Concrete Surface Temperatures Results Comparative Analysis ......................... 63

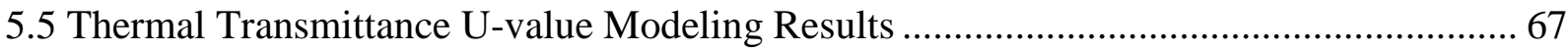

5.6 Thermal Transmittance U-value Modeling Results Analysis ........................................ 69

5.7 Thermal Transmittance U-value Modeling Results Comparative Analysis..................... 69

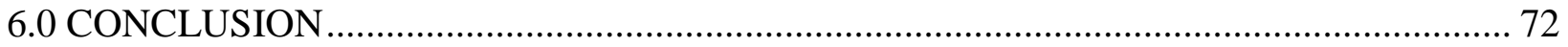

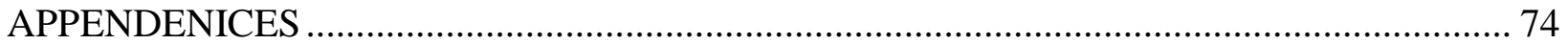

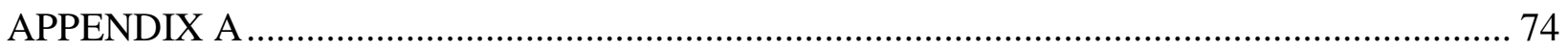

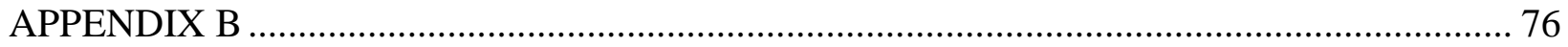

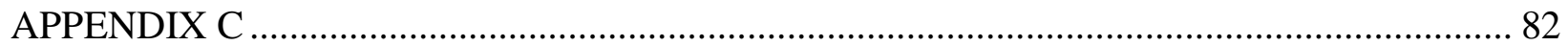

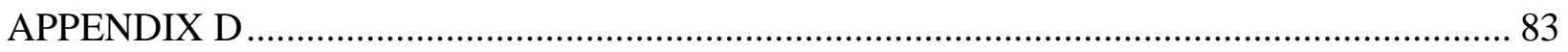

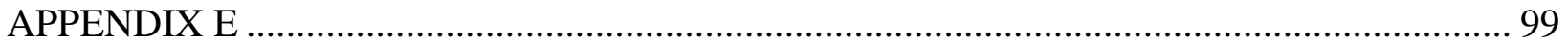

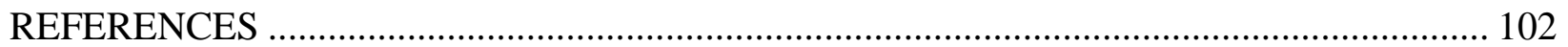




\section{LIST OF TABLES}

Table 1: U-values for each location of Scenarios I, II, III and VI and Overall U-value for each Scenario with and without a Thermal Break added and \% Reduction of U-value [3]17

Table 2: Minimum Concrete Surface Temperature for Scenarios I, II, III, and IV and Thermal

Profile Image Showing the Location of the surface Temperature [3] ...................... 18

Table 3: Overall U-values for Balcony Slab Scenarios with 3D detail showing Each Slab

Scenario and \% Reduction in Heat Flow by using Schöck Solution [4], [25] .......... 20

Table 4: Minimum Concrete Surface Temperature and if it does Meet the Condensation Design

Criteria for each Scenario with Thermal Profile Image showing Location of Surface

Temperature [4], [25]

Table 5: Illustrates Interior Surface Temperature at Concrete and Window -Wall Sliding Door

Sill and Spandrel Panel Head without Thermal Break and at Window-Wall Sliding

Door Sill and Spandrel Panel Head with Thermal Break [8]

Table 6: Thermal Profile for Sliding Door without a Curb and with Insulated Curb Scenarios

with Overall U-values and Temperature Indices [19]

Table 7: Summary of the Key Research Studies in terms of Glazing System used, Method of

Simulation used, Boundary Conditions and Simulated Scenarios

Table 8: Comparison of overall U-values for 3D Study $(\mathrm{MH})$ Conventional and Schöck Solutions and 2D Study (Ge, H, et, all) Configuration I with and without Thermal Break and \% transmittance reduction [14] \& [15]

Table 9: Comparison of Interior Surface Temperature from Key Studies Measured at Glazing

Frame and Concrete Surface Intersection and at Frame Above and Below Balcony

Slab [3], [4], [8] 32

Table 10: Cross Section detail for each Scenario of Group No. 1 with its Associated Label ...... 51

Table 11: Cross Section Detail for each Scenario of Group No. 2 with its Associated Label ..... 53

Table 12: Thermal Profile showing Interior Surface Temperature at Slab/Frame Intersection

Above and Below Slab and Length of Surface when it Reaches $20^{\circ} \mathrm{C}$ for Each

Proposed Modeled Scenario of Group No.1

Table 13: Thermal Profile showing Interior Surface Temperature at Slab/Frame Intersection

Above and Below Slab and Length of Surface when it Reaches $20^{\circ} \mathrm{C}$ for Each

Proposed Modeled Scenario of Group No.2

Table 14: Interior Surface Temperatures at Concrete Slab/Frame above and below Concrete Slab

Table 15: Interior Surface Temperature and Length until $20^{\circ} \mathrm{C}$ for Scenarios from $\mathrm{Ge}, \mathrm{H}$, et, all (2013) [14] and this MRP Study.... 64

Table 16: U-value for components and Overall U-value for of each Scenario from I to VIII (See Appendix D). 68

Table 17: Overall U-values for Scenarios (III and IV) from Ge, H, et, all (2013) and Scenarios (I, III, V, and VIII) from this MRP (Appendix D) 70 


\section{LIST OF FIGURES}

Figure 1: Temperature Decrease below Dewpoint will Result in Condensation and Mould

Growth [12] ............................................................................................. 4

Figure 2: Geometric Thermal Bridge. Left: Isotherm Lines Showing the Outward Flow of Heat at Joint of wall and Ceiling. Right: Infrared Image Showing an Interior View of the Corner at Joint of two Walls and a Ceiling [12]

Figure 3: Structural Thermal Bridge. Above: Isotherm Lines Showing the Flow of Heat Outward from Interior Slab towards Balcony. Below: Infrared Image Scan of a Balcony with Higher Temperatures at the Exterior Slab [12]

Figure 4: Left: Aqua Tower Balconies. Right: Infrared Image Scan Showing Higher

Temperatures at the Concrete Balcony [16].

Figure 5: Left: Typical Schöck Isokorb ${ }^{\circledR}$ Structural Thermal Break. Right: Schöck Isokorb ${ }^{\circledR}$

Structural Thermal Break Installed in Cantilevered Balcony [13] ............................ 7

Figure 6: Structural Isolation of Balcony, Clip-on balconies, French balconies, and Rail

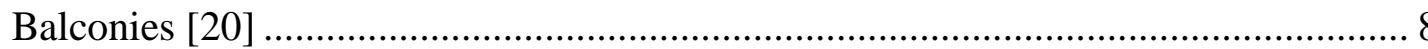

Figure 7: Balcony offset Point Supports Precast Balcony Supported Intermittently to Break

Thermal Bridge [21] ................................................................................. 9

Figure 8: Left: Balcony Precast Unit with Threaded Rods. Right: Stand-alone Supporting

Structure [21] .................................................................................... 9

Figure 9: Thermally Broken and Structurally Separated Balconies from the Building Structure

located in Fergus, Ontario ................................................................................... 10

Figure 10: Perforation of Concrete Balcony Slab: Top Left: Balcony with Perforation Pointed by

Arrows. Top Right: Images shows Reinforcement. Bottom Left: Thermal Profile

shows Minimum Temperature. Bottom Right: shows the Accumulation of Snow ON

Balcony surface and Melting of Snow at non-Perforated Location [13] .................. 11

Figure 11: Installed Schöck Isokorb ${ }^{\circledR}$ Thermal Break in Canadian Building's Balconies [22] .... 12

Figure 12: Illustration of Examples of Clear Field Transmittance Assembly, Linear

Transmittance Detail, and Point Transmittance Detail [23] 13

Figure 13: Determining Linear Transmittance for a Slab, where Heat Loss due to the Slab can be calculated by Subtracting the Heat Loss due to Anomalies from Heat Loss due to

Clear Field [23] ......

Figure 14: Left: Detail No. 26 from ASHRAE RP-1365, a Sliding Door Supported Directly on

Insulated Raised Concrete Curb. Right: Detail No. 27 From ASHRAE RP-1365, a

Sliding Door Supported Directly on Concrete Balcony Slab [19].......................... 26

Figure 15: Preliminary Plan View and Cross-Section Profile showing the Proposed Model of

$12.5 \mathrm{~mm}$ to $25.4 \mathrm{~mm}$ Depression (Curb) in the Concrete Slab and a $25.4 \mathrm{~mm}$ thick

EPS rigid insulation inserted beneath a Lower U-value Framed Sliding

Door/Spandrel panel Frame 39 
Figure 16: Cross Section of Proposed Model of an Insulated Curb Condition with a KAWNEER Sliding Door Sill Showing a $12.7 \mathrm{~mm}$ depression in the Concrete and a $25.4 \mathrm{~mm}$ EPS beneath the Sliding Door Sill Frame. 42

Figure 17: Cross Section of Proposed Model showing a Lower U-value Framed glazing system (Sliding door above/Spandrel Panel below), $12.7 \mathrm{~mm}$ Depression and $25.4 \mathrm{~mm}$ thick EPS insulation and Interior/Exterior Concrete Cover thickness.... 43

Figure 18: Right: Showing Lower U-value Sliding Door Sill (above balcony slab) and $12.7 \mathrm{~mm}$ depression and $25.4 \mathrm{~mm}$ thick EPS insulation. Left: Showing Lower U-value Spandrel Panel Sill (above Balcony Slab) and $12.7 \mathrm{~mm}$ depression and $25.4 \mathrm{~mm}$ thick EPS insulation. Both Cross Sections are showing Spandrel Panel Head and Sliding Door Head Blow Balcony Slab.

Figure 19: Plan view of Floor-to-Ceiling Assembly glazing Window-Wall Glazing System using a Spandrel Panel of KAWNEER 1600UT System ${ }^{\mathrm{TM}} 2$ curtain wall and KAWNEER $\mathrm{AA}^{\mathrm{TM}} 3900$ Thermal Sliding Door [29], [30] ................................................... 46

Figure 20: KAWNEER 1600 UT System $^{\mathrm{TM}} 2$ Spandrel Head and Sill Section Details [29] ........ 47 Figure 21: KAWNEER AA ${ }^{\mathrm{TM}_{3}} 300$ Sliding Door Head and Sill at Sliding Panel Section Details [30].

Figure 22: Insulated Curb Condition Solution showing $12.7 \mathrm{~mm}$ Depression in Concrete Slab and $25.4 \mathrm{~mm}$ thick EPS Rigid Insulation.

Figure 23: Concrete Balcony Slab Interior Boundaries Diagram showing Component U1, U2, U3, and U4 used in THERM to Calculate U-values and Overall U-values for Modeled Scenarios I to VIII. 


\section{LIST OF APPENDICES}

APPENDIX A: 2D THERM Study, Ge, $\mathrm{H}$ et al (2013)

APPENDIX B: 3D Heat Transfer Study, Roppel, P. et al (2013)

APPENDIX C: 3D Heat Transfer Study, RDH Building Engineering Limited (2013)

APPENDIX D: MRP Report

- Cantilevered Concrete Balcony Slab complete cross sections for Scenarios No. 1 to 8

- 2DTHERM (Isotherm) and thermal profile of each scenario from 1 to 8

- 2D THERM Modeled Scenarios No. I to VIII

- U-value and Overall U-values calculated for scenarios I to VIII

\section{APPENDIX E:}

Schöck Isokorb CM20 Thermal Break Insulating Element 


\subsection{INTODUCTION}

Thermal bridging of concrete floor slabs in Ontario is not a new situation. Many older buildings constructed prior to 1980's have exposed concrete slabs at the floor level. In buildings constructed in later years, this type of thermal bridge has been avoided by the use of curtain wall or a window-wall type of construction. However thermal bridging at balconies could not be avoided by this approach. The simplest architectural solution to avoid thermal bridges at balconies would be to enclose them; however, unenclosed balconies still present themselves as very desirable feature by potential purchasers and not readily dispensable by the developers.

It is possible that the growing need for energy efficiency in buildings will one day require the design and construction community to examine the role of balconies in energy efficiency as well as the architectural expression of the building. Currently, however, the community is focused on improving thermal efficiency by means of providing various types of thermal breaks in the protruding concrete slab at the balcony. A thermal break is an element of low thermal conductivity placed in an assembly to reduce or prevent the flow of thermal energy between conductive materials [2]. This has given rise to proprietary and non-proprietary thermal break technologies. Studies have demonstrated that using a thermal break improves the energy performance of the buildings and at the same time make a dent on comfort and performance related issues.

The focus of current practices has been on the introduction of thermal breaks in the concrete balcony slab and its effect on energy consumption [3], [4].These same studies have shown relatively less interest to study the impact of thermal comfort and condensation potential related improvements. The thermal performance of the window-wall assembly was largely 
unaffected by the thermal break introduction but has direct impact on performance related issues such as condensation potential and thermal comfort [4].

This MRP report presents the results of work undertaken to study the thermal performance of concrete balcony thermal bridge conditions with modifications to the thermal performance of adjacent wall assemblies. It's focus has been to study the impact of improvements in the thermal characteristics of the frame of the envelope at the thermal bridge location. The MURB industry may not readily accept a higher level of envelope with its additional costs as an alternative; however, in this study, it has been concluded that this issue warrants consideration.

The focus of this research project is to study the thermal performance of lower U-value envelope conditions at the thermal bridge location. Cost issues are important but are not part of the scope of this work. As part of the study the construction assembly of the proposed alternatives were developed. They were then modeled in THERM. The results of THERM for the alternative construction assemblies were then compared to the results from previous studies particularly as they related to the comfort and condensation potential.

This report provides an overview of previous studies, the method used for this study, the results and their analysis and thoughts for further work. 


\subsection{BACKGROUND TO THE MRP}

The vast majority of high-rise Multi-Unit Residential Buildings (MURBs) have exposed concrete balcony slabs. It has been recognized that they have a significant impact on the overall building's thermal performance because of heat loss due to thermal bridges, specifically during heating season and in cold weather [5]. In Canada, for many years, there were few attempts to address cantilevered concrete balcony slab thermal bridges through construction solution approaches. In Europe, on the other hand, the construction industry has embraced thermal break approaches for many years [6]. Inclusion of thermal breaks in concrete construction has become a normal practice in the all types of buildings and specifically MURBs in Europe.

Recently, in North America there have been several studies that have investigated the use of thermal breaks in cantilevered concrete balcony slab using European technology. These studies have applied the thermal break to typical construction assemblies that are commonly found in Canadian MURBs. They have developed simulation models and used 2-Dimensional (2D) or 3-Dimensional (3D) heat transfer thermal simulation approaches. They have studied the concrete balcony slab condition with and without the addition of thermal break. It has been evident through the various studies that there were a number of key factors and variables that contributed to the overall improvement of thermal performance when a thermal break was used in cantilevered concrete balcony slab [3], [4], [7], [8], [9], and [10].

This section provides an overview of the various issues related to thermal bridging, the approaches taken to deal with it and goes into more details about the Canadian studies dealing with the use of European technology. 


\subsection{Issues Related to Concrete Balcony Slab Thermal Bridges}

Cold floor at cantilevered concrete balcony slabs manifest themselves into thermal discomfort and surface condensation. During colder weather, the increase in heat loss decreases the inner concrete surface temperature. Temperature decrease to below the dewpoint impacts the thermal comfort, increases potential for condensation and related moisture damage and can also result in unanticipated structural stresses [11]. [Figure 1] illustrates condensation and mould growth when surface as a result of temperature falls below the dewpoint.
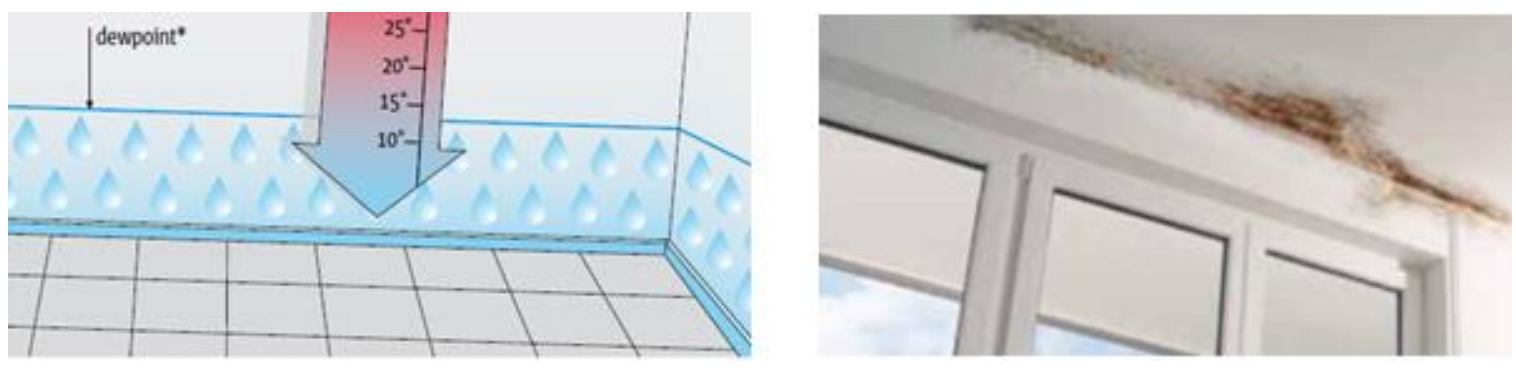

Figure 1: Temperature Decrease below Dewpoint will Result in Condensation and Mould Growth [12]

There are at least two types of thermal bridges typically encountered in MURB. They have been categorized as either geometric and structural or material. Purely geometric thermal bridges [Figure 2] is a result of the three dimensional character of a building [3]. Angles and corners, inner and outer exposure around windows and other typical condition found at the edges and top of a wall are some examples of this condition.
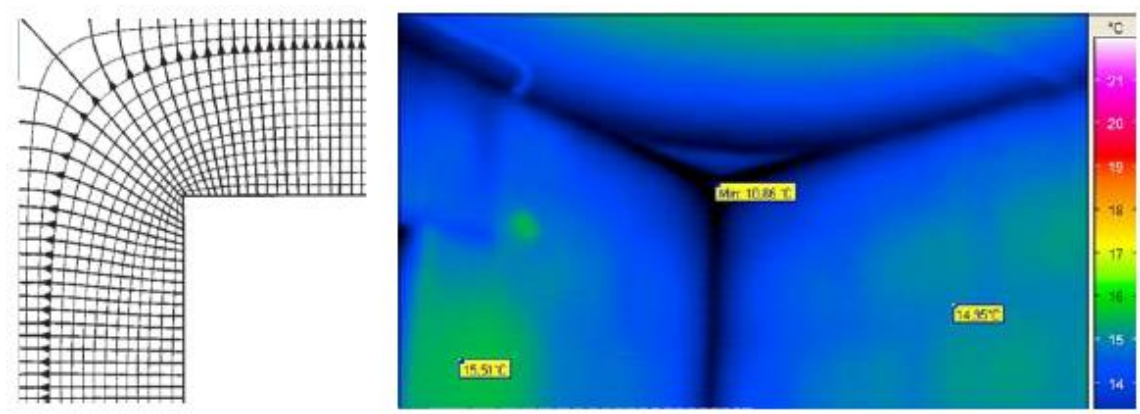

Figure 2: Geometric Thermal Bridge. Left: Isotherm Lines Showing the Outward Flow of Heat at Joint of wall and Ceiling. Right: Infrared Image Showing an Interior View of the Corner at Joint of two Walls and a Ceiling [12] 
A Structural thermal bridge [Figure 3] typically results from the need to accommodate load bearing elements. In case of a balcony, the cantilever moment cannot be balanced without continuity with the concrete floor inside [3]. Structural connections often lead to high heat loss and low surface temperature in the adjoining conditioned spaces [12].

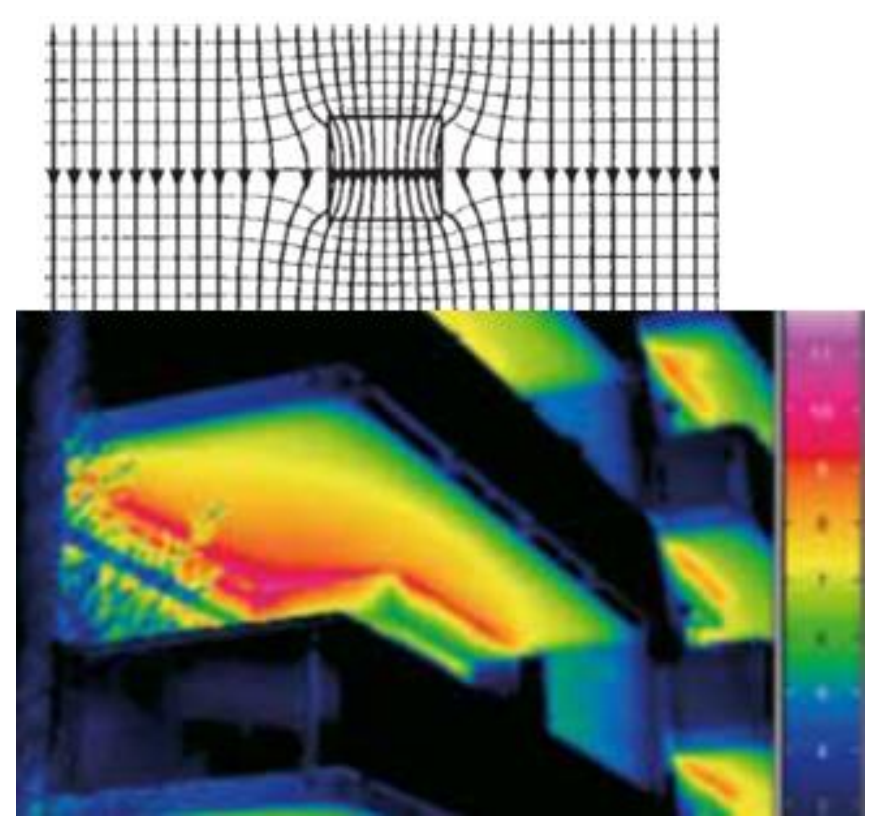

Figure 3: Structural Thermal Bridge. Above: Isotherm Lines Showing the Flow of Heat Outward from Interior Slab towards Balcony. Below: Infrared Image Scan of a Balcony with Higher Temperatures at the Exterior Slab [12]

Relationship between slabs and balconies are a combination of geometric "effect of cooling fins" and structural or material thermal bridges [14]. Fin is a surface that extends from an object to increase the rate of heat transfer to or from the environment by increasing convection [15]. In non-insulated cantilevered balcony slab connections, the interaction of the geometric thermal bridge effect of the balcony slab and the material thermal bridge "reinforced concrete slab" protruding through the insulated facade, results in an increased flow of heat.

As an example, a giant tower (Aqua) of an 82-storey concrete and glass in the heart of Chicago, USA with un-insulated cantilevered balcony slabs [16]. Figure 4 illustrates an infrared image of that tower where the color red is predominating as a clear indication of major heat loss. 

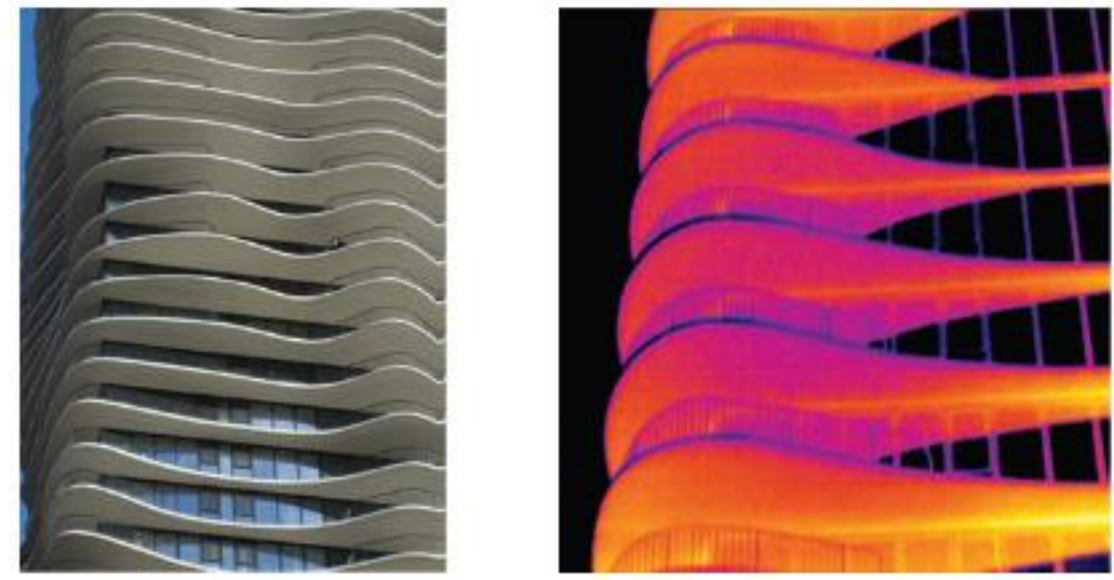

Figure 4: Left: Aqua Tower Balconies. Right: Infrared Image Scan Showing Higher Temperatures at the Concrete Balcony [16].

That tower captured the attention of many engineers and architects who wondered if it could have been constructed differently without the thermal bridges and without changing the appearance [16]. It was reported that the tower was meant to heat the outdoors. This could have been mitigated by using thermal breaks.

With the increasing number of high-rise condominium residential buildings in North America and specifically in Toronto where there are currently 130 high-rise construction projects underway [17], the un-insulated cantilevered concrete balcony slabs appears to be ignored from a thermal bridging point of view by many designers. Instead, the architectural look of protruding balconies is common and has a negligible impact on reducing the overall building thermal performance.

Quite the opposite, for more than 20 years, European countries and most specifically Germany, has played a major role in developing structural thermal break insulating technology. One such technology called Schöck Isokorb ${ }^{\circledR}[18]$ has over 10 million units installed since its production [Figure 4]. That technology has been recently introduced to Canada, and a handful of high-rise MURBs have used this product in concrete balcony slabs. 

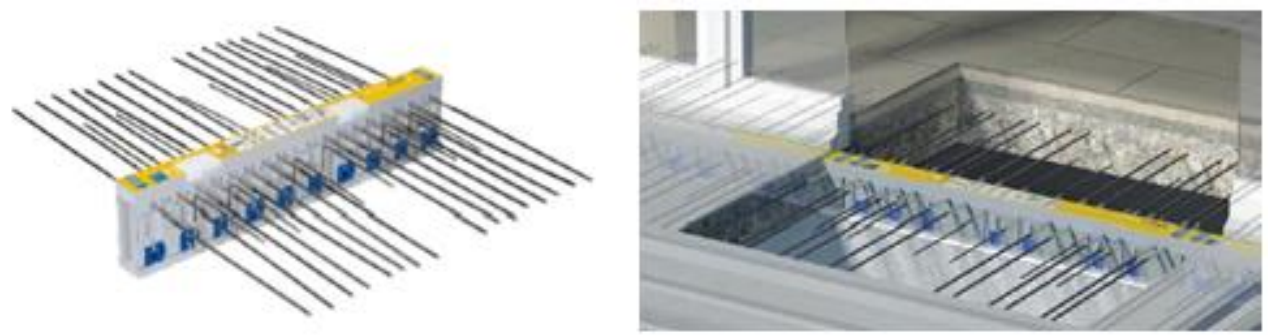

Figure 5: Left: Typical Schöck Isokorb ${ }^{\circledR}$ Structural Thermal Break. Right: Schöck Isokorb ${ }^{\circledR}$ Structural Thermal Break Installed in Cantilevered Balcony [13]

In the last few years, awareness of thermal bridging and its consequences in North America and specifically in Canada has risen to a level where many architects and engineers have started to explore and investigate it further for potential use on projects. It would appear that the implies for this came about from ASHRAE Research Project 1365 [19] which provided thermal performance data for 40 common building envelope construction details for mid and high-rise buildings including cantilevered concrete balcony slabs and slab edges. This ASHRAE study came first then followed by three other studies in Canada which specifically focused on cantilevered concrete balcony slab and use of thermal break.

\subsection{Addressing Thermal Bridging at Cantilevered Concrete Balcony Slabs}

Unlike the predominant development and use of a thermal break technology in Europe there was nothing that was developed locally in North America. As the requirements for energy efficiency become more stringent in North America it gave rise to an interest in heat loss at projecting balconies. The following section explores some of the approaches that have been considered in North America to reduce heat loss at balconies.

\subsubsection{Structural Isolation of Balcony}

One approach that has been used is to structurally isolate the balcony. This has been predominantly seen low to mid-rise buildings. This is a structural response to the concern of 
thermal bridging. From considerations of energy and thermal comfort this approach can provide the most efficient solution. However, this approach results in significant changes to design and construction practises and resulting cost increases.

Figure 6 illustrates some of these isolation technologies including more elaborate structural schemes like clip-on balconies, French balconies and rail balconies [20]. There appears to be much reluctance from structural engineers to design in this manner due to durability issues.
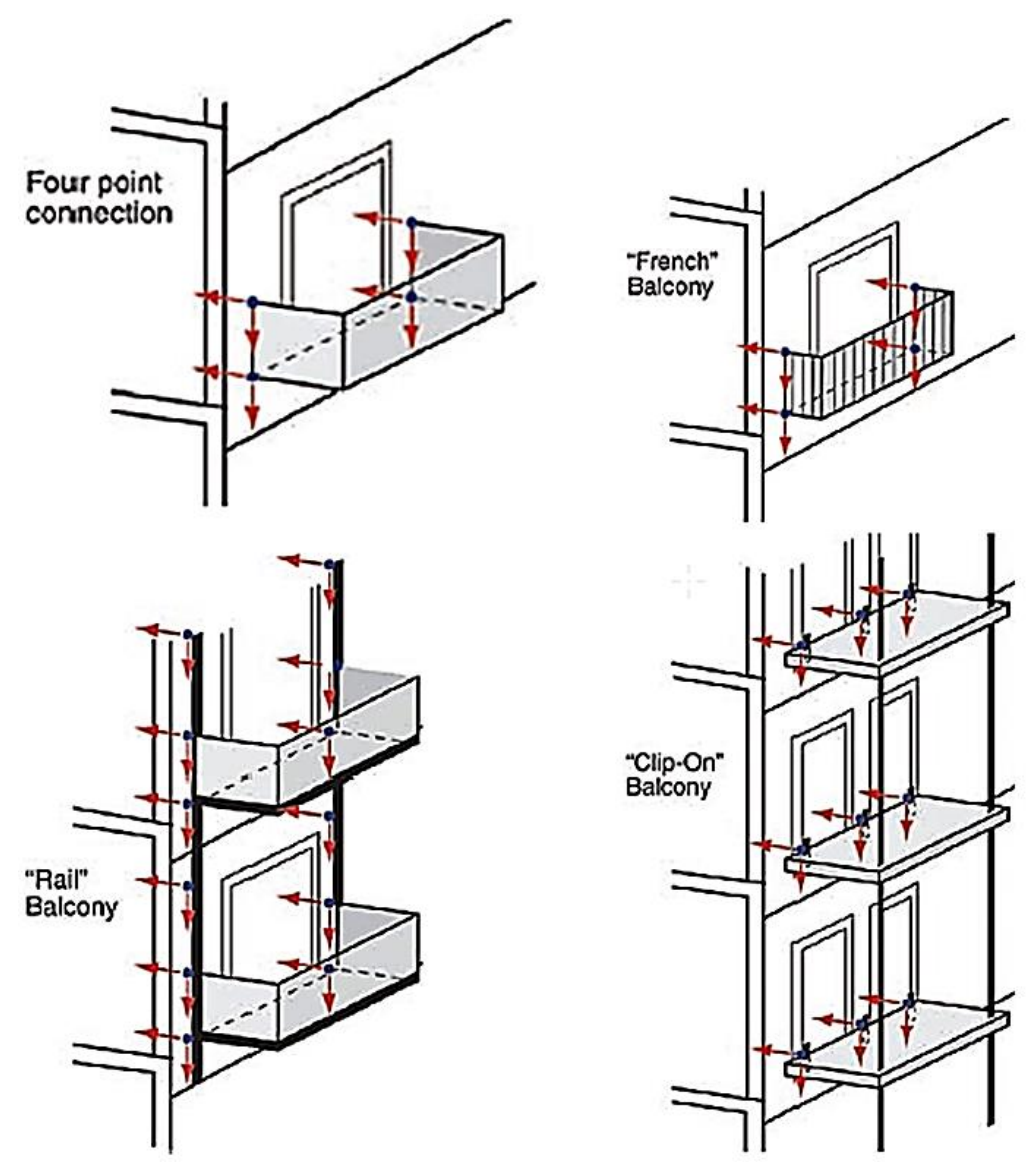

Figure 6: Structural Isolation of Balcony, Clip-on balconies, French balconies, and Rail Balconies [20]

A few construction methods [21] were proposed on how to build a structural slab cantilevered past the primary structural frame of a building projected outward by considering offset point supports rather than cantilevering the slab [Figure 7]. Technique works well with an articulated façade with pivoting parts where the balcony can be a precast unit that is gapped from 
the wall allowing exterior insulation to run past the balcony between the balcony and the structural frame of the building [21].
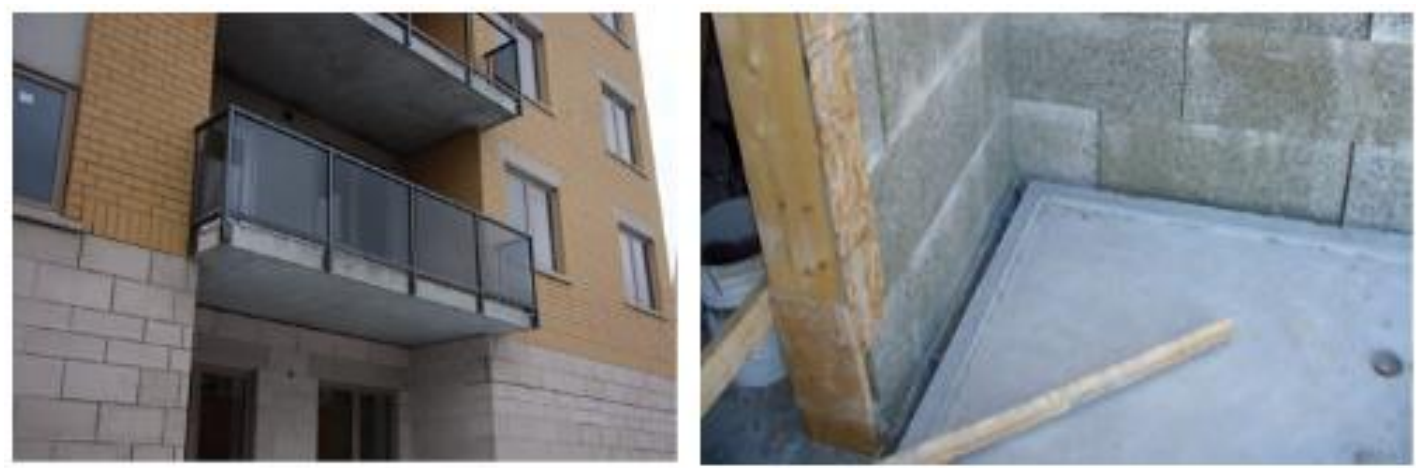

Figure 7: Balcony offset Point Supports Precast Balcony Supported Intermittently to Break Thermal Bridge [21]

If there is no articulated façade available, then offset point supports can be used to hang the balcony precast units with threaded rods tied back to the columns of the structural frame [21]. Another approach is to use a stand-alone supporting structure that is tied back to the structure at top and resting at grade at it base [Figure 8].
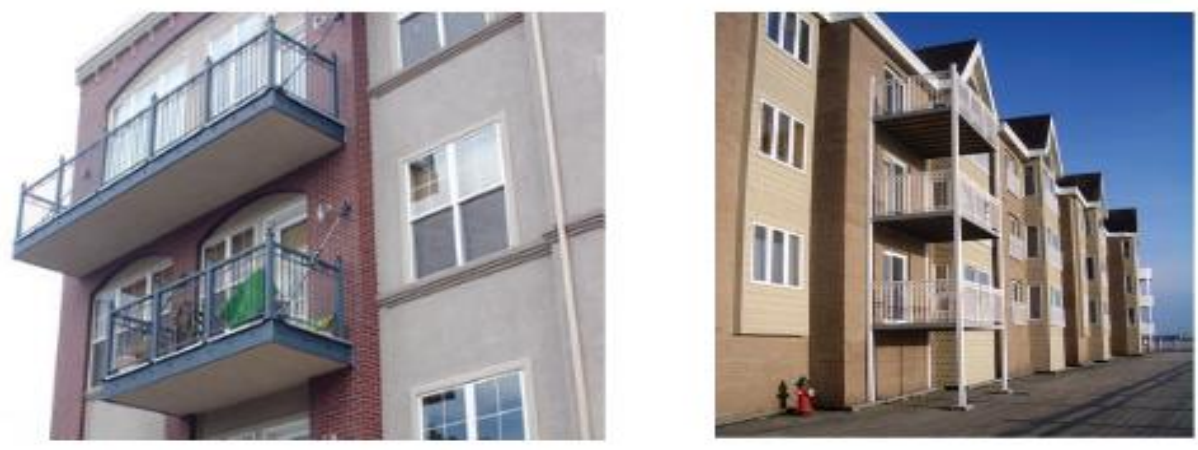

Figure 8: Left: Balcony Precast Unit with Threaded Rods. Right: Stand-alone Supporting Structure [21]

A low-rise residential building called "Pier Point Place Condo" located in Fergus,

Ontario was recently observed with exterior columns. Balconies to this project were structurally isolated from the primary building structural frame and the exterior wall insulation was left to be continuous within the wall assembly [Figure 9]. The balcony slabs for the $2^{\text {nd }}$ and higher floors 
are made of wood frame and the $1^{\text {st }}$ floor slab is constructed of cast-in-place concrete. None of these balconies are cantilevered as they are supported at the edges by steel columns.
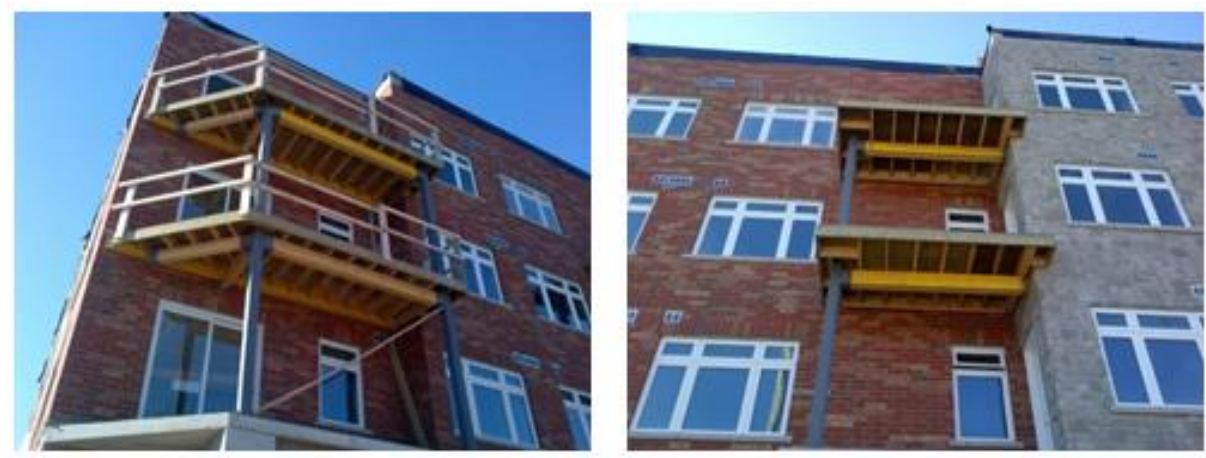

Figure 9: Thermally Broken and Structurally Separated Balconies from the Building Structure located in Fergus, Ontario

The writer was advised by the developer that there were no reports or claims of cold surfaces and/or condensation or mould growth adjacent to balcony perimeters during the past winter. This approach comes with extra cost to support the balconies from exterior; however, as advised by the developer, the extra cost could recoup in a short term from savings on energy bills during winter season.

\subsubsection{Isolation by Perforation of Slab at Wall Location}

The method of "perforation" is illustrated in Figure 10. The main objective of this method is to control the inner surface temperature of a structure and keep it within the minimum requirements to avoid mould growth and surface condensation [13]. This method involves special reinforcement details during the process of "perforation". Structurally this method works like a framed concrete system with projecting beams supporting a floor. The space between the beams provides the thermal break thereby reducing the thermal bridging to areas corresponding to the projecting beams. 

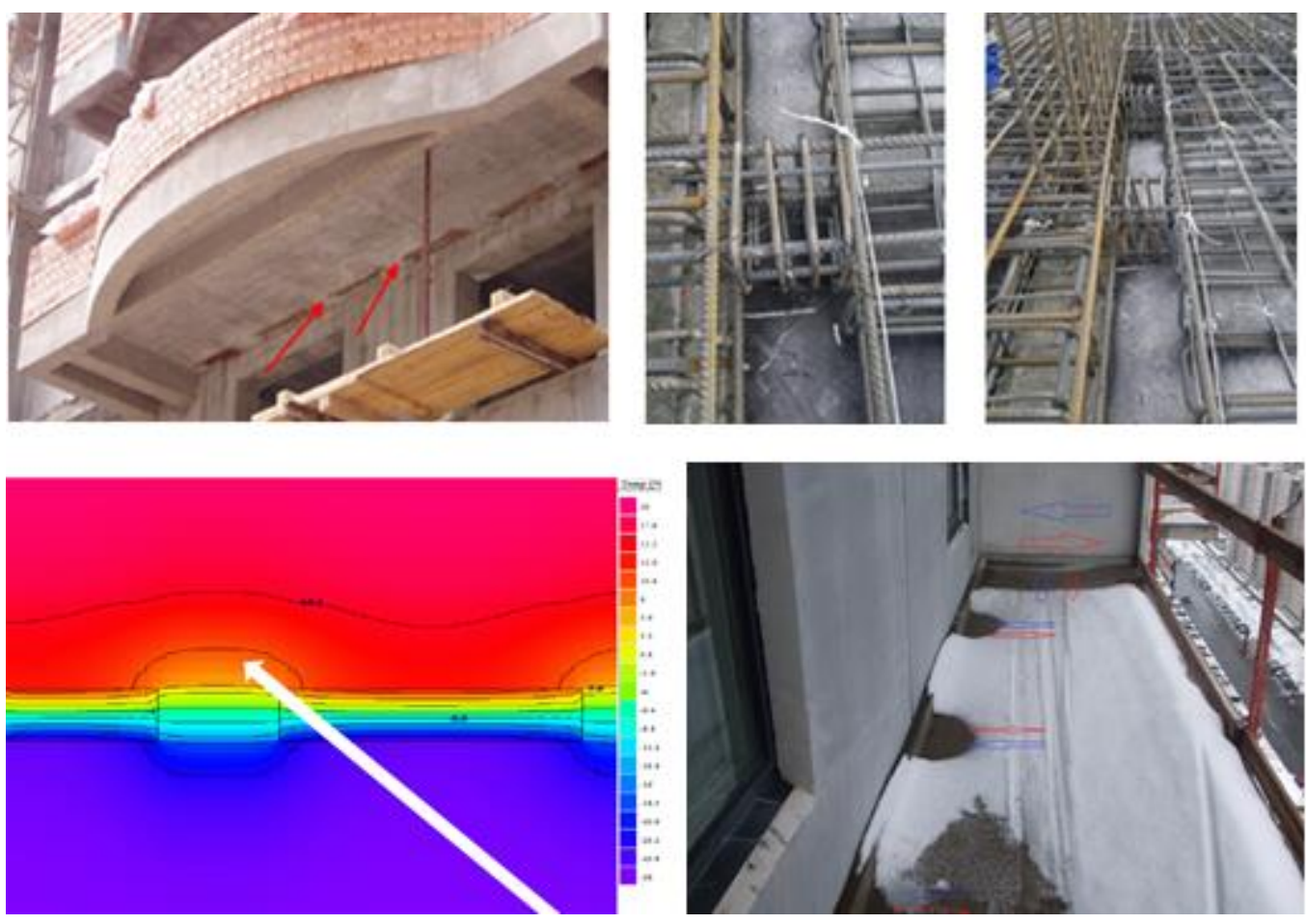

Figure 10: Perforation of Concrete Balcony Slab: Top Left: Balcony with Perforation Pointed by Arrows. Top Right: Images shows Reinforcement. Bottom Left: Thermal Profile shows Minimum Temperature. Bottom Right: shows the Accumulation of Snow ON Balcony surface and Melting of Snow at non-Perforated Location [13]

A thermal profile and an arrow are pointing at the area that is perforated. The Perforation process aims to minimize the heat loss and keep the interior concrete surface temperature warm enough to avoid condensation and mould growth. This method can be implemented in high-rise MURBs; however, rebar reinforcement placement requires intensive labour may not be provided by builder.

\subsubsection{Isolation by Installing a Thermal Break}

A proprietary structural thermal break insulating element by Schöck Isokorb ${ }^{\circledR}[18]$ appears to be the only option being considered by the construction industry. Currently this technology is relatively new to the Canadian market. There are a few projects with this thermal break insulating element installed in the cantilevered balcony slab e.g. a 30 storey high-rise residential building called Ventus at Metrogate, in Scarborough, Ontario and a 6 storey MURB 
called Beaver Barracks in Ottawa, Ontario [22]. Figure 11 shows Schöck Isokorb ${ }^{\circledR}$ thermal break previously shown in Figure 5 installed in cantilevered balcony slab in Canada.
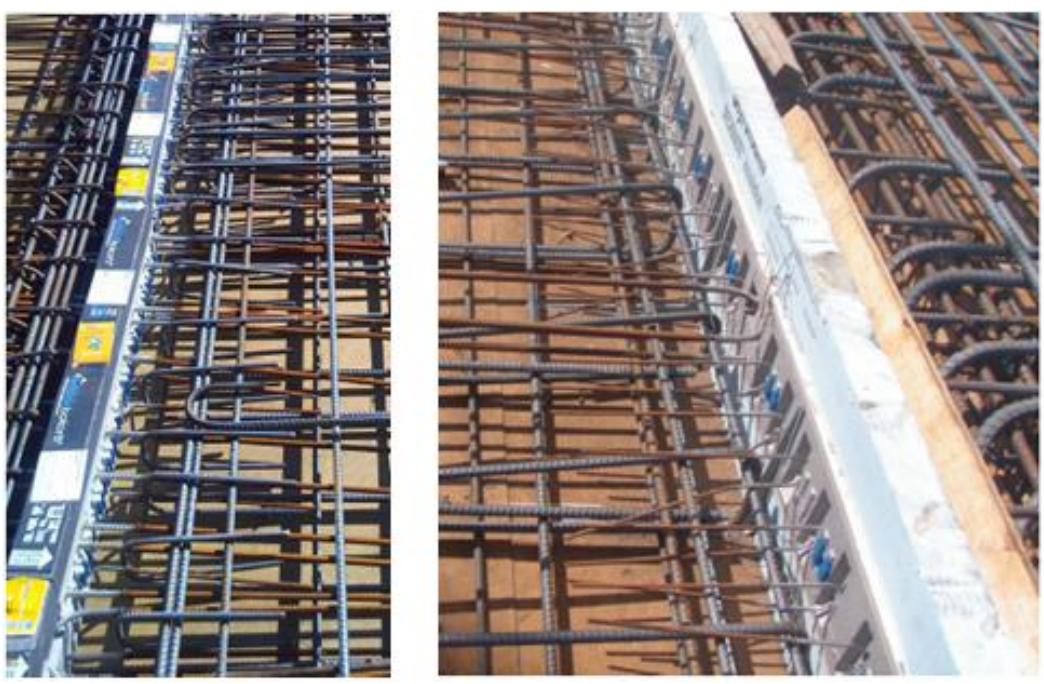

Figure 11: Installed Schöck Isokorb ${ }^{\circledR}$ Thermal Break in Canadian Building's Balconies [22]

The proponents of this technology claim that it is light and easily handled by one person;

drop-in fast installation is averaging less than five minutes per unit and it reduces thermal conductivity by $50 \%$ [18]. It has been shown that the increase in installed cost of this technology is low.

\subsubsection{Concluding Remarks on Dealing with Thermal Bridges}

It appears that increasing requirements for energy efficiency are finally catching on to desire to have a balcony and its associated heat loss when acting as a thermal bridge.

There is reluctance from the local builder community to changes in construction practices. Several approaches have been used in building structural isolation and structural modification. Most buildings still continue to be built without any consideration to thermal bridges.

The European technology seems to provide the most promise and the next few sections deals with the approaches and reports that have studied the benefits of this technology. 


\subsection{Thermal Bridges and Their Treatment in Analysis}

Heat flow through thermal bridging increases the energy use in buildings. Researchers have used either 2D simulation such as THERM and/or 3D simulation software such as $\mathrm{Nx}$ from Siemens to show thermal performance of thermal bridges. Many assumptions have been introduced to validate models. The choice of the mesh, time step and time resolution is crucial and must be decided and chosen in accordance with mesh density. Poor choice of meshing and time step in the software may result in an unreliable solution [5].

The 2D assumption of a "flat" surface does not apply when looking in detail at the heat transfer through building facades, which is why Control Volume Method (CVM) or Finite Element Method (FEM) is used. These details are composed of rectangular shaped material volumes; CVM may include a maximum of eight materials in 3D simulation approach. In 2D simulation approach that maximum is only four.

In practice, when evaluating thermal bridges during a design stage, using CVM or FEM is neither practical nor economical [5]. Therefore, as far as additional heat loss is concerned, thermal bridges are calculated by a linear transmittance psi $(\Psi=\mathrm{W} / \mathrm{m} . \mathrm{K})$ or a point thermal transmittance $(\chi=\mathrm{W} / \mathrm{K})$ [Figure 12].

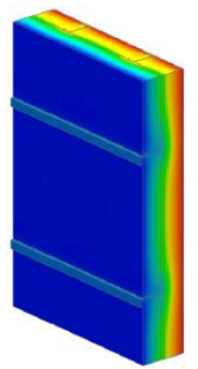

Clear Field $U_{o}$

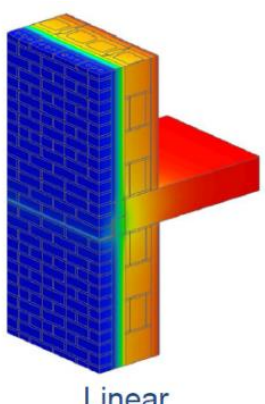

inear $\Psi$

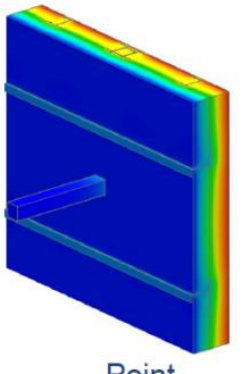

Point

$\chi$

Figure 12: Illustration of Examples of Clear Field Transmittance Assembly, Linear Transmittance Detail, and Point Transmittance Detail [23] 
Once the linear and the point thermal transmittance are known, then the average whole wall thermal transmittance of a flat part containing thermal bridges is calculated as:

$U=U o+\frac{\sum_{i=1}^{n}(\Psi i L i)+\sum_{j=1}^{m} \chi j}{A}$ [5]. Where $U o$ is the thermal transmittance of the base part or clear field, $A$ its surface, $n$ the number of linear thermal bridges, $L_{i}$ their length and $m$ the number of local or point thermal bridges.

When dealing with 3D heat flow paths, standard practice in North America to account for thermal bridging is by using typical methods such as the area-weighted average of U-values. This method considers all thermal bridge effects as one, assuming no interaction between materials and amalgamates them as one component.

This is done by weighting the heat flow through the material by their area or over the "area of influence" or "effective length" of the thermal bridge. This is the most difficult part, as assigning "effective lengths" or "area of influence" to complex 3D heat flow paths can be subjective and complex [19].

Using such method has led to great uncertainty about the thermal performance of the building envelope [19], [23], and [24]. This uncertainty can lead to inadequate design of HVAC systems which compromise occupant thermal comfort [19], [23].

ASHRAE Research Project 1365 (RP-1365) [19] was initiated and introduced in 2011 to address the concerns with the area weighted approach and the linear/point approach. Instead of trying to find "areas of influence", this method takes the "additional" heat flow due to a thermal bridge and assigns it to simple mathematical concept of lines or points [23]. The additional heat flow caused by a thermal bridge is the difference between the heat flow from an assembly with and without the detail present. This method simplifies calculations because the areas of the thermal bridges are not required [23]. 

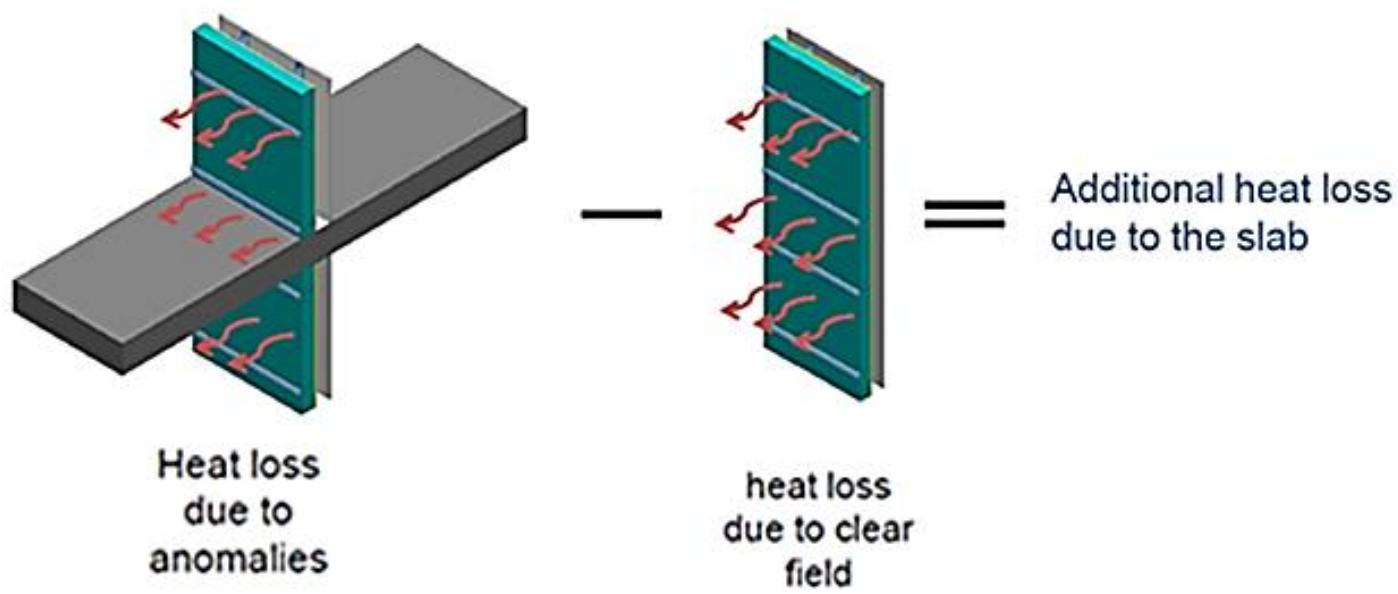

Figure 13: Determining Linear Transmittance for a Slab, where Heat Loss due to the Slab can be calculated by Subtracting the Heat Loss due to Anomalies from Heat Loss due to Clear Field [23]

Figure 13 shows how to calculate the additional heat loss due to an exposed concrete

slab. The additional heat loss can be calculated by subtracting the total heat loss of the assembly (half way above and below the slab) from the heat loss of clear field (where there is no slab)

[23]. The ASHRAE report provides values for heat loss due to anomalies for various standard conditions.

\subsection{Thermal Breaks in Concrete Balcony Thermal Bridges Condition}

Right after the issuance of ASHRAE RP-1365 Report, North American researchers and engineering firms have felt challenged and have started investigating the impact of thermal bridges on cantilevered concrete balcony slabs and investigating the usage of proprietary structural thermal break insulating element on overall thermal performance of a building. In recent years, three research publications have specifically investigated thermal bridges and usage of proprietary thermal break in most common cantilevered concrete balcony slabs assembly details in high-rise MURBs. These research publications will be further explored in these following sections. 


\subsubsection{D Heat Transfer Study: Impact of Balcony Thermal Bridges on the overall}

\section{Thermal Performance of MURBs}

In a study by $\mathrm{Ge}, \mathrm{H}$ et al (2013) [3], the main objective was to investigate the significance of thermal bridges, specifically concrete balcony slabs, on overall energy performance of the building when using a thermal break technology [3].

Of particular interest to this study are the results of U-values and concrete surface temperatures in the assemblies that were examined.

This study selected a building 26 storey high with mixed-use residential and commercial sections. The residential section has a fully glazed façade using a standard window-wall assembly. The energy performance of the building with none-thermally broken balcony is compared with that using a thermal break. Additional conditions have been modeled using thermally improved adjoining walls. A proprietary thermal break was used in the study.

The exterior boundary conditions were specified as $\left(-18^{\circ} \mathrm{C}\right)$ and $\left(h o=30 \mathrm{~W} / \mathrm{m}^{2} . \mathrm{K}\right)$ and the interior boundary conditions were specified as $\left(22^{\circ} \mathrm{C}\right)$ and $\left(h i=8.3 \mathrm{~W} / \mathrm{m}^{2} . \mathrm{K}\right)$ per CSA A440.2 [22]. The vertical face of the slab on the interior was specified as an adiabatic surface.

Scenarios representing the most common construction assembly in high-rise MURBs have been established; 2D THERM models were generated for each scenario and modeled with and without thermal break in order to determine their overall thermal transmittance [3] (See Appendix A).

Of particular interest to this study are scenarios I, II, III and IV. Scenario I is as-designed section with glass sliding door above balcony slab, and a spandrel panel below balcony slab. Scenario II is as-designed section with spandrel panel above and below the balcony slab. Scenario III is a hypothetical section with generic solid material to imitate a clear double glazing 
unit (DGU) above (RSI 0.35) and spandrel panel (RSI 2.50) below balcony slab. Scenario IV is a hypothetical section with generic solid material to imitate a clear DGU with Argon gas filling and low-e-coating above (RSI 0.73) and a spandrel panel (RSI 2.50) below the balcony slab [3]

Table 1: U-values for each location of Scenarios I, II, III and VI and Overall U-value for each Scenario with and without a Thermal Break added and \% Reduction of U-value [3]

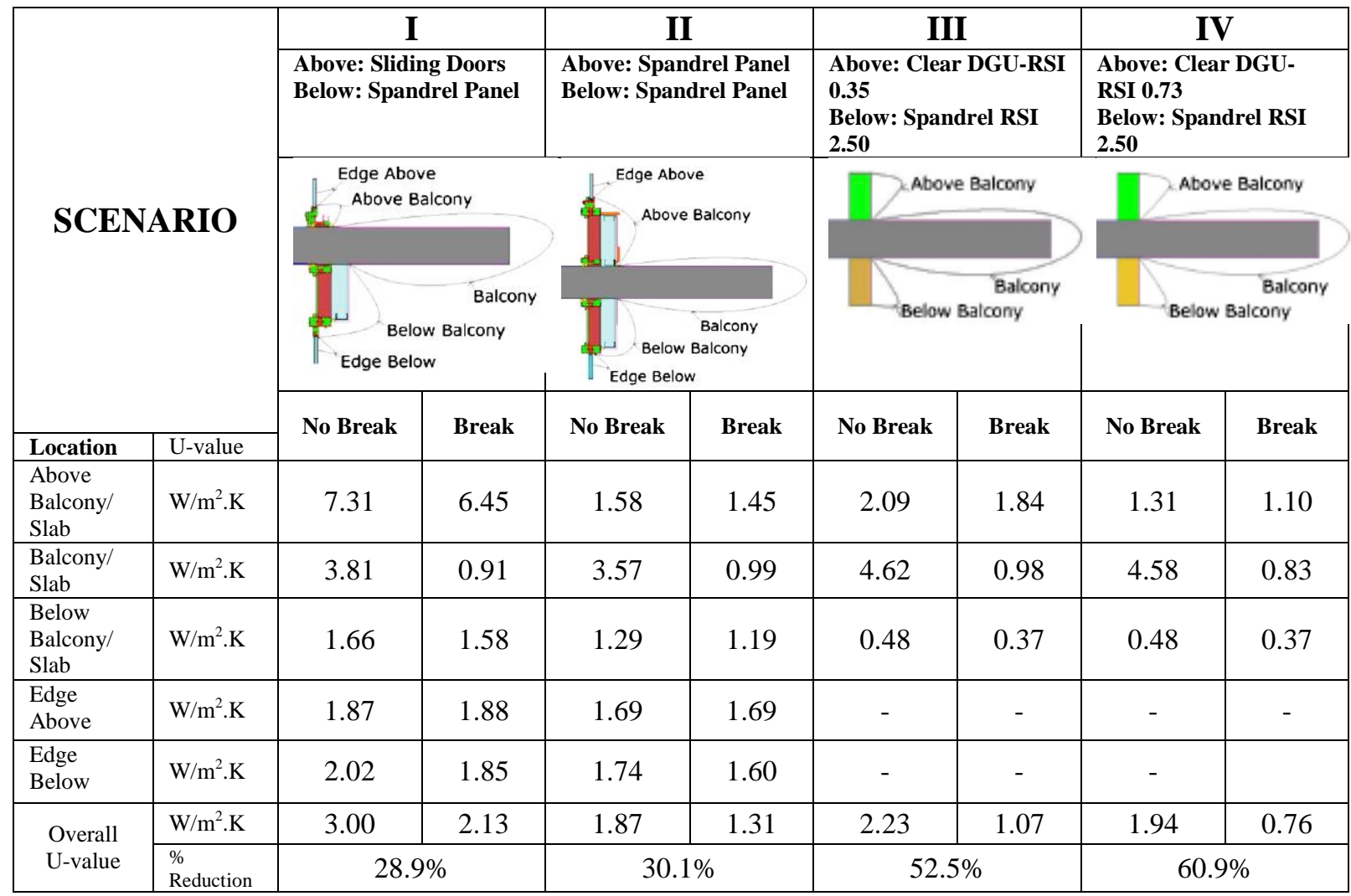

Table 1 illustrates U-values for each location bounded areas of scenarios I, II, III, and IV with and without the proprietary thermal break added. It also provides the overall U-value for each scenario with \% reduction resulted from the addition of the thermal break in the concrete balcony slab. It should be noted that the overall U-value pertain only to the height being modeled and not the whole wall. In the overall U-value therefore, the influence of slab condition is exaggerated. 
Table 2: Minimum Concrete Surface Temperature for Scenarios I, II, III, and IV and Thermal Profile Image Showing the Location of the surface Temperature [3]

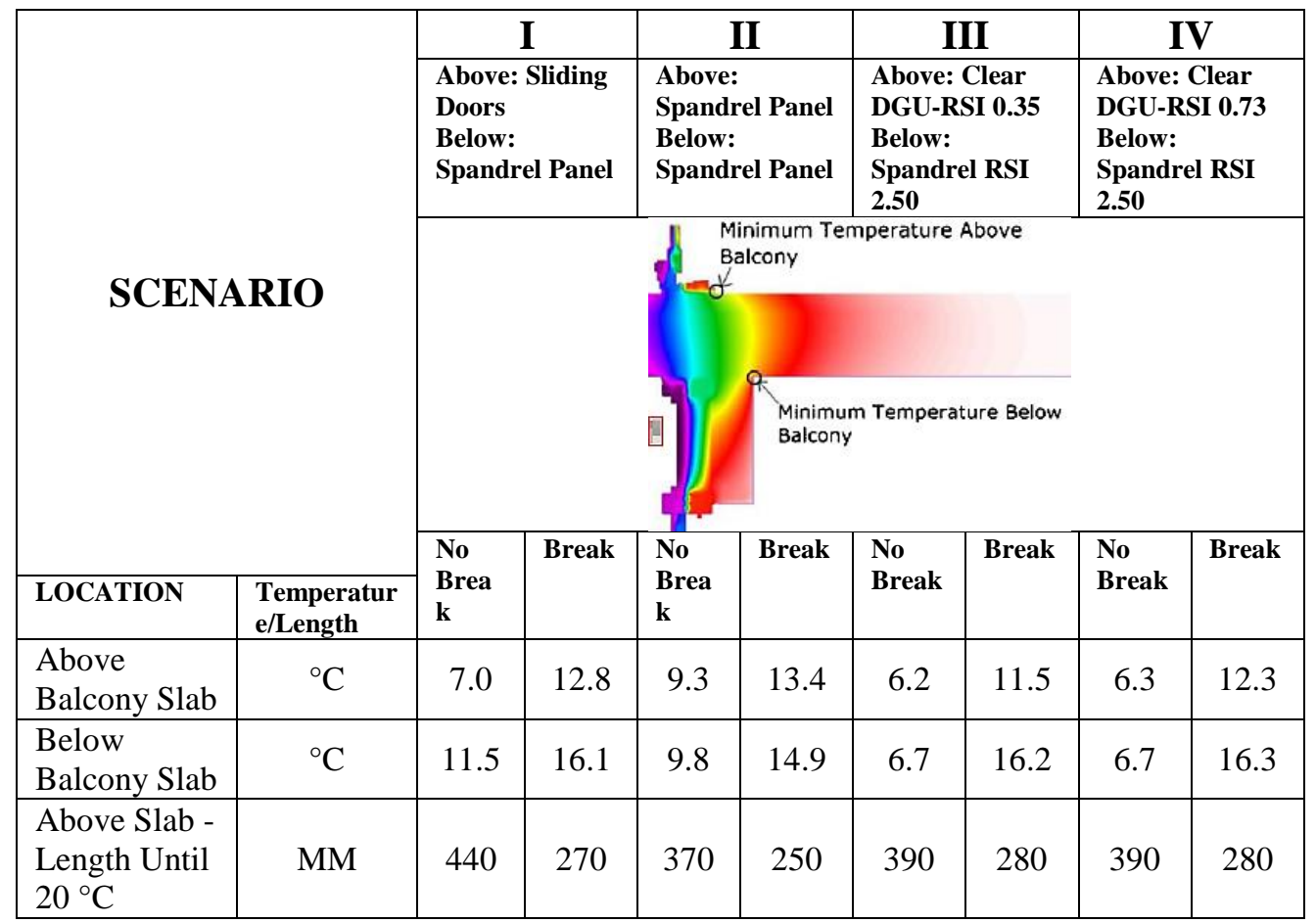

Table 2 illustrates the minimum surface temperature of concrete at the intersection of the glazing frame and concrete surface above and below the balcony slab.

From the data presented in Table 1 and 2, having a thermal break installed in the concrete balcony slab could reduce the overall U-values up to $60.9 \%$ and increase the interior concrete surface temperatures up to $6.0^{\circ} \mathrm{C}$. From Table 1 , the lowest $\%$ reduction in U-value of $28.9 \%$ occurred at scenario I (thermal break with sliding door above and spandrel panel below balcony slab). This is the lowest thermal performing assembly adjacent to concrete balcony slab.

In terms of interior concrete surface temperature, it was noticed from the data presented in Table 2 that the worst case was in scenario III (no thermal break) where surface temperature was $6.2^{\circ} \mathrm{C}$. It should be noted also that scenario I had the highest length of $440 \mathrm{~mm}$ to reach $20^{\circ} \mathrm{C}$ from the sliding door frame edge [3]. 
This study took the U-values from their models and applied them to determine the total energy consumption of the building with and without the thermal break. The overall impact of thermal break to reduce the U-value of entire building was $8.9 \%$. For the total energy consumption, the overall impact was $5.3 \%$ for heating and $-0.2 \%$ for cooling.

\subsubsection{D Heat Transfer Study: Thermal and whole building Energy Performance of} Thermal Break Technology for Concrete Balconies in High-Rise MURBs

In a study by Roppel, P. et al (2013) [4], [25] of Morrison Hershfield Limited (MH)

which was retained by Schöck Bauteile GmbH (Schöck) to evaluate the potential improvement on overall energy efficiency of a high-rise MURB by using a proprietary structural thermal break insulating element in concrete balcony slabs. The study's main objective was to to provide the construction industry and jurisdictions with guidance regarding questions which developers and designers are asking about the impact of thermal breaks for cantilevered balconies specifically in cold climates [4].

Of particular interest of this study are the results of U-values and concrete surface temperatures in the assemblies that were examined.

This study analyzed a common 32 storey typical high-rise MURB in Toronto, Ontario with approximately 40\% "vision glass" and 3.5\% exposed cantilevered concrete slab area of 2581 m length. The window-wall system was Starline 9000 series (vision and spandrel sections) spans from floor to ceiling at the balconies. 50\% vision area was assumed at a sliding door [4]. A proprietary structural thermal break insulating element was used.

The boundary conditions were specified for the evaluation of the condensation resistance as $\left(-18^{\circ} \mathrm{C}\right)$ exterior and $\left(+21^{\circ} \mathrm{C}\right)$ interior for Toronto's cold climate which is close to ASHRAE 2009 Handbook-Fundamentals [4]. 
Three scenarios were established; cantilevered balcony slab without interruption (conventional), cantilevered balcony slab with interruption consisting of reinforced concrete (500 $\mathrm{mm}$ ) and rigid insulation ( $800 \mathrm{~mm}$ ) of $40 \mathrm{~mm}$ thickness (site solution) and cantilevered balcony slab with proprietary thermal break (Schöck solution), [4], [25] (See Appendix B).

The thermal analysis was completed using 3D heat transfer software, published thermal properties of materials and information provided from manufacturers. Interior slab surface temperatures were calculated and thermal profile was modelled for each scenario and the condensation resistance of the floor slab was evaluated at Toronto design conditions [4] (see Appendix B).

Table 3: Overall U-values for Balcony Slab Scenarios with 3D detail showing Each Slab Scenario and \% Reduction in Heat Flow by using Schöck Solution [4], [25]

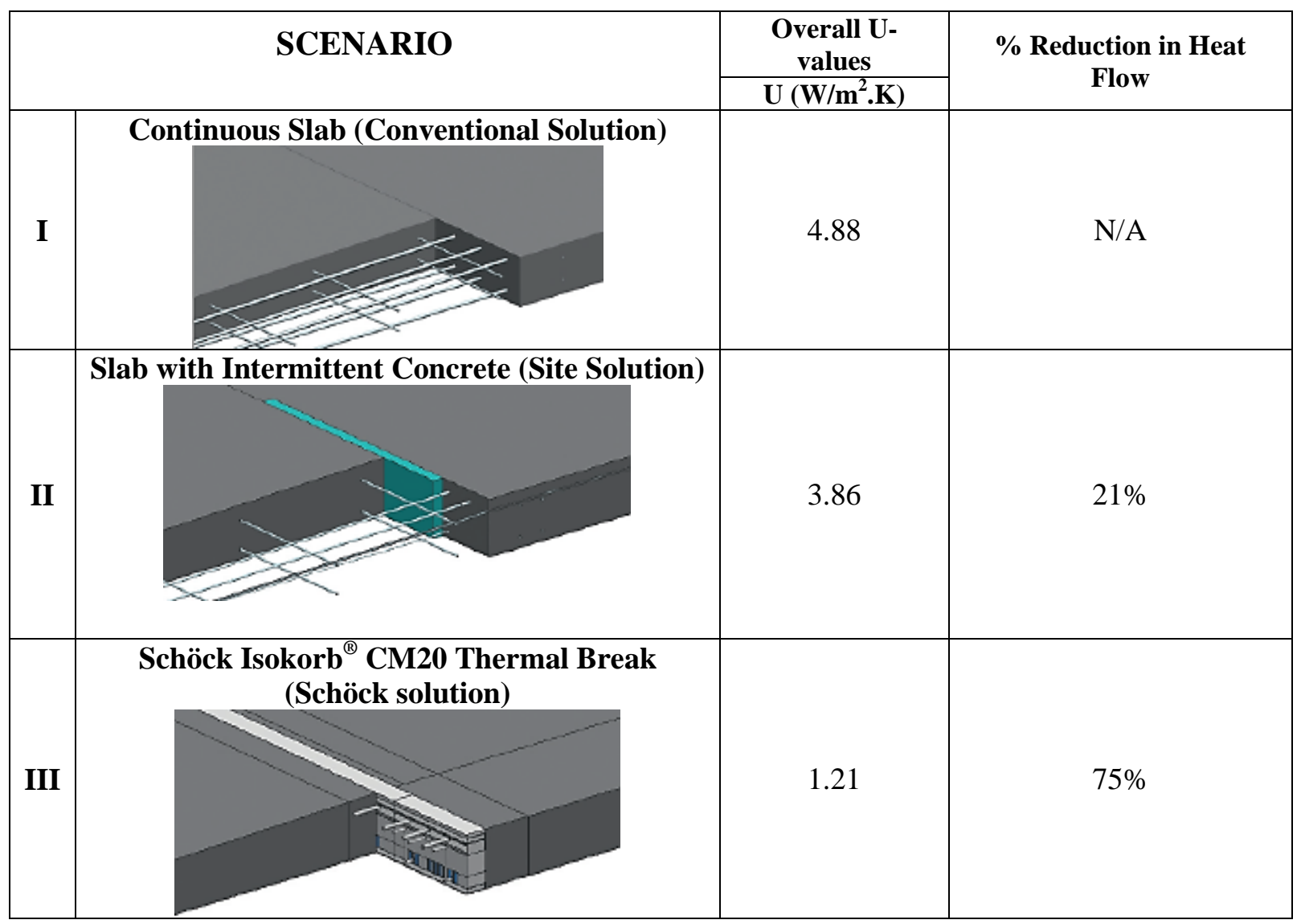


Table 3 illustrates the modeled scenarios with the corresponded thermal transmittance Uvalue calculated. The U-value of Schöck solution experienced a dramatic decrease over the conventional and the site solution. It even shows that Schöck solution reduces the heat flow through and around the slab by $75 \%$ when compared to a conventional continuous balcony slab. This is huge difference to the slab with intermittent insulation and concrete connections, which only provides a $21 \%$ improvement over a conventional slab [4].

Table 4: Minimum Concrete Surface Temperature and if it does Meet the Condensation Design Criteria for each Scenario with Thermal Profile Image showing Location of Surface Temperature [4], [25]

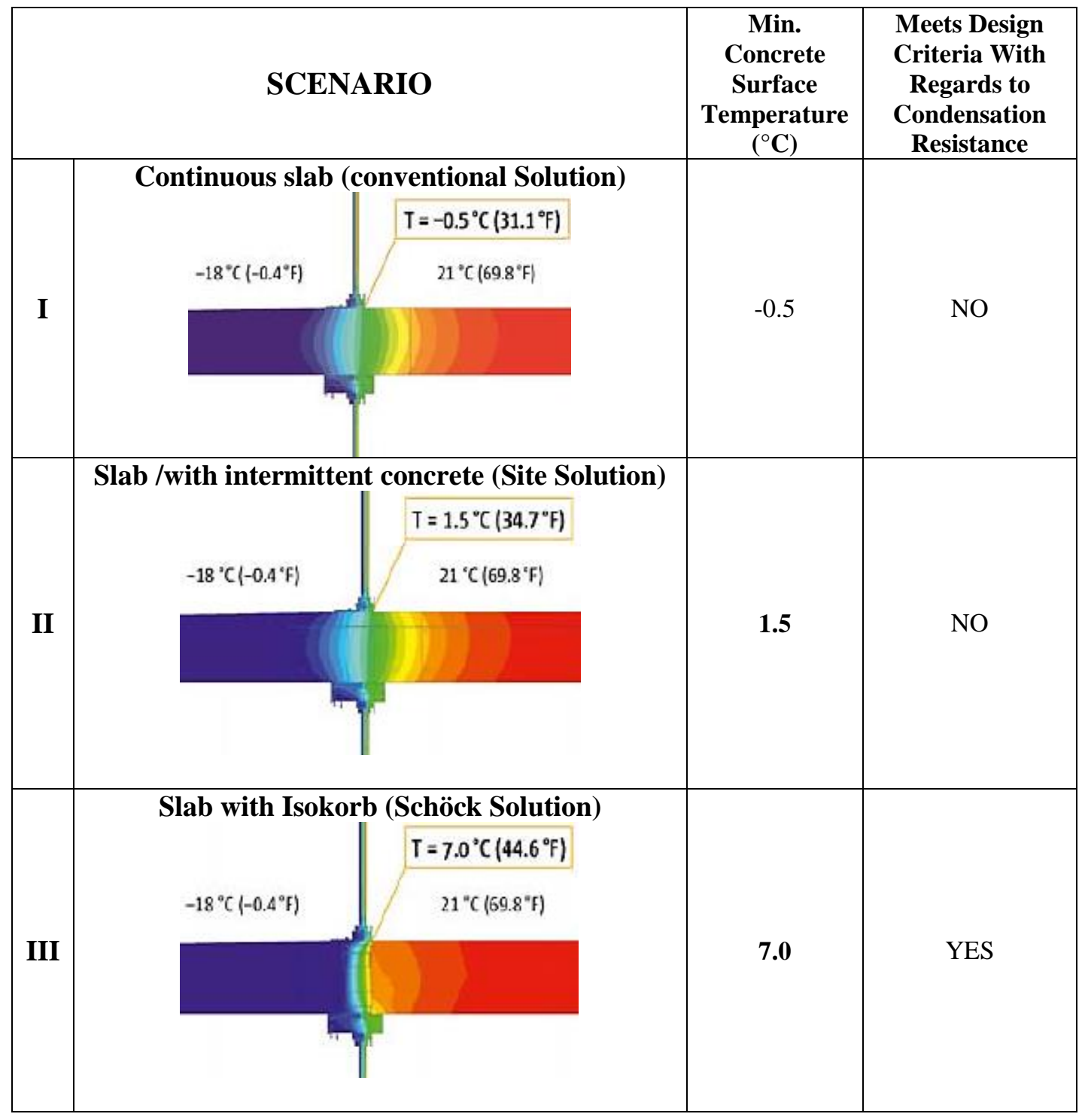


Table 4 illustrates the minimum concrete surface temperatures found for each scenario and summarizes an evaluation of the condensation resistance of the floor slab at Toronto design conditions. Toronto design conditions for exterior temperature of $-18^{\circ} \mathrm{C}$ represents the $2.5 \%$ January Mean Temperature provided in the National Building Code 2005 and is close to the 99.6\% peak heating design condition of $-18.8^{\circ} \mathrm{C}$, which is specified in the ASHRAE Handbook Fundamentals for Toronto [4].

It should be noted this overall U-value is only around the slab and exaggerates the results compared to the impact on the U-value of the wall when taken over its full height.

Schöck solution scenario appeared to meet the design criteria specified for surfaces exposed to the interior air of residential buildings designed for Toronto's cold climate and meet the design criteria with regards to the condensation resistance for temperature greater that the dewpoint of $5^{\circ} \mathrm{Cat} \mathrm{RH} 35 \%$ and $21{ }^{\circ} \mathrm{C}$ interior air [4].

By using a proprietary thermal break in a cantilever concrete balcony slab, this study confirmed that it makes the slab much warmer in the winter time adjacent to the glazing area from $\left(-0.5^{\circ} \mathrm{C}\right)$ to $\left(+7.0^{\circ} \mathrm{C}\right)$ than the other solutions, this will benefit the condensation resistance and thermal comfort for occupants [4].

It should be noted that this study had no evaluation of the impact of the glazing adjacent to the slab for the three (3) scenarios; but, according to the authors, they have noticed that the coldest temperatures on the sliding door was mostly unaffected by the three (3) slab scenarios and the sliding door is much colder than the floor slab for all scenarios [4].

In terms of the energy consumption of the whole building energy, the results indicated a $7.3 \%$ decrease in the heating energy consumption. 


\subsubsection{D Heat Transfer Study: The Importance of Slab Edge \& Balcony Thermal}

\section{Bridges}

In a study by RDH Building Engineering Limited (2013), RDH had published four (4) reports investigating the importance of balcony and slab edge thermal bridges; each of these reports focused on certain research criteria, and targeted three Canadian cities. Report No. 1 [7] covers the impact of balcony and slab edge thermal break products on effective R-values and energy code compliance. Report No.2 [8] covers thermal comfort and condensation control. Report No. 3 [9] covers energy consumption and cost savings. Report No. 4 [10] covers thermal modeling considerations for balconies and compare alternate thermal break strategies.

The objective of these reports was to show that there are solutions for thermal bridges available in the market that help reduce the thermal bridging impact at concrete balconies and provide more design alternatives in terms of increasing stringent energy code requirements.

These reports used a representative typical 20storey high-rise MURB to perform a wholebuilding energy modelling. However, this study did not identify any typical details or what type of glazing system used in the modelling.

The focus of this MRP is on studies that have overall U-values and concrete surface temperatures results generated from modeling specific scenarios related to cantilevered concrete balcony slab with glazing system. The focus will be only on report No.2 [8] that covers thermal comfort \& condensation control and on results related to City of Toronto only. It should be noted that there was no overall U-value generated in this report.

Inputs for building enclosure assemblies were provided and comprised of ASHRAE 90.12010 prescriptive R-value minimums for the windows and roof. A proprietary structural thermal 
break insulating element was used and modeled and compared to a non-thermally broken situation [8].

Scenarios were modeled using 3D heat transfer software, and used published thermal properties of materials and information provided for the proprietary structural thermal break. The boundary conditions used are $\left(-10^{\circ} \mathrm{C}\right)$ for the exterior and $\left(+21^{\circ} \mathrm{C}\right)$ for the interior. Three (3) scenarios were modelled with and without the proprietary structural thermal break [8].

Thermal profiles resulted from thermal modelling for the three scenarios with and without the proprietary thermal break installation are shown in Appendix C.

Table 5: Illustrates Interior Surface Temperature at Concrete and Window -Wall Sliding Door Sill and Spandrel Panel Head without Thermal Break and at Window-Wall Sliding Door Sill and Spandrel Panel Head with Thermal Break [8]

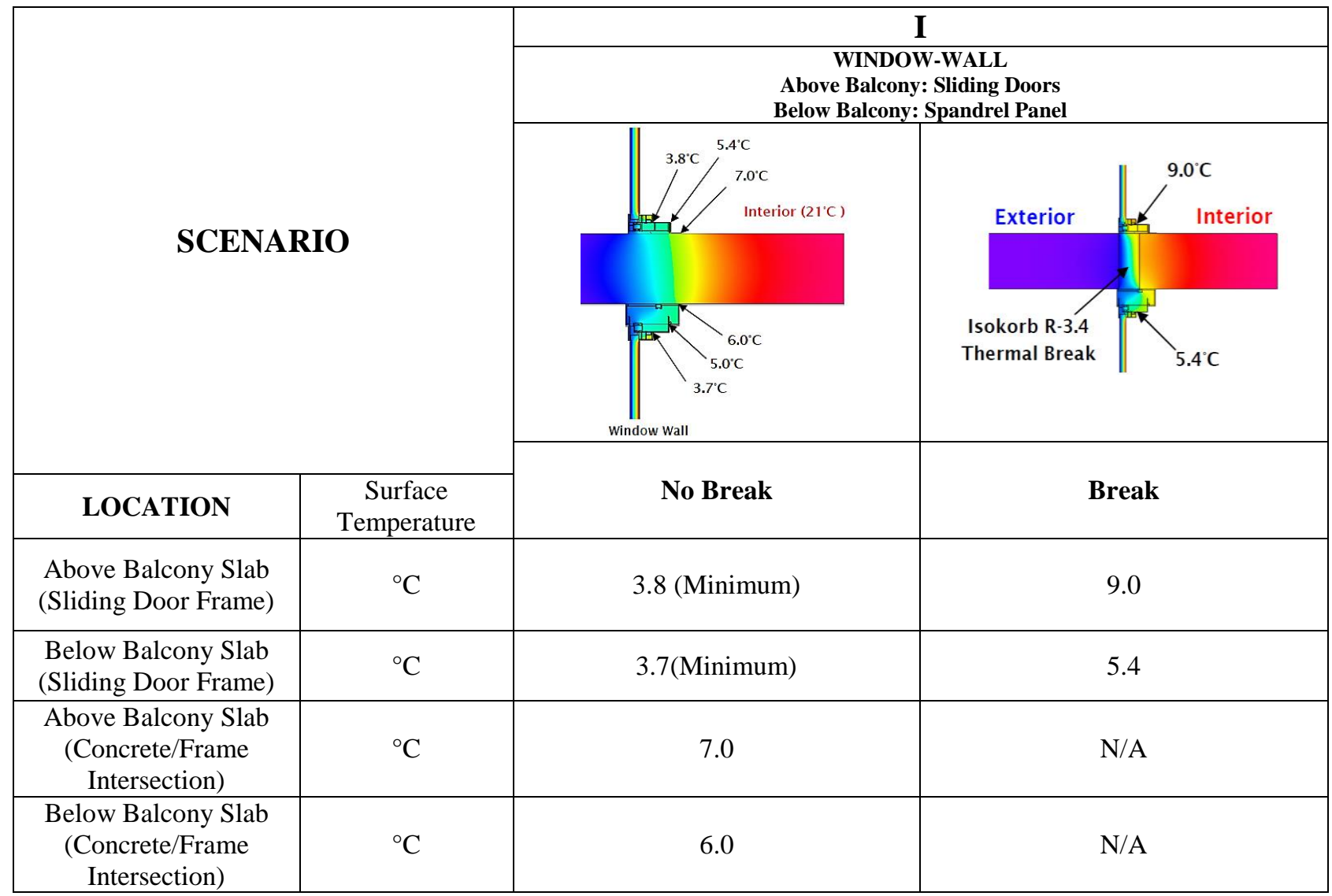


Of particular interest to this study is scenario I that has a window-wall system (sliding door/spandrel panel above and below concrete balcony slab) [8].

Table 5 illustrated interior surface temperatures which confirmed that it did increase when a thermal break was added, however, it was noted that the minimum temperatures used for comparison were measured on the sliding door/spandrel panel frame.

It should be noted that this report had an energy analysis of whole building having $100 \%$ balcony coverage on the exterior for Toronto climate and the reduction in total energy. A comparison of " 6 feet" balcony with and without thermal break gave an energy saving of $4 \%$ to $7 \%$ with the $\mathrm{R}$ value of wall ranging from $\mathrm{R}-2$ to $\mathrm{R}-20$. 


\subsubsection{ASHRAE Research Project (RP 1365)}

In a study by Roppel, P. et al (2011) [19], called ASHRAE RP -1365 Report, this study investigated 40 common building envelope scenarios for MURB façade. Among the 40 scenarios, only two construction detail conditions were related to most common construction assembly used in the majority of high-rise MURBs in cantilevered concrete balcony slabs. A sliding door supported directly on an insulated raised concrete curb (Detail No.26) and a sliding door supported directly on concrete balcony slab (Detail No. 27] [Figure 14]. It should be noted that a thermally broken aluminum sliding door was used in both details and no thermal break is installed in the concrete balcony slab [19].
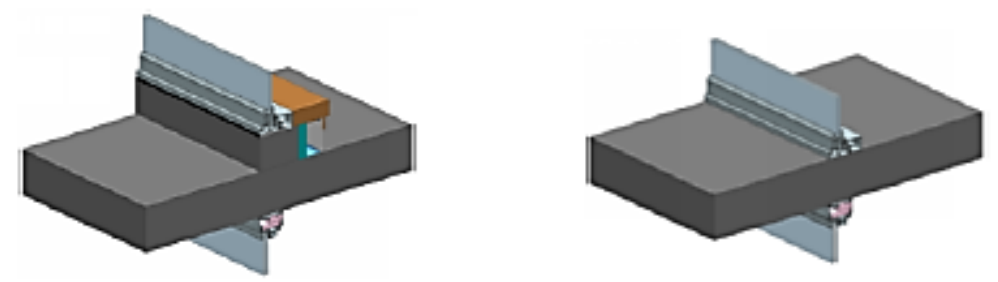

Figure 14: Left: Detail No. 26 from ASHRAE RP-1365, a Sliding Door Supported Directly on Insulated Raised Concrete Curb. Right: Detail No. 27 From ASHRAE RP-1365, a Sliding Door Supported Directly on Concrete Balcony Slab [19].

These two scenarios were modelled using 3D heat transfer software, and used published thermal properties of materials of 2009 ASHRAE Handbook - Fundamentals [19]. Thermal profiles resulted from thermal modelling are illustrated in Table 6 along with the Overall Uvalues and temperature indices for each scenario. Temperature index is the ratio of a surface temperature to the overall temperature difference [19].

Projected distance for thermal performance indicators is from bottom of slab to top of curb. Also, surface temperatures are as a result of steady-state conductive heat flow with constant heat transfer coefficients [19]. 
Table 6: Thermal Profile for Sliding Door without a Curb and with Insulated Curb Scenarios with Overall Uvalues and Temperature Indices [19]

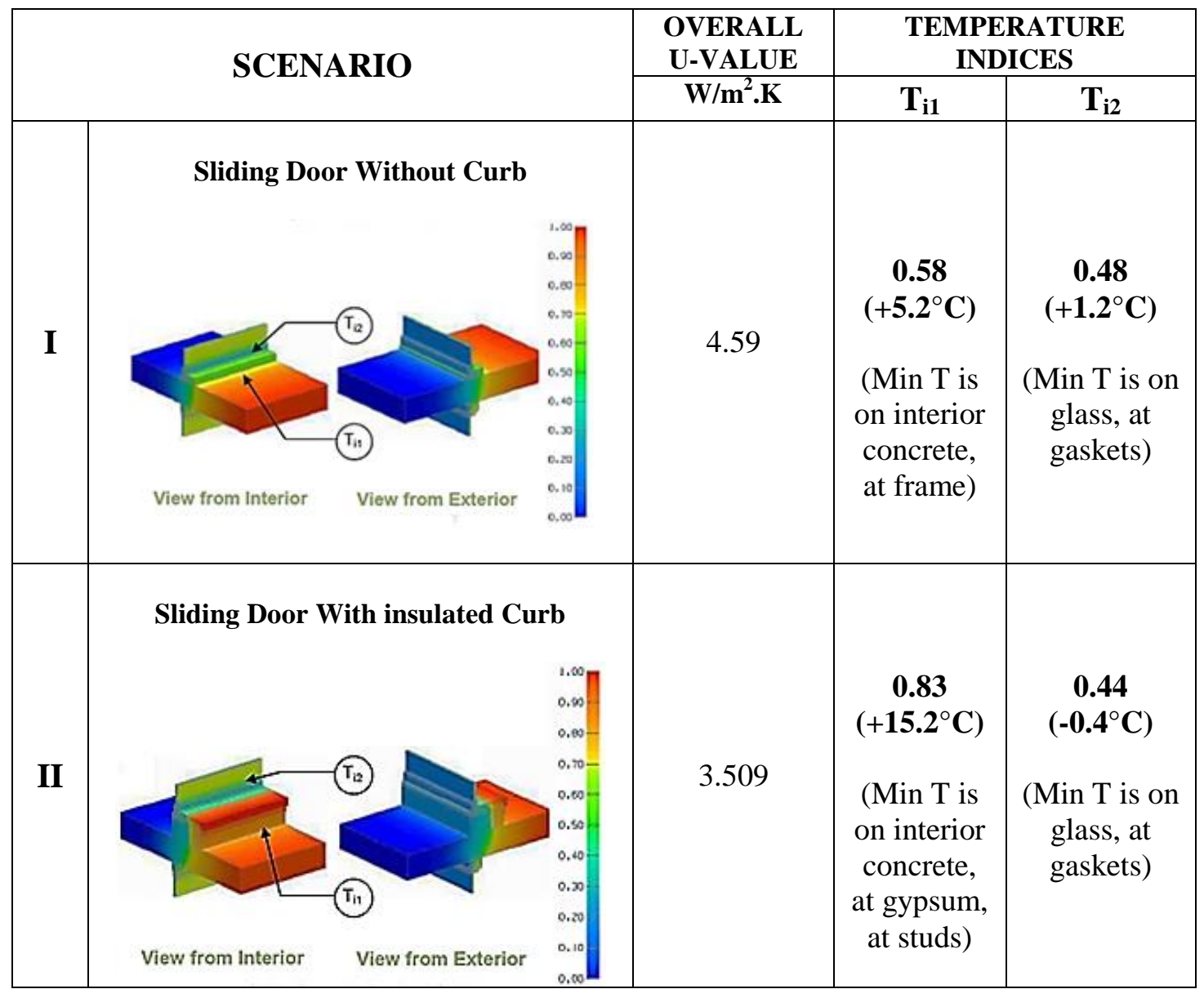

Table 6 indicates that the overall U-value of the sliding door with insulated curb condition is $3.509 \mathrm{~W} / \mathrm{m}^{2}$.K. Although the U-value numbers were high, it indicates that this condition could reduce the thermal transmittance by $31 \%$ from $4.59 \mathrm{~W} / \mathrm{m}^{2} . \mathrm{K}$ to $3.509 \mathrm{~W} / \mathrm{m}^{2} . \mathrm{K}$ which is significant. Also, the temperature indices indicated a significant increase from 0.58 to $0.83\left(+5.2^{\circ} \mathrm{C}\right.$ to $+15.2^{\circ} \mathrm{C}$ when exterior and interior boundary condition are $-18^{\circ} \mathrm{C},+22^{\circ} \mathrm{C}$ respectively) on interior concrete surface right at the curb (gypsum board, at studs), however, despite of the fact that the aluminum window and sliding door is thermally broken, there was slight decrease of temperature indices from 0.48 to $0.44\left(+1.2{ }^{\circ} \mathrm{C}\right.$ to $-0.4{ }^{\circ} \mathrm{C}$ when exterior and 
interior boundary condition are $-18^{\circ} \mathrm{C},+22^{\circ} \mathrm{C}$ respectively) on sliding door glass right at gasket [19].

In the author's experience with high-rise residential buildings, the raised insulated concrete curb detail is very effective to improve thermal comfort and decrease condensation potential. Homeowners had no condensation or thermal discomfort related issues adjacent to the sliding door where the raised insulated curbs are situated. However, it was noticed that in the recent years, that detail condition is no longer used by designers unless the balcony or terrace is situated above a living/ heated space.

\subsection{Comparative Analysis of Findings from Key Studies:}

Each of the key studies presented previously had some contribution to the overall objective i.e. minimizing thermal bridges in a concrete balcony slab, despite differences in approaches, assumptions, boundary conditions and many other factors that may or may not have an impact on the overall final results.

All studies used similar common glazing system with similar thermal properties, and used similar proprietary structural thermal break insulating element in cantilevered concrete balcony slab. The concrete balcony slab thickness used varies between $200 \mathrm{~mm}$ to $210 \mathrm{~mm}$ depending on the proprietary thermal break thickness used [18]. It appeared that the studies had no other alternative but to use similar proprietary structural thermal break since it is the only choice available.

Table 7 below summarizes the approaches used by each key research study in terms of

glazing system used, method of simulation, interior/exterior temperature for boundary conditions and simulated scenarios. ASHRAE RP-1365 was not included in the summary due to the fact 
that the chosen scenarios did not incorporate a thermal break; however, the overall U-values from Table 6 will be used for comparative analysis.

Table 7: Summary of the Key Research Studies in terms of Glazing System used, Method of Simulation used, Boundary Conditions and Simulated Scenarios

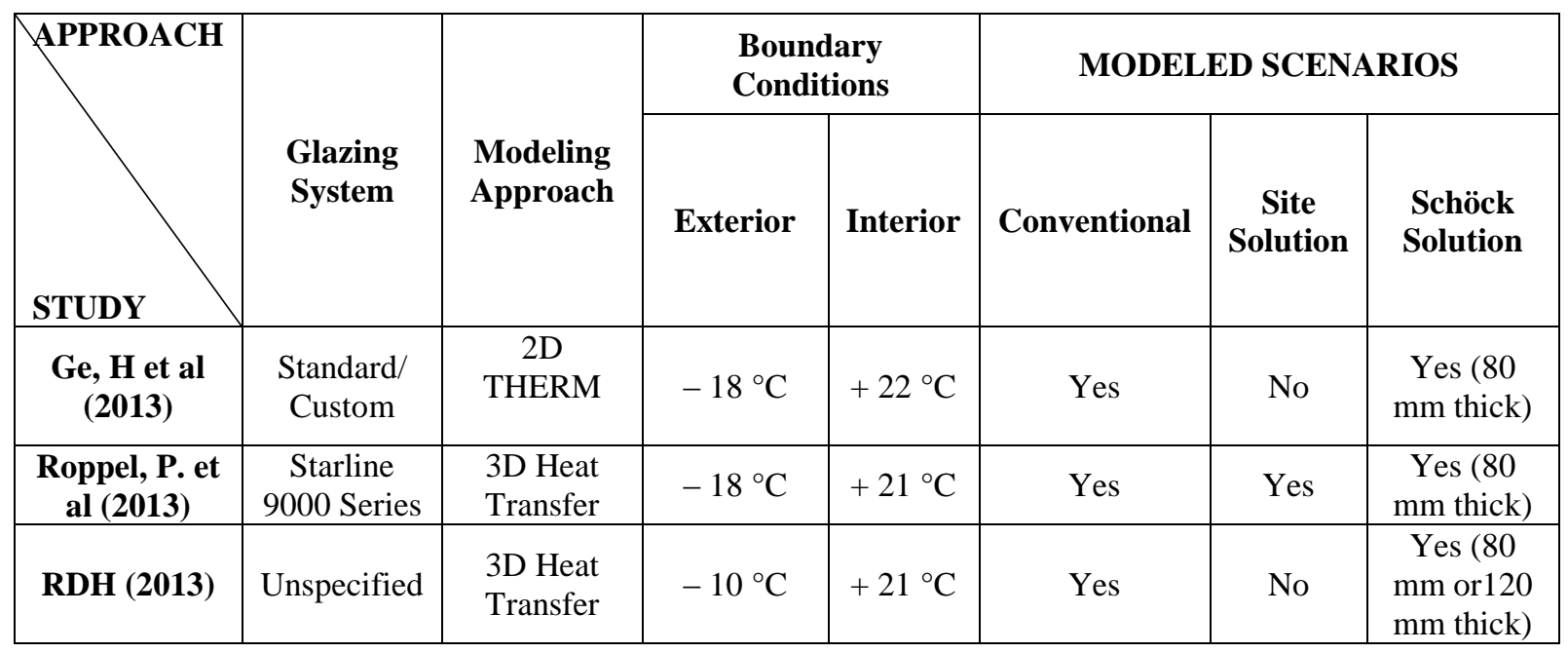

The key studies were analyzed based on the overall U-values and interior surface temperatures results presented in Tables 1, 2, 3, 4, 5 and 6. It should be noted that RDH (2013) study [8] only provided interior surface temperatures for the modelled scenarios. For the purpose of this MRP, the comparative analysis is focused on the selected scenarios identified in each table. The comparative analysis will be based on the following parameters:

1. Thermal transmittance U-values calculated by either $2 \mathrm{D}$ or $3 \mathrm{D}$ heat transfer software used by each study and to verify if and why there is a significant difference between the results of the two methods.

2. Interior concrete surface temperature values varies based on different various assumption and boundary conditions used by each study.

3. Other considerations and concerns i.e. glazing system, thermal break and chosen scenarios. 


\subsubsection{Thermal Transmittance U-values:}

Table 8 illustrates overall U-values from Ge, $\mathrm{H}$ et al (2013) [3], and Roppel, P. et al (2013) [4] for particular scenarios that are similar in terms of glazing portion above and below balcony slab (sliding door/spandrel panel) with and without the addition of thermal break. This table also incorporated the two scenarios from ASHRAE RP-1365 (2011) [19] that had no thermal break added (see tables 1, 3, and 6).

It should be noted that the overall U-values are for the slab and immediately adjacent portion and not the whole wall.

The overall U-values in table 8 indicated a $75 \%$ reduction in heat flow when thermal break was added for scenarios I and II from Roppel, P. et al (2013). It also indicated to a $29 \%$ reduction in heat flow when a thermal break was added for a similar scenario from $\mathrm{Ge}, \mathrm{H}$ et al (2013). Same positive results in heat flow reduction, but big difference in $\%$ values (29\% versus $75 \%$ ) generated from the 2D and 3D simulation methods.

Researchers in ASHRAE RP-1365 (2011) argued that a 2D model cannot capture the actual heat flow path through complex 3D intersections and, therefore, cannot accurately estimate Uvalue [19]. The difference in the U-values obtained by each study relates to many factors and assumptions that control the calculation of areas, boundary lines, thickness of slab, rebar assumed area, effective length and area of influence. These factors must have a significant impact on each element calculated U-value and on the overall U-value. Most importantly is that the U-values in both studies showed significant improvement in thermal performance when thermal break was added regardless of what the simulation method was. 
Table 8: Comparison of overall U-values for 3D Study (MH) Conventional and Schöck Solutions and 2D Study (Ge, H, et, all) Configuration I with and without Thermal Break and \% transmittance reduction [14] \& [15]

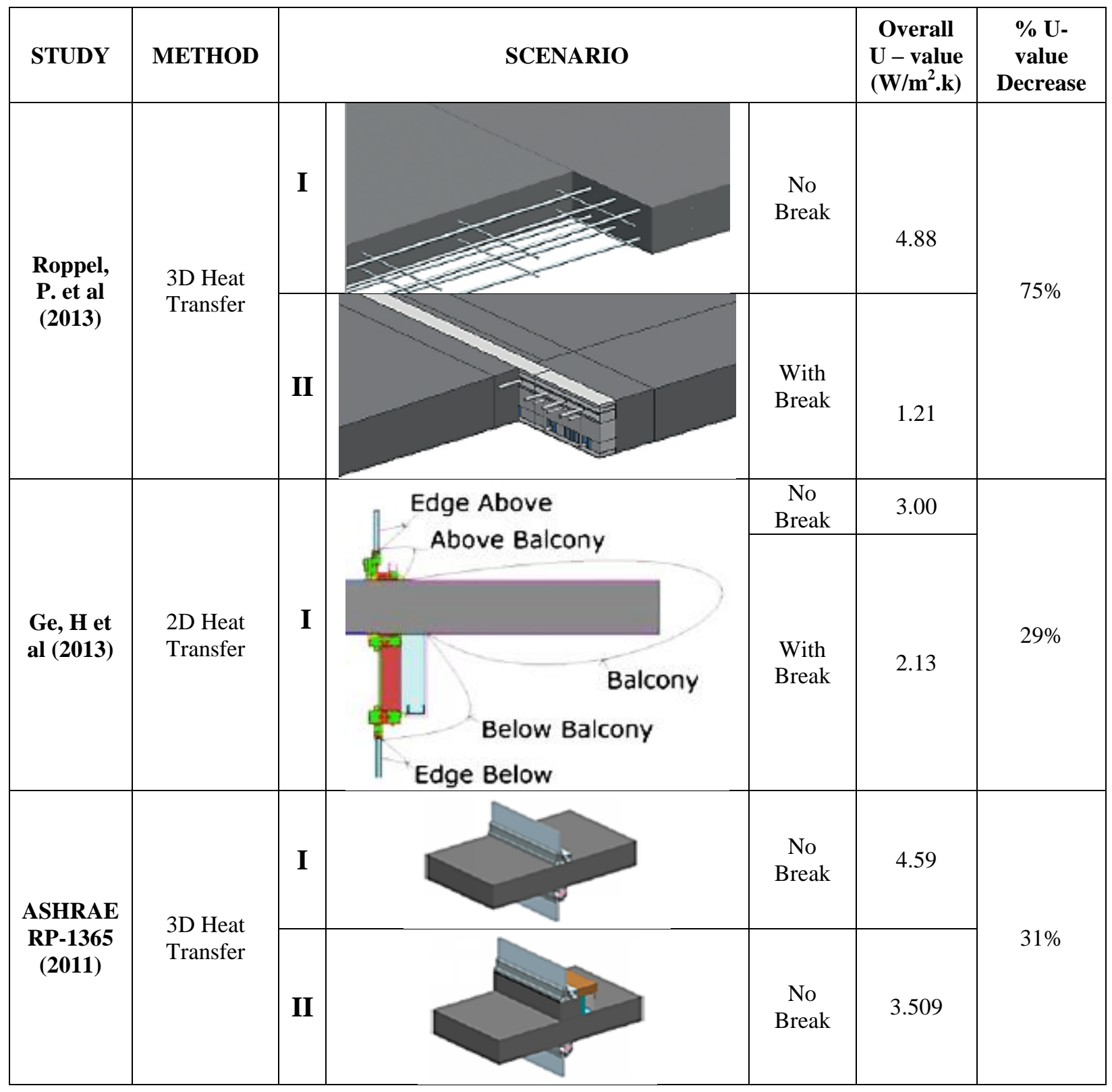

In Table 8, the overall U-values from ASHRAE RP-1365 (2011) indicated a significant reduction of $31 \%$ in heat flow with no added thermal break. The only difference between the two scenarios was the raised insulated concrete curb. This suggests that being proactive in using innovative construction methods and details to enhance the thermal performance of an assembly 
must not be ignored. Unfortunately, this construction detail is slowly disappearing from high-rise MURBs unless the exterior balcony is located above a living space.

\subsubsection{Interior Concrete Surface Temperatures:}

The review of the interior concrete surface temperature presented by the key studies and illustrated in tables 2, 4 and 5, indicated that without installing a proprietary structural thermal break in cantilevered concrete balcony slab, the interior concrete surface temperature would not get warmer. However, it must be noted that in scenarios that had no thermal break installed (see table 5), with a raised insulated concrete curb, the temperature indices indicated a fair increase in interior concrete surface right at the curb (gypsum board, at studs).

Table 9: Comparison of Interior Surface Temperature from Key Studies Measured at Glazing Frame and Concrete Surface Intersection and at Frame Above and Below Balcony Slab [3], [4], [8]

\begin{tabular}{|c|c|c|c|c|c|c|c|}
\hline \multirow[t]{2}{*}{ STUDY } & \multicolumn{2}{|c|}{$\begin{array}{c}\text { Boundary } \\
\text { Conditions / } \\
\text { Design } \\
\text { Temperature } \\
\end{array}$} & \multirow{2}{*}{\multicolumn{2}{|c|}{ SCENARIO }} & \multirow{2}{*}{$\begin{array}{l}\text { Interior Surface } \\
\text { Temperature } \\
\text { Location }\end{array}$} & \multicolumn{2}{|c|}{$\begin{array}{c}\text { Minimum Concrete } \\
\text { Floor Temperature }\left({ }^{\circ} \mathrm{C}\right) \\
\text { at Design Temperature }\end{array}$} \\
\hline & Exterior & Interior & & & & No Break & $\begin{array}{l}\text { With } \\
\text { Break }\end{array}$ \\
\hline \multirow{3}{*}{$\begin{array}{c}\text { Roppel, } \\
\text { P. et al } \\
(2013)\end{array}$} & \multirow{3}{*}{$-18^{\circ} \mathrm{C}$} & \multirow{3}{*}{$-21^{\circ} \mathrm{C}$} & I & $\begin{array}{l}\text { Conventional + } \\
\text { Sliding/Spandrel } \\
\end{array}$ & $\begin{array}{l}\text { ABOVE SLAB (AT } \\
\text { CONCRETE) }\end{array}$ & -0.5 & - \\
\hline & & & II & $\begin{array}{l}\text { Site Solution + } \\
\text { Sliding/Spandrel }\end{array}$ & $\begin{array}{l}\text { ABOVE SLAB (AT } \\
\text { CONCRETE) }\end{array}$ & - & 1.5 \\
\hline & & & III & $\begin{array}{l}\text { Schöck Solution + } \\
\text { Sliding/Spandrel }\end{array}$ & $\begin{array}{l}\text { ABOVE SLAB (AT } \\
\text { CONCRETE) }\end{array}$ & - & 7.0 \\
\hline \multirow{4}{*}{$\begin{array}{c}\text { Ge, H } \\
\text { et al } \\
(2013)\end{array}$} & \multirow{4}{*}{$-18^{\circ} \mathrm{C}$} & \multirow{4}{*}{$+22^{\circ} \mathrm{C}$} & \multirow{2}{*}{ I } & \multirow{2}{*}{$\begin{array}{l}\text { Conventional + } \\
\text { Sliding/Spandrel }\end{array}$} & $\begin{array}{l}\text { ABOVE SLAB (AT } \\
\text { CONCRETE) }\end{array}$ & 7.0 & 12.8 \\
\hline & & & & & $\begin{array}{l}\text { BELOW SLAB (AT } \\
\text { CONCRETE) }\end{array}$ & 11.5 & 16.1 \\
\hline & & & \multirow{2}{*}{ II } & \multirow{2}{*}{$\begin{array}{l}\text { Conventional + } \\
\text { Spandrel /Spandrel }\end{array}$} & $\begin{array}{l}\text { ABOVE SLAB (AT } \\
\text { CONCRETE) }\end{array}$ & 9.3 & 13.4 \\
\hline & & & & & $\begin{array}{l}\text { BELOW SLAB (AT } \\
\text { CONCRETE) }\end{array}$ & 9.8 & 14.9 \\
\hline \multirow{4}{*}{$\begin{array}{c}\text { RDH } \\
(2013)\end{array}$} & \multirow{4}{*}{$-10^{\circ} \mathrm{C}$} & \multirow{4}{*}{$+21^{\circ} \mathrm{C}$} & \multirow{4}{*}{ I } & \multirow{4}{*}{$\begin{array}{l}\text { Conventional + Window- } \\
\text { Wall }\end{array}$} & $\begin{array}{l}\text { ABOVE SLAB (AT } \\
\text { FRAME) }\end{array}$ & 3.8 & 9.0 \\
\hline & & & & & $\begin{array}{l}\text { ABOVE SLAB (AT } \\
\text { CONCRETE) }\end{array}$ & 7.0 & - \\
\hline & & & & & $\begin{array}{l}\text { BELOW SLAB (AT } \\
\text { FRAME) }\end{array}$ & 3.7 & 5.4 \\
\hline & & & & & $\begin{array}{l}\text { BELOW SLAB (AT } \\
\text { CONCRETE) }\end{array}$ & 6.0 & - \\
\hline
\end{tabular}

Table 9 illustrates interior concrete surface temperatures from key studies gathered from tables 2, 4, and 5. All scenarios from the 3 key studies were simulated by different simulation 
methods, and at similar boundary conditions and design temperatures, except for RDH (2013) [8] where scenarios were simulated at different exterior design temperature of $\left(-10^{\circ} \mathrm{C}\right)$ lesser that those were used by other studies.

The three studies have selected different thermal films coefficients for the components used, Ge, H et al (2013) [3] used $h o=30 \mathrm{~W} / \mathrm{m}^{2} . \mathrm{K}$ for exterior boundaries and $h i=8.3 \mathrm{~W} / \mathrm{m}^{2} . \mathrm{K}$ for interior boundaries per CSA A440.2 [22], Roppel, P. et al (2013) [4] used undisclosed different thermal films coefficients. As for RDH (2013) [8], they used $h o=30 \mathrm{~W} / \mathrm{m}^{2} . \mathrm{K}$ for exterior surface boundaries and $4.0 \mathrm{~W} / \mathrm{m}^{2} . \mathrm{K}$ to $7.7 \mathrm{~W} / \mathrm{m}^{2} . \mathrm{K}$ for interior boundaries.

Selecting thermal films coefficients for surface temperatures can be a challenge for components for results accuracy and may affect the temperature results where a large percentage of the overall thermal resistance is the surface resistance [19]. Also, inconsistencies in assumptions will affect the simulation of the models and the surface temperatures results.

At most scenarios, when thermal break was installed, Table 9 evidently showed an increase in interior surface temperature adequately or significantly above the dewpoint so it minimizes the risk of condensation potential. This is a positive indication that the thermal break had contributed in warming up the interior surfaces within the near vicinity of the balcony slab.

However, in table 6, for a scenario from ASHRAE RP-1365 (2011) that has an insulated concrete curb without the addition of a thermal break, the interior surface temperature indices increased from 0.58 to 0.83 right at the curb (gypsum board, at studs).

The following can be concluded from the results in Table 9:

- The minimum interior surface temperature values for all scenarios were above the condensation resistance criterion, where temperature are greater than the dewpoint of $5^{\circ} \mathrm{C}$ when $\mathrm{RH}=35 \%$ and interior temperature is $21^{\circ} \mathrm{C}$. 
- Minimum interior surface temperature values of scenario III from Roppel, P. et al (2013) and scenario I from $\mathrm{Ge}, \mathrm{H}$ et al (2013) showed significant difference in values $\left(7.0^{\circ} \mathrm{C}\right.$ versus $12.8^{\circ} \mathrm{C}$ ) despite the fact that both studies used similar glazing system. This difference could be related to the simulation method used and to different assumptions made during the simulation process.

- Minimum interior surface temperature values of RDH (2013) appeared lower than the other two studies. Although, the temperature values met the condensation design criteria, these values raise some questions due to the fact that the design temperature for the exterior boundary condition was $8^{\circ} \mathrm{C}$ warmer than the design temperatures of the other studies.

The risk of condensation grows if a room interior temperature is $22{ }^{\circ} \mathrm{C}$ and the concrete surface temperature is $6^{\circ} \mathrm{C}$ and if the interior Relative Humidity $(\mathrm{RH})$ rises above $35 \%$. Whether or not a thermal break was installed in the balcony slab, condensation is still an issue for the balcony sliding door frames that have surface temperatures varies from $\left(-5^{\circ} \mathrm{C}\right)$ to $\left(+3^{\circ} \mathrm{C}\right)[3]$.

Even though the temperature values shown from Table 9 indicated that the risk of condensation may not be an issue for the floor slab, however, thermal comfort might create a big issue given that the floor surface temperatures is quite low in the vicinity close to the exterior wall [3]. In Roppel, P. et al (2013) study, it was noted that the coldest temperature on the sliding door was mostly unaffected by the three slab scenarios without forced heat across the door. 


\subsubsection{Other Considerations and Concerns}

The presented studies appeared as marketing tools for the proprietary approach of structural thermal break insulating element. The author was not sure if this was the intention, nevertheless it exhibited that using such thermal break solution for cantilevered concrete balcony slab would be of great benefit for heat loss reduction. But according to RDH (2013) it appeared that the cost of such proprietary approach is high that the high-rise MURBs community are reluctant to propose such addition.

It appears the most important factor that is driving the need for a thermal break is meeting the requirements of the energy codes. Prescriptive requirements stipulate a minimum R-value for walls. In situation with high percentage of glass, the requirements may not be met without a thermal break or reduction in balconies. It is however, probable that a simulated approach may allow the balconies to meet the code without addressing the thermal bridging at balcony.

Roppel, P. et al (2013) [14] study had investigated a site solution where a cantilevered concrete balcony slab has interruptions consisting of reinforced tensioned concrete beams of 500 $\mathrm{mm}$ and $800 \mathrm{~mm}$ voids for rigid insulation of $40 \mathrm{~mm}$ thickness. The results of modeling this site solution were not satisfactory in both overall U-values and surface concrete temperature. This site solution appeared neither practical nor cost effective due to being labour intensive.

The three key studies have focused only on the thermal break approach. Although Roppel, P. et al (2011) or ASHRAE RP-1365 Report [19] allow the determination of thermal parameters for an assembly without a thermal break but differing wall conditions at the thermal bridge location.

Aside from all studies, ASHRAE RP-1365 Report have investigated and analyzed an important construction details of a sliding door supported directly on an insulated raised concrete 
curb that have achieved significant results without using a thermal break in the concrete slab. This was due to simple construction details that led to a lower overall U-value and to an increase in surface temperature that established thermal comfort.

Roppel, P. et al (2011) or ASHRAE RP-1365 Report [19] was issued in 2011, which was the starting point of all studies that came after. Two years later, in 2013, the three key studies were subsequently issued, but none of them paid attention to the unique scenario of the insulated raised concrete curb with sliding door details or even suggested an enhanced scenario that could include such details.

That situation raises a question of what makes a proprietary thermal break unique. Although it is a state-of-art innovative product, it is costly. This could be the reason why the high-rise MURBs communities are reluctant to consider installing such technology in cantilevered concrete balcony slab. Then, if there are alternative construction detail options that are readily available and can provide similar benefit to heat loss reduction, and thermal comfort, then why it have been ignored by researchers? 


\subsection{MRP RSERACH QUESTIONS}

The review of the presented studies and by referring to the comparative analysis section 2.5 and Tables 7, 8, and 9, have shown that adding a thermal break in cantilevered concrete balcony slab could improve the thermal performance of the assembly by reducing the U-value, and increase the surface temperature to enhance thermal comfort.

Comparative analysis of the key studies, however, showed inconsistency in terms of Uvalues and surface temperatures due to variation in simulation methods, glazing system used, and many other factors. Despite this, the overall results have shown that using a proprietary thermal break in cantilevered concrete balcony slab could be of great benefit for heat loss reduction and thermal comfort.

Conversely, similar overall results in Tables 6 and 8 have shown that using other thermal break approaches/existing innovative construction details i.e. an insulated raised concrete curb could lead to same benefits of reducing heat loss and enhance thermal comfort. That situation raises the following questions:

1. What makes a proprietary thermal break unique? Although it is a state-of-art innovative product, it is costly. This could be the reason why the high-rise MURBs communities are reluctant to consider installing such technology in cantilevered concrete balcony slab.

2. If the main objective of adding a proprietary thermal break was to reduce the heat loss and enhance thermal comfort in lieu of increasing the interior surface temperature, then, the three key studies, regardless of the differences in the results, had established that objective. In ASHRAE RP-1365 Report, that objective has been established without adding a proprietary thermal break and by insulating a raised concrete curb. 
3. If there is an alternative construction detail option that is readily available in the high-rise MURBs industry which can provide similar benefits to heat loss reduction, and enhance thermal comfort in lieu of increasing interior surface temperatures, then why it has been ignored by researchers? This is a warranted question since ASHRAE RP-1365 Report or Roppel, P. et al (2011) [19] was issued at least two years prior to the issuance of the 3 key studies, and none of which had mentioned the uniqueness of that detail or even explored option of modification in case that option may create a tripping hazard when stepping onto the balcony.

To answer these questions, the author explored the use of lower U-value framed glazing system with either sliding door and/or spandrel panel with better thermal characteristics than those were used by the previously presented three key studies. The author also considered applying modification to the concrete balcony slab and proposing an insulated curb condition solution.

The concrete modification is to create a $12.5 \mathrm{~mm}$ to $25.4 \mathrm{~mm}$ depression (curb) in the concrete balcony slab right beneath where the sliding door/spandrel panel frame is intended to be installed so that a $25.4 \mathrm{~mm}$ thick Extruded Expanded Polystyrene (EPS) rigid insulation can be inserted below the sliding door/spandrel panel frame and separate the concrete surface from sill of the glazing system frame [Figure 15].

Figure 15 illustrates the proposed model plan view and cross section showing the depression (curb) in concrete slab and the EPS insulation inserted right beneath a lower U-value framed glazing condition (sliding door/spandrel panel sill). This idea stems from the existing raised insulated concrete curb condition exhibited in ASHRAE RP-1365 (2011) [19] and in 
Table 6, which has been used for many years by architects and engineers in concrete balcony slab in high -rise MURBs.

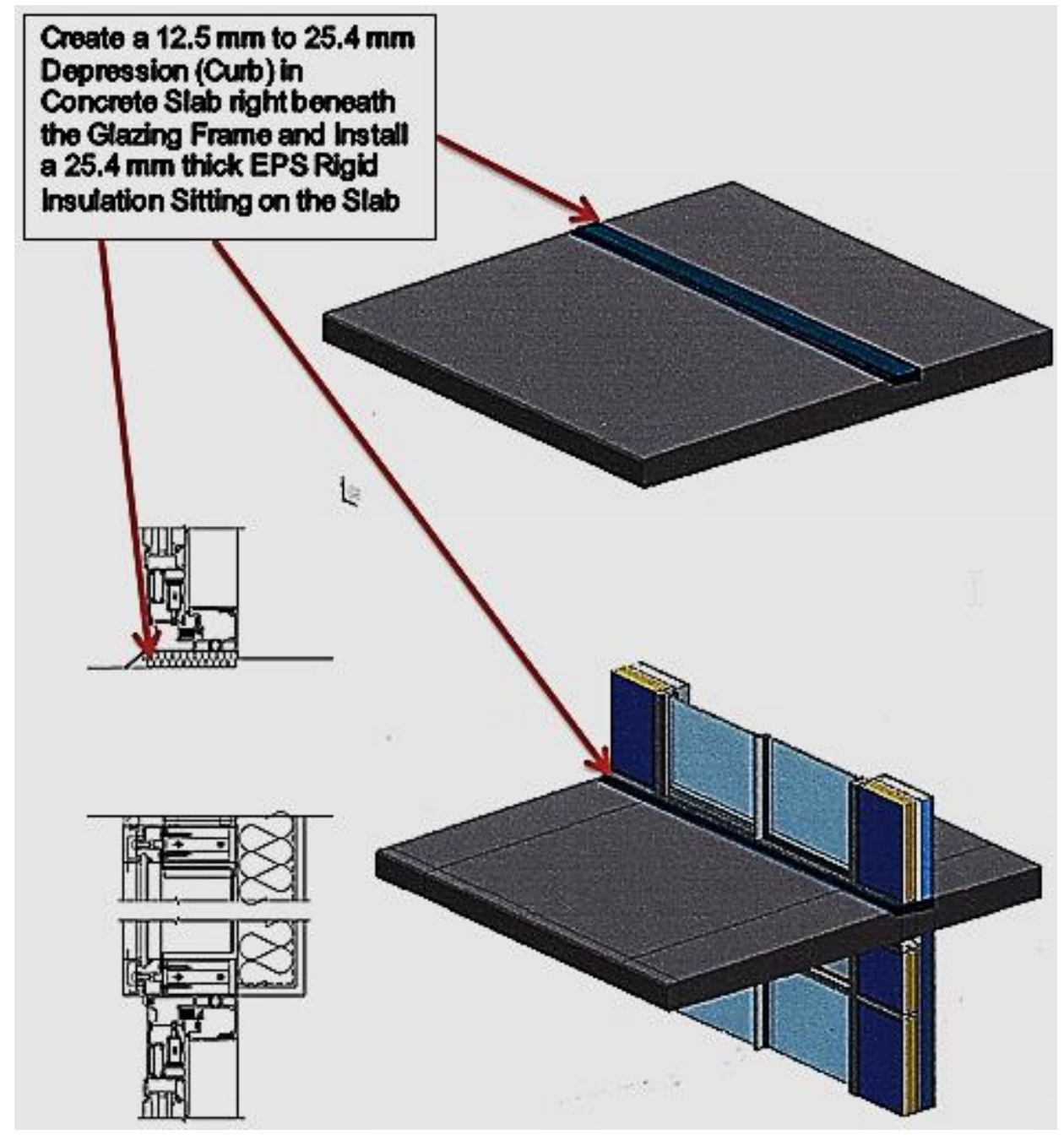

Figure 15: Preliminary Plan View and Cross-Section Profile showing the Proposed Model of $12.5 \mathrm{~mm}$ to 25.4 mm Depression (Curb) in the Concrete Slab and a $25.4 \mathrm{~mm}$ thick EPS rigid insulation inserted beneath a Lower U-value Framed Sliding Door/Spandrel panel Frame

The creation of a $12.5 \mathrm{~mm}$ to $25.4 \mathrm{~mm}$ depression (curb) in the cantilevered concrete balcony slab to install a $25.4 \mathrm{~mm}$ thick EPS rigid insulation was for the following reasons:

- Eliminate any water or moisture ingress into the interior space through balcony sliding doors sill. 
- Keep the bottom sill frame of the sliding door and the interior adjacent vicinity of concrete surface fairly warm during winter months.

- Create a flat construction detail approach with horizontal insulation similar in principal to the vertically insulated raised concrete curb to avoid potential tripping hazard claims because of the raised curb.

New construction assembly cross sections are created, thermal models and scenarios are generated, and simulated using 2D THERM heat transfer software. Predicted results analysis and comparison with the results reported from previous three key studies in terms of overall U-values and interior concrete surface temperatures are completed. That comparison may assist in determining if the new proposed model can lower the overall the U-value of the assembly, increase the concrete surface temperature to an acceptable level where occupant's thermal comfort can be achieved.

That comparison may also assist in bringing a new approved construction details to assist designers and developers in the MURBs community to adopt more options to minimize the effect of thermal bridges and pave the road for more innovative construction ideas and more cost effective solutions. 


\subsection{ANALYSIS AND SIMULATION MODELS}

The concept behind the proposed model is to explore a lower U-value framed sliding door and spandrel panel and apply modification to the concrete balcony slab.

Concrete modification is done by creating a $12.5 \mathrm{~mm}$ to $25.4 \mathrm{~mm}$ depression (curb) beneath where the sliding door or spandrel panel frame is intended to be installed and to install a 25.4 $\mathrm{mm}$ of EPS rigid insulation sitting on the slab separating the concrete surface from the glazing system frame [Figure 15].

Proposed construction solution details and proposed simulation models are generated. The proposed simulated models and scenarios are similar to those used by the previously presented three studies in terms of construction assembly, assumptions and boundary conditions, glazing system will utilize a lower U-value framed sliding door and spandrel panel assembly.

For the purpose of comparison, the proposed scenarios are using a proprietary thermal break similar to the one that was used by Roppel, P. et al (2013) [14] study. Simulation is completed utilizing 2D THERM heat transfer software. Overall U-values are calculated and interior surface temperatures are obtained and analyzed.

The objectives of the thermal analysis are to determine if the predicted model with lower U-value framed glazing assembly with or without the addition of $25.4 \mathrm{~mm}$ of EPS rigid insulation beneath the glazing assembly sill frame without a thermal break could make a significant difference in terms of overall U-values and interior concrete surface temperatures when compared with results from similar scenarios from the previous three key studies. 


\subsection{Description of Proposed Construction Assembly}

The development of the proposed construction assembly was reliant on the models established in the previously presented three key studies in terms of the glazing system assembly and proprietary thermal break and the modeled scenarios.

The proposed scenarios are using a lower U-value framed glazing system from KAWNEER. An insulated curb condition is utilized by creating a $12.7 \mathrm{~mm}$ depression (curb) in the concrete balcony slab and installing $25.4 \mathrm{~mm}$ thick EPS rigid insulation sitting on the concrete slab and separating the sliding door/spandrel panel sill frame from the surface of the concrete slab [Figure 16].

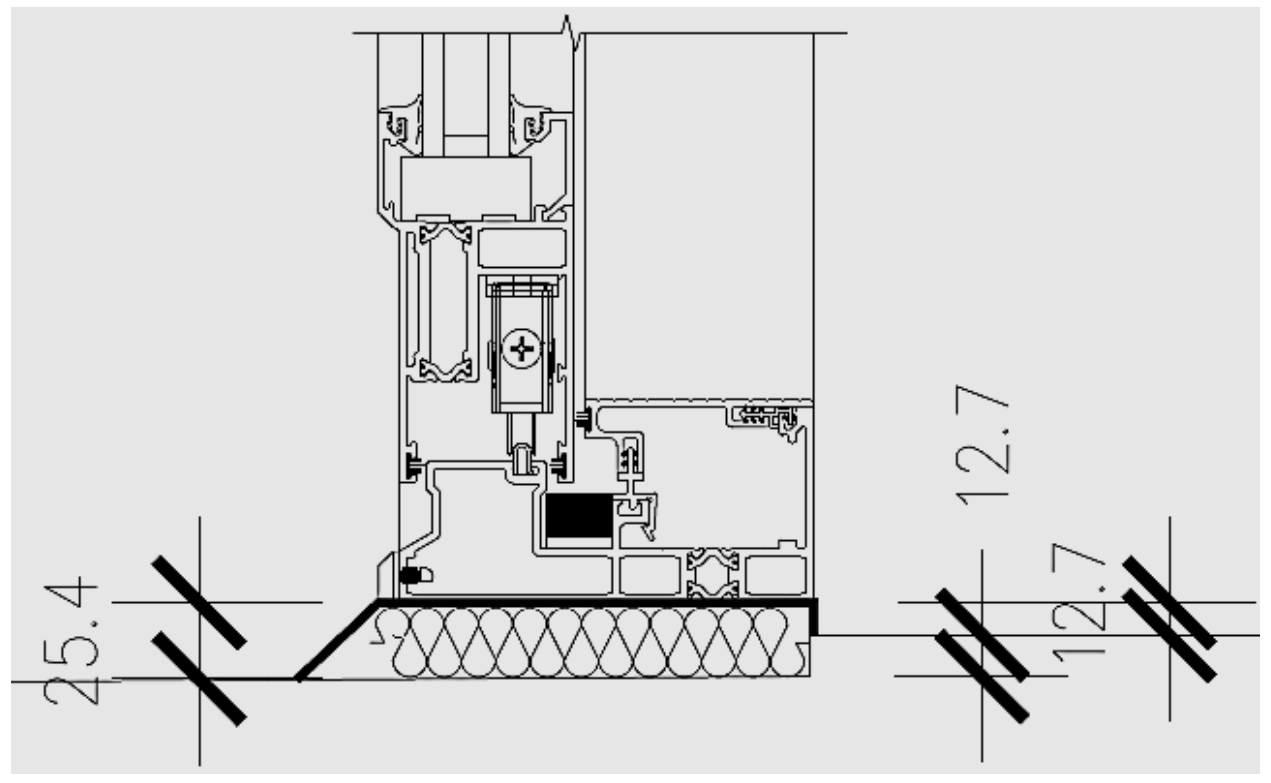

Figure 16: Cross Section of Proposed Model of an Insulated Curb Condition with a KAWNEER Sliding Door Sill Showing a $12.7 \mathrm{~mm}$ depression in the Concrete and a $25.4 \mathrm{~mm}$ EPS beneath the Sliding Door Sill Frame

Figure 16 illustrates details of an insulated curb condition of $12.7 \mathrm{~mm}$ depression in the concrete slab and a $25.4 \mathrm{~mm}$ of EPS rigid insulation sitting in the depression created.

Since few of the modeled scenarios are incorporating a proprietary thermal break, certain dimensions must adhere to the manufacturer requirements in terms of height, thickness and placement of thermal break, cantilever maximum length, and concrete cover for tension bars [18] 
(see appendix D). Therefore, careful consideration was given when choosing the concrete depression thickness to create the insulated curb condition.

The total thickness of the concrete slab is $200 \mathrm{~mm}$ and the concrete cover for tension bars (from exterior) is $55 \mathrm{~mm}$ and (from interior) is $40 \mathrm{~mm}$ to accommodate the $2 \%$ slope of the cantilevered concrete balcony slab [18]. In the case of a $12.7 \mathrm{~mm}$ depression in the concrete, the remaining concrete cover is $55-12.7=42.3 \mathrm{~mm}$ which is above $40 \mathrm{~mm}$, and therefore, the concrete cover conditions are met.

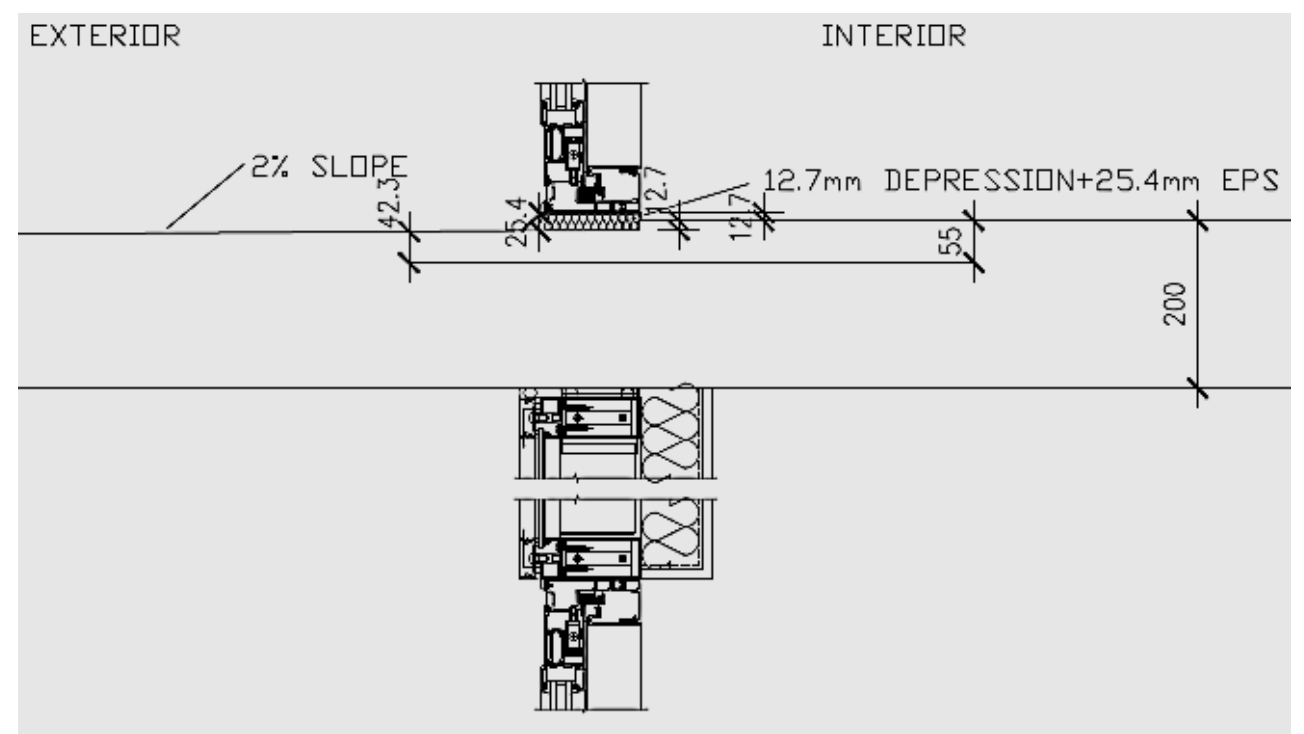

Figure 17: Cross Section of Proposed Model showing a Lower U-value Framed glazing system (Sliding door above/Spandrel Panel below), $12.7 \mathrm{~mm}$ Depression and $25.4 \mathrm{~mm}$ thick EPS insulation and Interior/Exterior Concrete Cover thickness

Figure 17 illustrates section detail of the proposed construction assembly showing a cantilevered concrete balcony slab with a typical $2 \%$ slope towards the edge of the slab, the glazing system comprised of sliding door sill above the concrete slab and sliding door head with spandrel head below the concrete balcony slab. A $12.7 \mathrm{~mm}$ of concrete depression curb) was created right at the edge of the cantilever where the sliding door is intended to be installed, and a 25.4 $\mathrm{mm}$ thick EPS insulation is sitting right in the $12.7 \mathrm{~mm}$ depression (curb) protruding 12.7 
$\mathrm{mm}$ above the surface of the concrete [Figure 16]. Also, Figure 17 shows the tension bar lines from interior and exterior with the concrete cover thickness measurements.

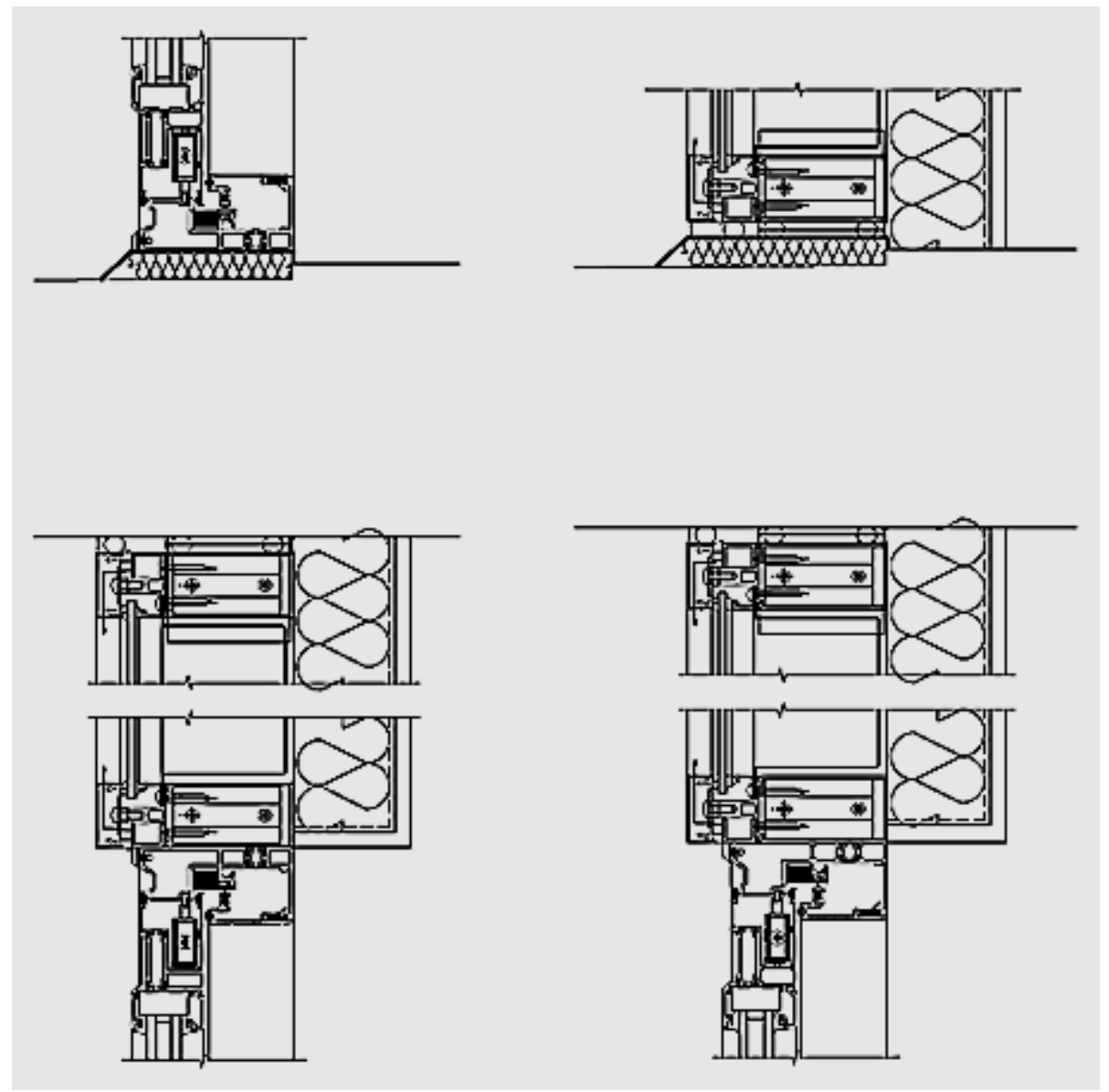

Figure 18: Right: Showing Lower U-value Sliding Door Sill (above balcony slab) and $12.7 \mathbf{~ m m}$ depression and $25.4 \mathrm{~mm}$ thick EPS insulation. Left: Showing Lower U-value Spandrel Panel Sill (above Balcony Slab) and $12.7 \mathrm{~mm}$ depression and $25.4 \mathrm{~mm}$ thick EPS insulation. Both Cross Sections are showing Spandrel Panel Head and Sliding Door Head Blow Balcony Slab.

Figure 18 illustrates typical cross section details for lower U-value framed glazing system (sliding door sill/head and spandrel panel sill/head) used in all modeled scenarios. Both cross section details are showing the insulated curb condition solution of $12.7 \mathrm{~mm}$ depression (curb) in concrete slab and $25.4 \mathrm{~mm}$ thick EPS insulation. 


\subsection{Description of Variables}

\subsubsection{Description of KAWNEER Glazing System}

Exploring the use of lower U-value framed sliding door/spandrel panel with better Uvalue characteristics was proposed to verify if that option could have a positive impact on the overall thermal transmittance of the assembly and on the concrete surface temperature.

The previously presented studies have used what it appeared to be a standard glazing system and standard window-wall system (Starline 9000 series) [27] that is commonly used by the high-rise MURBs industry, that included an opaque spandrel section and a sliding door with assumed typical vision area of 50\% at a sliding door [4].

In Ge, $\mathrm{H}$ et al (2013) study [3], it was indicated that the actual minimum temperatures were found in locations above the slab, but are more indicative of the performance of the window frames, as they do not change significantly with and without the addition of the thermal break. In Roppel, P. et al (2013) study [4] it was noticed that the coldest temperatures on the sliding door was mostly unaffected by the three slab scenarios and the sliding door was much colder than the floor slab for all scenarios. There was no indication in any those studies that the glazing system used does meet the current energy efficiency requirements [28].

As an alternative, the author is exploring a commercially available glazing system such as KAWNEER with better U characteristics. KAWNEER manufacturer representative has verbally confirmed that their product meet the current energy efficiency requirements and it has been used comprehensively in high-rise commercial building applications, no window -wall system is available, however, their products have the flexibility to assemble a typical floor-to-ceiling high thermal performance glazing system by attaching a spandrel panel from any of curtain wall assembly to a sliding door assembly. 
A fully glazed façade is designed for a typical condominium balcony for a floor-toceiling window-wall assembly of $2438 \mathrm{~mm}$ standard height commonly used in high-rise MURBs. A choice of $1600 \mathrm{UT}_{\text {System }}{ }^{\mathrm{TM}} 2$ curtain wall [29] and $\mathrm{AA}^{\mathrm{TM}} 3900$ Thermal Sliding Door [30] was made to assemble the floor-to-ceiling glazing window-wall system [Figure 19].

The typical construction details i.e. balcony connection, spandrel walls, sliding doors shown in Figure 18 for sliding /spandrel and spandrel/spandrel are used for the heat transfer analysis.

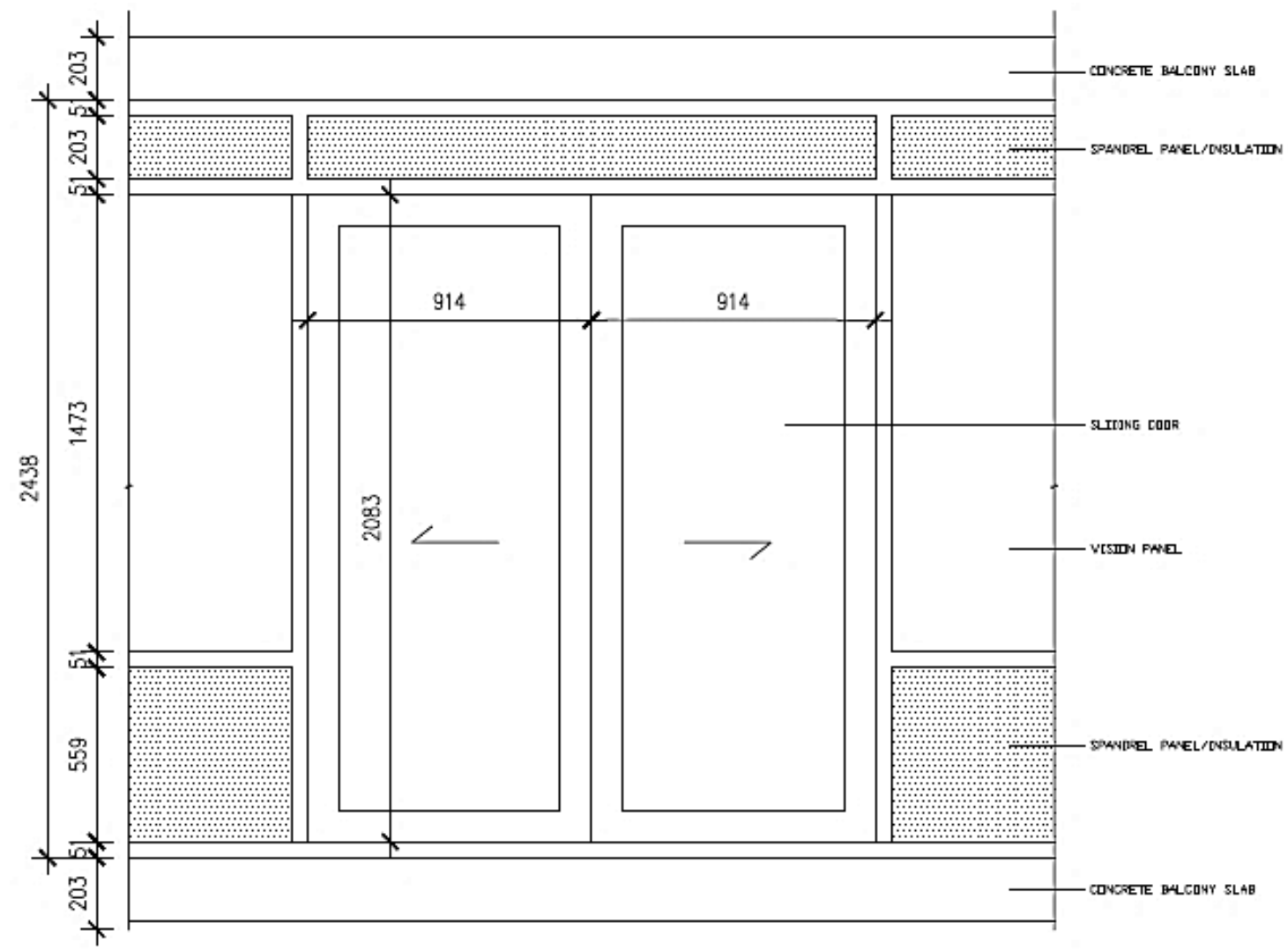

Figure 19: Plan view of Floor-to-Ceiling Assembly glazing Window-Wall Glazing System using a Spandrel Panel of KAWNEER 1600UT System ${ }^{\mathrm{TM}} 2$ curtain wall and KAWNEER AA ${ }^{\mathrm{TM}_{3900}}$ Thermal Sliding Door [29], [30]

Figure 19, illustrates a plan view of a $2438 \mathrm{~mm}$ floor-to-ceiling window-wall assembly by using a spandrel head section of 1600 UT System $^{\mathrm{TM}} 2$ and $\mathrm{AA}^{\mathrm{TM}} 3900$ Sliding Door Head and Sill and $203 \mathrm{~mm}$ thick concrete balcony slab. 


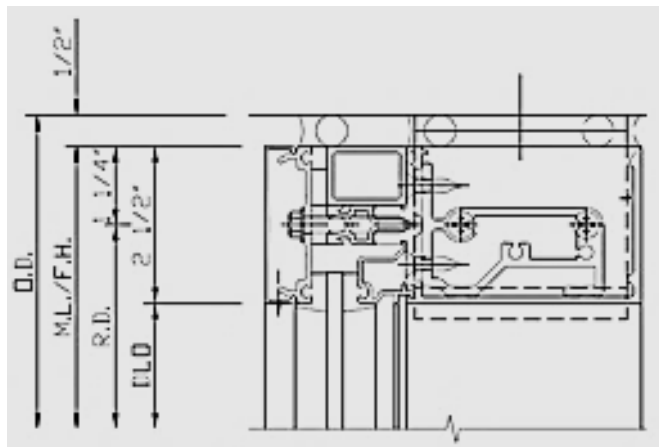

Spandrel Head

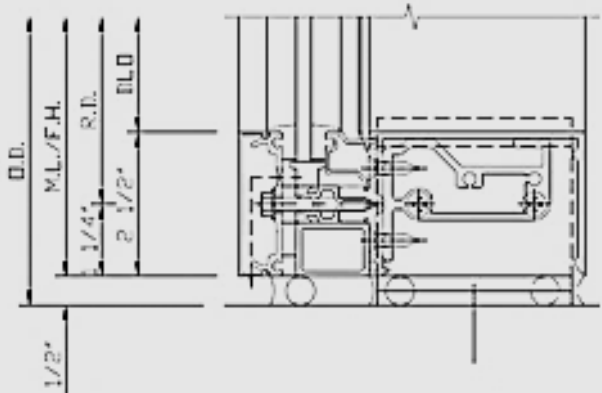

Spandrel Sill

Figure 20: KAWNEER 1600 UT System ${ }^{\mathrm{TM}} 2$ Spandrel Head and Sill Section Details [29]

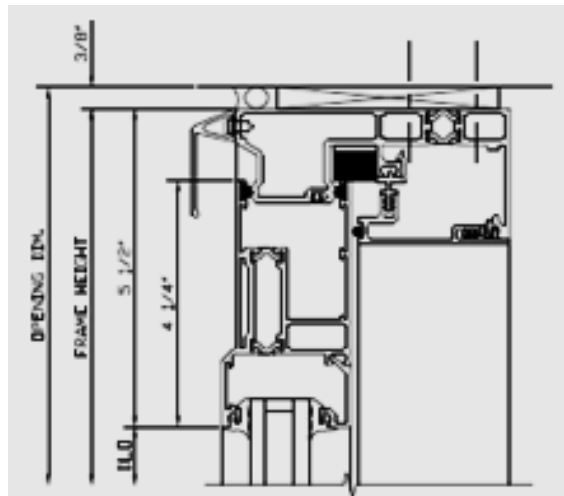

Head at Sliding Panel

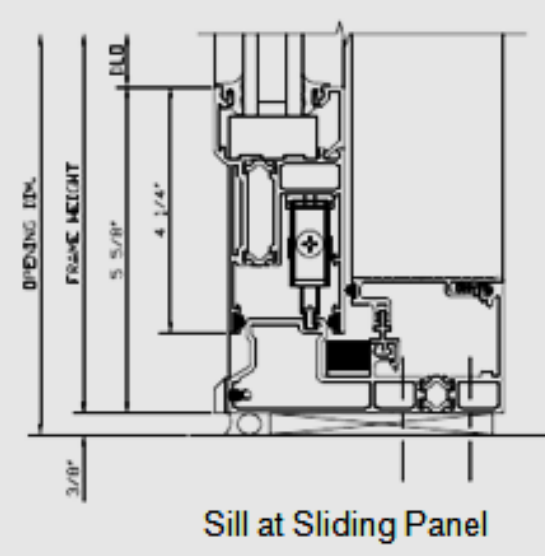

Figure 21: KAWNEER AA ${ }^{\mathrm{TM}} 3900$ Sliding Door Head and Sill at Sliding Panel Section Details [30]

System $^{\mathrm{TM}} 2$ curtain wall and Figure 21 illustrates cross sections of a head and a sill of sliding panel of $\mathrm{AA}^{\mathrm{TM}} 3900$ Thermal Sliding Door.

$\mathrm{AA}^{\mathrm{TM}} 3900$ Thermal Sliding Door glazing used is a $25.4 \mathrm{~mm}$ total thickness $(2 \times 6 \mathrm{~mm}$ glass and $12.7 \mathrm{~mm}$ spacer) double glazed unit (DGU) with Argon gas-filling and low-e coating with a Centre-Of-Glass (COG) U-value of $1.324 \mathrm{~W} / \mathrm{m}^{2} . \mathrm{K}$. Spandrel panel is used from 1600UT System $^{\mathrm{TM}} 2$ with an R-value of $2.645 \mathrm{~m}^{2} . \mathrm{K} / \mathrm{W}$, or an equivalent U-value of $0.378 \mathrm{~W} / \mathrm{m}^{2} . \mathrm{K}$. 


\subsubsection{Description of the Insulated Curb Condition Solution}

The depression (curb) in the cantilevered concrete balcony slab could have been greater than $12.7 \mathrm{~mm}$; however, more depression requires maintaining the concrete cover of tension bars as well as a structural verification to maintain the integrity of the cantilevered slab.

The author's approach is to utilize $12.7 \mathrm{~mm}$ as a minimum so the structural integrity still intact and the concrete cover are still maintained. In the $12.7 \mathrm{~mm}$ depression, a $25.4 \mathrm{~mm}$ thick EPS rigid insulation is positioned to separate the concrete surface from the sliding door/spandrel panel frame [Figure 22].

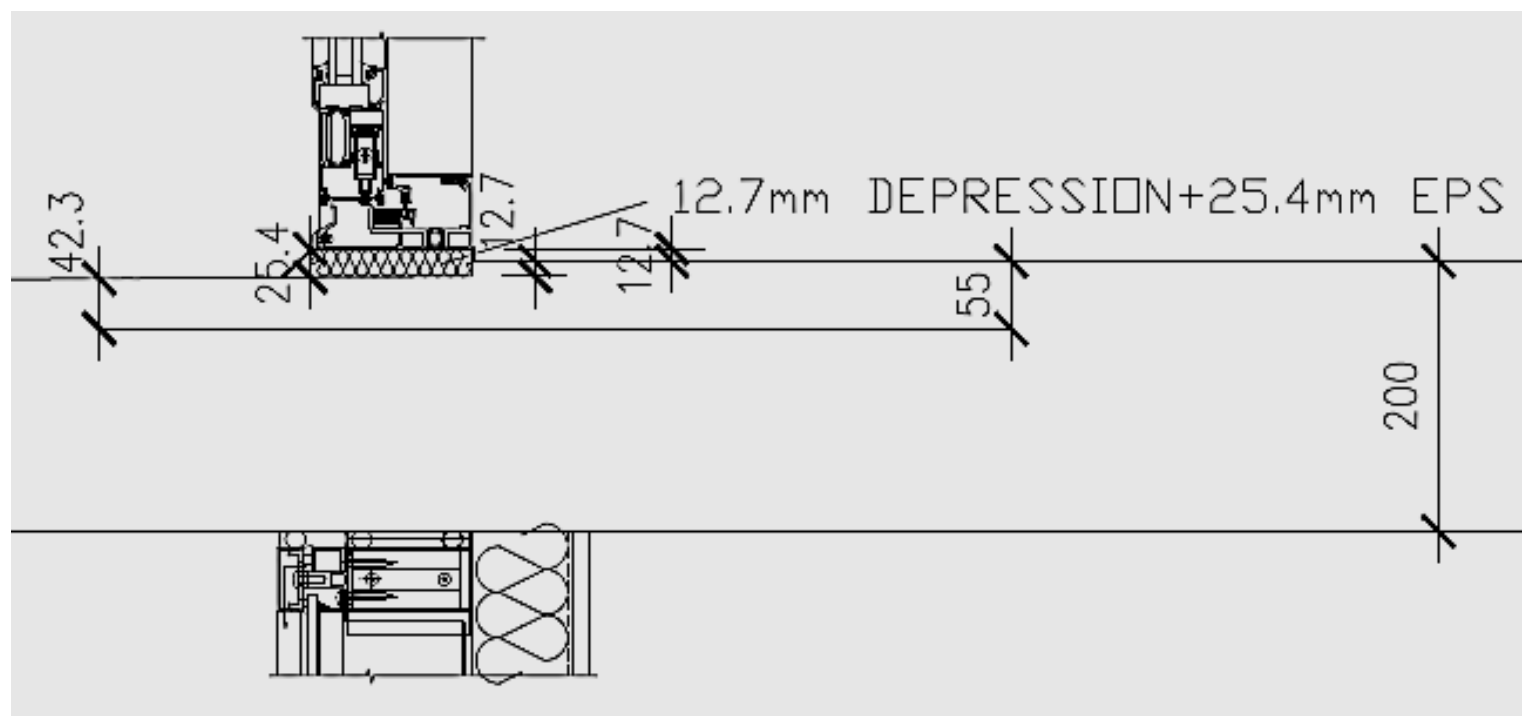

Figure 22: Insulated Curb Condition Solution showing $12.7 \mathrm{~mm}$ Depression in Concrete Slab and $25.4 \mathrm{~mm}$ thick EPS Rigid Insulation

EPS rigid insulation has the ability to retain its specific thermal and mechanical properties even after being subjected to in-situ freeze-thaw cycling [31]. EPS rigid insulation doesn't support mold or mildew growth and it is a moisture resistance product and has been confirmed through in-situ testing by the Expanded Polystyrene Association of Canada (EPAC) that its ability to retain moisture is very low [32]. 
From the aforementioned facts, the suggestion of using EPS rigid insulation underneath the sliding door frame is very advantageous and important in terms of durability and maintaining its thermal properties and being a moisture rebelling material and is expected to perform properly when exposed to severe weather conditions.

\subsection{Description of Modelling Approach}

To achieve the objectives of this MRP, the proposed construction model assembly was developed to allow simulation to evaluate the predicted U-values and concrete surface temperature for the modeled scenarios in an objective manner.

Some consideration has been given to the scenarios from previously presented key studies. However, these proposed models and scenarios were chosen to demonstrate the benefits of having a lower U-value framed sliding door and spandrel panel installed in a cantilevered concrete balcony slab. Also, to demonstrate the benefits of adding the proposed insulated curb condition with or without a proprietary thermal break [18].

The balcony slab was modeled in THERM with and without the proposed insulated curb condition and with and without a proprietary thermal break to determine the overall thermal resistance, thermal comfort and condensation resistance.

The scenarios are categorized under two sets of groups:

- Group No. 1: All scenarios of this group are modeled with low U-value framed spandrel panel sill and head above and below balcony slab with R-value of $2.645 \mathrm{~m}^{2} . \mathrm{K} / \mathrm{W}$, or an equivalent $\mathrm{U}$-value of $0.378 \mathrm{~W} / \mathrm{m}^{2} . \mathrm{K}$. This group is labeled as $\mathrm{KSP}$

This group has the following 4 scenarios numbered from 1 to 4 :

Scenario 1: Conventional - Cantilevered Concrete Balcony Slab with Spandrel/Spandrel of Uvalue of $0.378 \mathrm{~W} / \mathrm{m}^{2} . \mathrm{K}$ above and below balcony slab with nothing added. 


\section{Labeled as KSP-NEPS-NTB}

Scenario 2: Cantilevered Concrete Balcony Slab with Spandrel/Spandrel of U-value of 0.378 W/ $\mathrm{m}^{2} . \mathrm{K}$ above and below balcony slab with Insulated Curb Condition of $12.7 \mathrm{~mm}$ EPS.

Labeled as KSP-EPS-NTB

Scenario3: Cantilevered Concrete Balcony Slab with Spandrel/Spandrel of U-value of 0.378 W/ $\mathrm{m}^{2} . \mathrm{K}$ above and below balcony slab with a Proprietary Thermal Break "Schöck Isokorb" Labeled as KSP-NEPS-TBSI

Scenario 4: Cantilevered Concrete Balcony Slab with Spandrel/Spandrel of U-value of 0.378 W/

$\mathrm{m}^{2} . \mathrm{K}$ above and below balcony slab with Insulated Curb Condition and proprietary thermal break “Schöck Isokorb ${ }^{\circledR} "$. Labeled as KSP-EPS-TBSI

It should be noted that the stud cavity was left open with no insulation. However, for comparison purposes only, each scenario was remodeled by installing a $78.8 \mathrm{~mm}$ (3.1 inches) of glass wool insulation in the frame cavity with R-value of $2.07 \mathrm{~m}^{2} . \mathrm{K} / \mathrm{W}$, or an equivalent U-value of $0.481 \mathrm{~W} / \mathrm{m}^{2} . \mathrm{K}$ and a thermal conductivity of $0.0380 \mathrm{~W} / \mathrm{m} . \mathrm{k}$.

Table 10 illustrates cross sections for each scenario identified under group No. 1. Cantilevered concrete balcony slab complete cross sections are illustrated in Appendix D. 
Table 10: Cross Section detail for each Scenario of Group No. 1 with its Associated Label
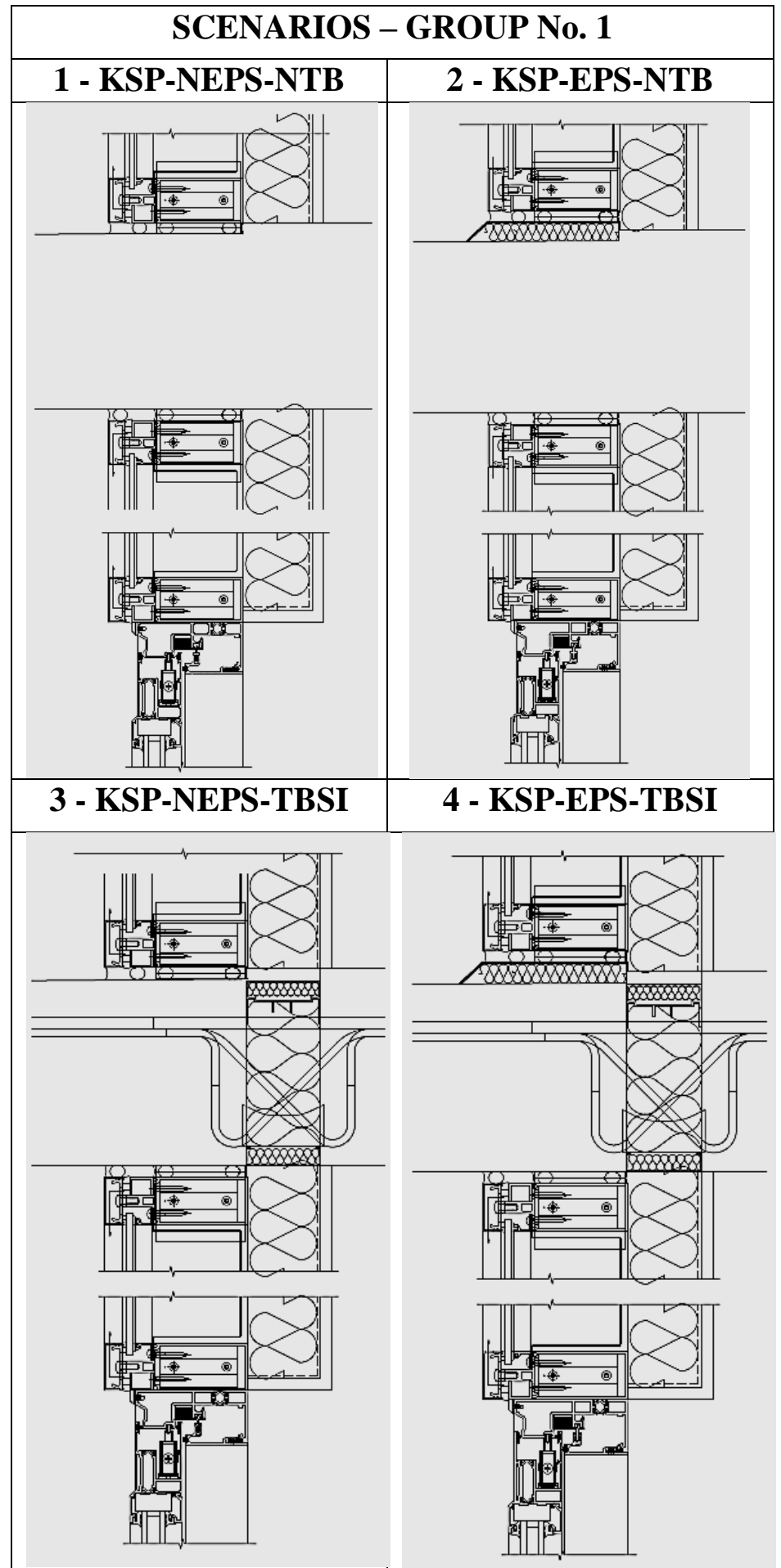
- Group No. 2: All scenarios of this group are modeled with low U-value framed sliding door sill with a U-value used of $1.324 \mathrm{~W} / \mathrm{m}^{2} . \mathrm{K}$ above balcony slab and a low U-value spandrel panel head below balcony slab with R-value used of $2.645 \mathrm{~m}^{2} . \mathrm{K} / \mathrm{W}$, or an equivalent $\mathrm{U}$-value of $0.378 \mathrm{~W} / \mathrm{m}^{2} . \mathrm{K}$. This group is labeled as $\mathrm{KSD}$.

This group has the following 4 scenarios numbered 5 to 8 :

Scenario 5: Conventional - Cantilevered Concrete Balcony Slab with Sliding Door Sill of Uvalue of $1.324 \mathrm{~W} / \mathrm{m}^{2} . \mathrm{K}$ above and Spandrel Panel Head of U-value of $0.378 \mathrm{~W} / \mathrm{m}^{2} . \mathrm{K}$ below balcony slab with nothing added. Labeled as KSD-NEPS-NTB

Scenario 6: Cantilevered Concrete Balcony Slab with Sliding Door Sill of U-value of 1.324 $\mathrm{W} / \mathrm{m}^{2} . \mathrm{K}$ above and Spandrel Panel Head of U-value of $0.378 \mathrm{~W} / \mathrm{m}^{2} . \mathrm{K}$ below balcony slab with Insulated Curb Condition of 12.7 mm EPS. Labeled as KSD-EPS-NTB

Scenario 7: Cantilevered Concrete Balcony Slab with Sliding Door Sill of U-value of 1.324 $\mathrm{W} / \mathrm{m}^{2} . \mathrm{K}$ above and Spandrel Panel Head of U-value of $0.378 \mathrm{~W} / \mathrm{m}^{2} . \mathrm{K}$ below balcony slab with a Proprietary Thermal Break "Schöck Isokorb ${ }^{\circledR}$ ". Labeled as KSD-NEPS-TBSI

Scenario 8: Cantilevered Concrete Balcony Slab with Sliding Door Sill of U-value of 1.324 W $/ \mathrm{m}^{2} . \mathrm{K}$ above and Spandrel Panel Head of U-value of $0.378 \mathrm{~W} / \mathrm{m}^{2} . \mathrm{K}$ below balcony slab with insulated curb condition and proprietary thermal break "Schöck Isokorb" ${ }^{\circledR,}$. Labeled as KSP-EPS-TBSI

It should be noted that the stud cavity was left open with no insulation. However, for comparison purposes only, each scenario was remodeled by installing a $78.8 \mathrm{~mm}$ (3.1 inches) of glass wool insulation in the frame cavity with R-value of $2.07 \mathrm{~m}^{2} . \mathrm{K} / \mathrm{W}$, or an equivalent U-value of $0.481 \mathrm{~W} / \mathrm{m}^{2} . \mathrm{K}$ and a thermal conductivity of $0.0380 \mathrm{~W} / \mathrm{m} . \mathrm{k}$. 
Table 11 illustrates cross sections for each scenario identified under group No. 2. Cantilevered concrete balcony slab complete cross sections are illustrated in Appendix D.

Table 11: Cross Section Detail for each Scenario of Group No. 2 with its Associated Label

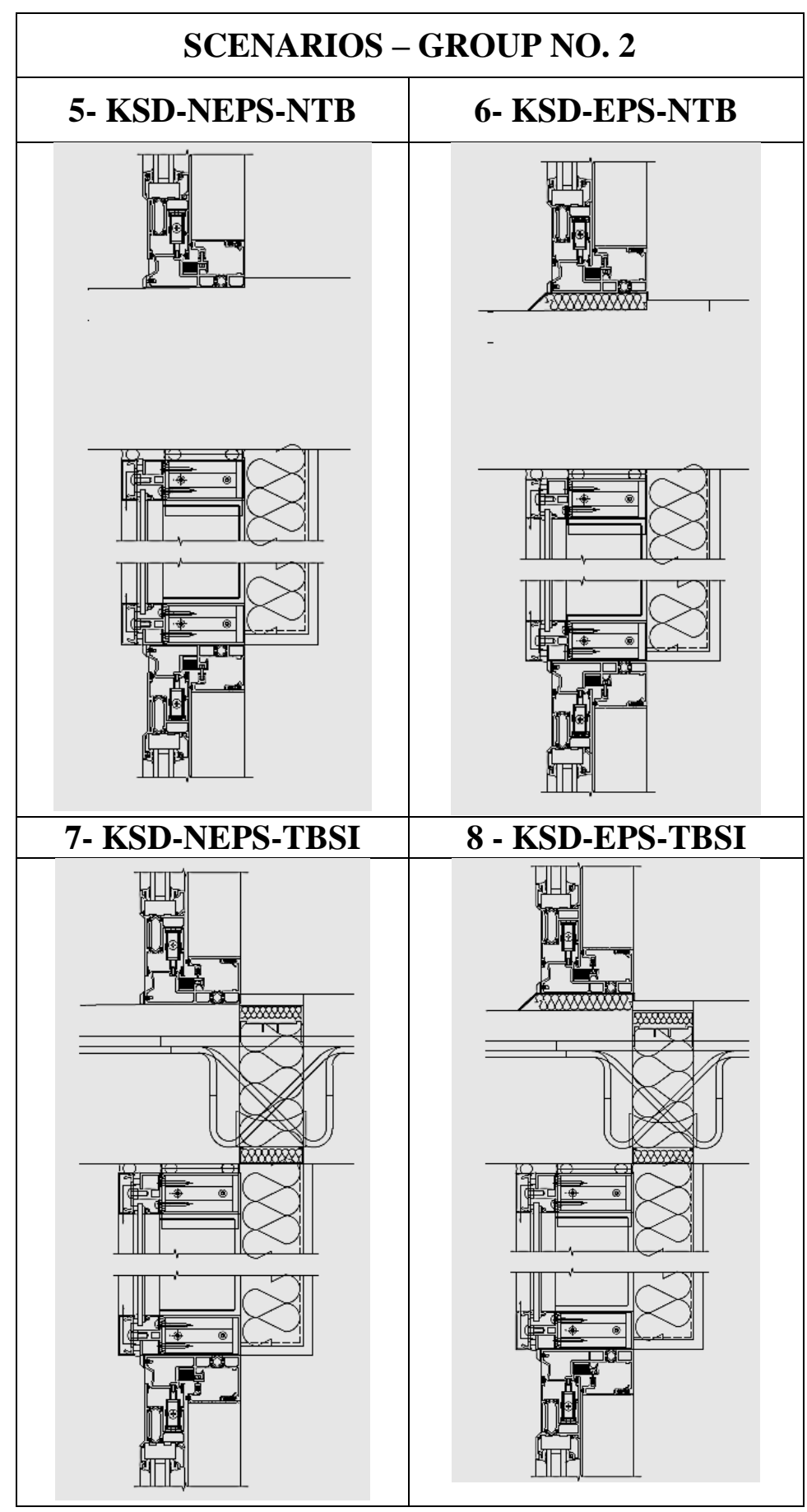




\subsubsection{Developing Models for 2D THERM Simulation}

Table 10 and Table 11 demonstrated 8 proposed construction scenarios numbered from (1 to 8) that reflects the most possible conditions that are encountered in an actual design condition. These scenarios are meant to show variety of design decisions that could be taken by designers in order to achieve higher thermal performance assemblies with best cost effective approach.

The balcony slab was modeled in THERM with and without the incorporation of the proposed insulated curb condition and with and without the incorporation of the proprietary thermal break to determine the overall thermal resistance, thermal comfort and condensation resistance of the proposed assemblies.

The insulated curb condition was purposely incorporated with each individual case i.e. conventional KSP, conventional KSD, and with proprietary thermal break with the intention of properly identify any significant changes that could occur to the interior concrete surface temperatures the overall U-value of such scenarios.

It should be noted that the stud cavity was left open with no insulation. However, for comparison purposes only, each scenario was remodeled with glass wool insulation installed in the frame cavity.

In a similar approach and for the purpose of thermal transmittance comparative analysis, a set of additional eight scenarios labeled similar to the scenarios demonstrated in Table 10 and 11, but are numbered from (I to VIII) (See Appendix D). These scenarios were modeled and simulated, using simplified spandrel section and sliding door section. Both sections used 25.4 mm total thickness DGU with Argon gas-filling and low-e coating with a COG U-value of 1.324 $\mathrm{W} / \mathrm{m}^{2} . \mathrm{K}$ above and below slab. Component U-values and overall U-values were calculated for each scenario. 


\subsubsection{Assumption and Boundary Conditions}

For the purpose of simulation, boundary conditions were chosen in a manner similar to those was used by the previously presented key studies. Exterior and interior boundary conditions were used for Toronto's cold climate conditions which are close to ASHRAE 2009 Handbook-Fundamentals [4]. The boundary conditions chosen are applicable to an extreme winter scenario in the Canadian environment.

Exterior boundary condition is $\left(-18^{\circ} \mathrm{C}\right)$, and $50 \%$ Relative Humidity $(\mathrm{RH})$ and surface film coefficient is $h o=26.00 \mathrm{~W} / \mathrm{m}^{2} . \mathrm{K}$ for blackbody radiation model with Emissivity of 0.9 . Interior boundary conditions is $\left(+21^{\circ} \mathrm{C}\right), 30 \% \mathrm{RH}$ and surface film coefficient is $h i=8.3 \mathrm{~W} / \mathrm{m}^{2} . \mathrm{K}$ for simplified model simulation. The vertical face of the slab on the interior was specified as an adiabatic surface. Dewpoint for interior boundary conditions is $\left(+3{ }^{\circ} \mathrm{C}\right)$.

Each section was modeled with a balcony slab length of $1.95 \mathrm{~m}$ on the exterior and the floor slab was continued for $0.65 \mathrm{~m}$ on the inside of the wall assemblies (See Appendix D). The thickness of the modeled concrete slab is $200 \mathrm{~mm}$ with $55 \mathrm{~mm}$ concrete cover over the reinforcement bars from interior and $42.3 \mathrm{~mm}$ from exterior due to $2 \%$ slope towards the outer edge of the cantilevered concrete balcony slab [Figure 17]. THERM models generated using the connection details shown in Figures 18.

Materials used in the proposed construction assemblies and scenarios are as per technical details provided by manufacturer for the low U-value framed glazing system and proprietary thermal break. Specific material properties are consistent between all the models, and therefore it established a baseline for overall performance. For the scenarios/models that incorporated the proprietary thermal break, an equivalent thermal conductivity $\mathrm{k}_{\mathrm{eq}}$-value of $0.194 \mathrm{~W} / \mathrm{m} . \mathrm{k}$ was used which incorporated the steel rebar placement. 


\subsubsection{D THERM Scenario's Simulation Limitations}

Simulated numbers generated from any software are not $100 \%$ accurate, and it should be noted that there is an inherent margin of error within the 2D THERM modelling program itself. The default value for the maximum \% error energy norm in THERM is 10\% [33], all simulated scenarios had less than $10 \%$ error energy norm. However, simulated numbers are being used for comparative purposes only and are not expected to impact the overall results of the analysis for the purpose of this study.

\subsection{Treatment of Modelling Results}

All scenarios had shared the low U-value framed glazing system, the rest of the options were varied either with or without the insulated curb condition of $12.7 \mathrm{~mm}$ thick EPS which was shared with and without a proprietary thermal break.

The main core of all scenarios was the insulated curb condition of $12.7 \mathrm{~mm}$ thick EPS rigid insulation which was intentionally added to the conventional cantilevered concrete balcony slab and added to scenarios with and without a proprietary thermal break to verify the effectiveness of such addition on the thermal performance of the model assembly scenarios.

Interior surface temperatures are obtained from scenarios (1 to 8) at slab/frame intersection above slab and at slab/frame intersection below slab; in addition to that, a length of the interior concrete surface was measured from the slab/frame intersection to where the interior surface temperature reaches $20^{\circ} \mathrm{C}$. From the 2D THERM isotherm models generated, a full review of each scenario was accomplished for each scenario to substantiate existence of potential risk of condensation at a dew point line of $\left(+3^{\circ} \mathrm{C}\right)$ interior boundary condition.

U-values and overall U-values are calculated from scenarios (I to VIII) and all results including interior surface temperatures are analysed among the scenarios themselves and a 
comparative analysis is conducted with the results from previous presented key studies in section 2.4 of this report. 


\subsection{RESULTS AND DISCUSSION}

All the proposed scenarios are incorporated a lower U-value framed glazing system and therefore, a comparative analysis of the results with the ones of the previous key studies, could provide meaningful conclusion despite the many differences in the assumption and simulation approach among the studies and this MRP.

In order to evaluate the improvement of the thermal performance of the proposed scenarios (1 to 8$)$ that had the inclusion of the insulated curb condition, this report is focused on the interior surface temperature results at slab/frame intersection above and below slab from the modeled scenarios that are relevant to surface areas that have significant influence on thermal comfort and condensation resistance and on the length of the interior concrete surface that reaches $20^{\circ} \mathrm{C}$.

Dewpoint of $\left(+3^{\circ} \mathrm{C}\right)$ and $\mathrm{RH}$ of $30 \%$ with $21^{\circ} \mathrm{C}$ interior temperature are the interior boundary condition used to verify potential risk of condensation. A review of equal temperature lines (isotherm) is implemented at each scenario (1 to 8) in order to verify if any potential risk of condensation could occur at any location and/or interior surface.

In terms of evaluating thermal transmittance of the proposed scenarios (I to VIII) that had the inclusion of the insulated curb condition, U-values and overall U-values are calculated for each component and for each scenario. This report is focused on the U-values of the upper surface of the concrete slab surface to analyse if a significant decrease occurred in the U-value because of that inclusion. A comparative analysis of overall U-values for specific scenarios from this report with similar scenarios from previous presented studies is complete to verify the significance of the inclusion of a lower U-value framed condition and the insulated curb condition in the proposed models. 


\subsection{Interior Surface Temperature Modeling Results}

Interior surface temperature values and length from slab/frame intersection until it reaches $20^{\circ} \mathrm{C}$ from scenarios ( 1 to 8$)$ are demonstrated in Table 12 and 13.

Table 12: Thermal Profile showing Interior Surface Temperature at Slab/Frame Intersection Above and Below Slab and Length of Surface when it Reaches $20^{\circ} \mathrm{C}$ for Each Proposed Modeled Scenario of Group No.1

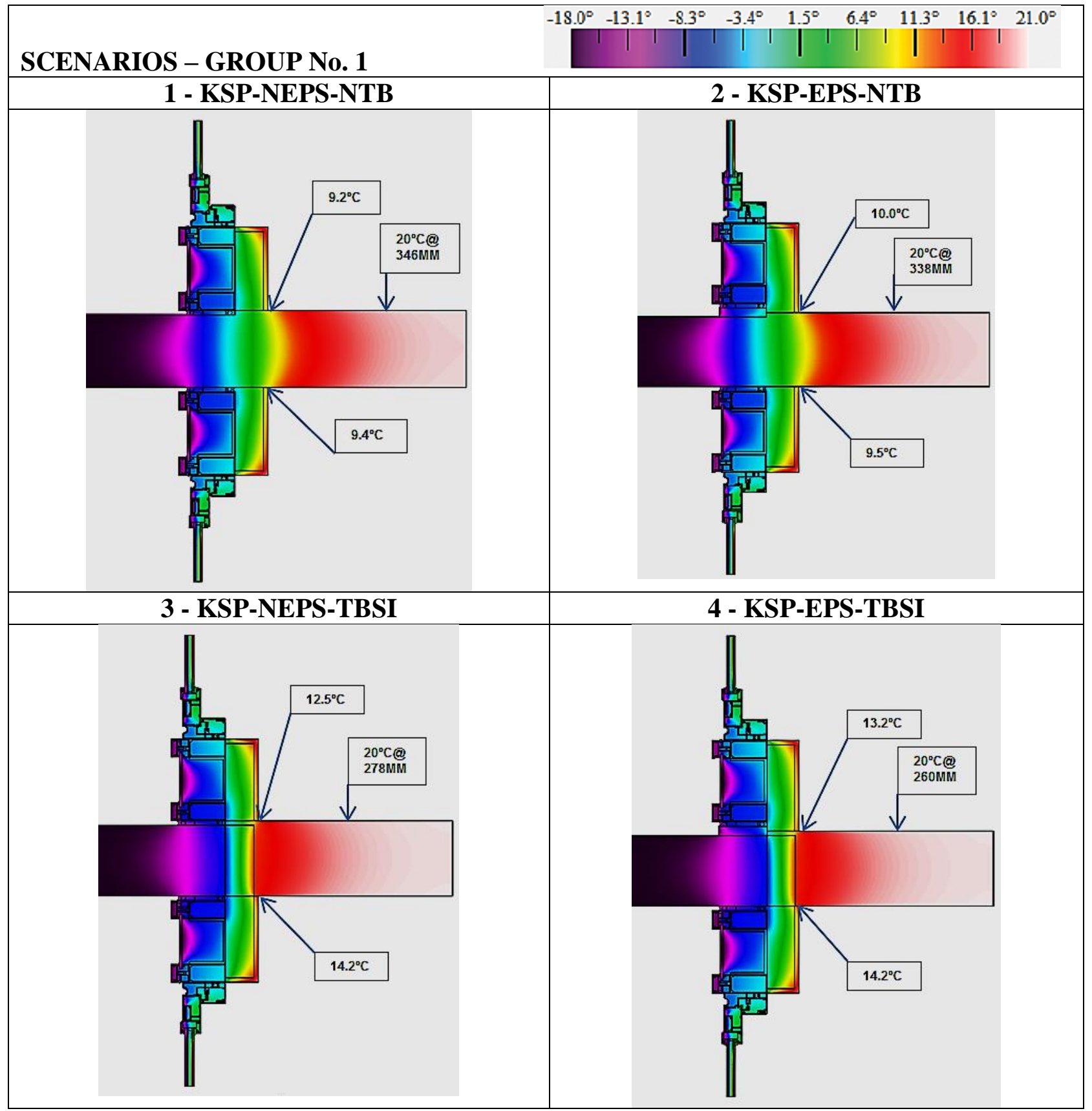


Table 13: Thermal Profile showing Interior Surface Temperature at Slab/Frame Intersection Above and Below Slab and Length of Surface when it Reaches $20^{\circ} \mathrm{C}$ for Each Proposed Modeled Scenario of Group No.2

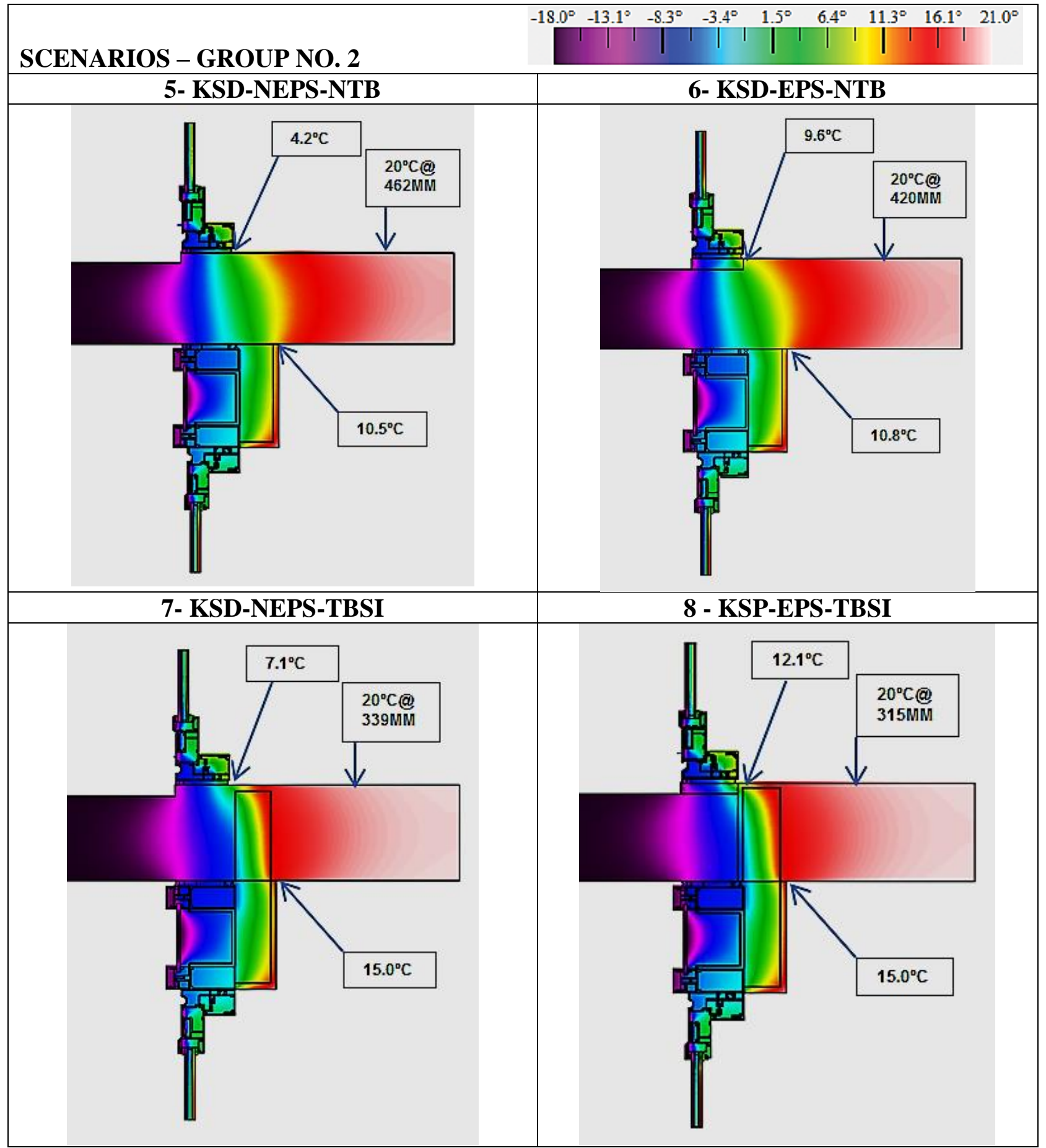


Table 12 and 13 illustrates thermal profile of each scenario (1 to 8) showing interior surface temperature captured at slab/frame intersection above and below slab and length of the interior surface temperature from slab/frame intersection until it reaches $20^{\circ} \mathrm{C}$.

The scenarios in both tables are deliberately set in two columns to illustrate the results of temperatures of each scenario that had no insulated curb condition adjacent to the scenario that had the inclusion of that condition.

Full scales of thermal profiles and lines of equal temperature (isotherm) for scenarios (1 to 8) are located in Appendix D.

For the purpose of analysis and comparison, Table 14 captured only interior surface temperature of slab/frame intersection above and below slab for each scenario. It also captured interior surface temperature of slab/frame intersection for each scenario when the stud cavity is filled with glass wool insulation.

Table 14: Interior Surface Temperatures at Concrete Slab/Frame above and below Concrete Slab

\begin{tabular}{|l|l|c|c|c|c|c|}
\hline \multicolumn{2}{|c|}{ SCENARIO } & \multirow{2}{*}{ ABOVE } & \multirow{2}{*}{ BELOW } & Length Until 20 & \multicolumn{2}{|l|}{ With Cavity Insulation } \\
\cline { 5 - 7 } 1 & $\begin{array}{l}\text { Conventional } \\
\text { KSP-NEPS-NTB }\end{array}$ & $9.2^{\circ} \mathrm{C}$ & $9.4^{\circ} \mathrm{C}$ & $346 \mathrm{~mm}$ & $9.6^{\circ} \mathrm{C}$ & $9.7^{\circ} \mathrm{C}$ \\
\hline $\mathbf{2}$ & KSP-EPS-NTB & $10.0^{\circ} \mathrm{C}$ & $9.5^{\circ} \mathrm{C}$ & $338 \mathrm{~mm}$ & $10.5^{\circ} \mathrm{C}$ & $10.2^{\circ} \mathrm{C}$ \\
\hline $\mathbf{3}$ & KSP-NEPS-TBSI & $12.5^{\circ} \mathrm{C}$ & $14.2^{\circ} \mathrm{C}$ & $278 \mathrm{~mm}$ & $13.7^{\circ} \mathrm{C}$ & $15.8^{\circ} \mathrm{C}$ \\
\hline $\mathbf{4}$ & KSP-EPS-TBSI & $13.2^{\circ} \mathrm{C}$ & $14.2^{\circ} \mathrm{C}$ & $260 \mathrm{~mm}$ & $14.4^{\circ} \mathrm{C}$ & $16.0^{\circ} \mathrm{C}$ \\
\hline $\mathbf{5}$ & $\begin{array}{l}\text { Conventional } \\
\text { KSD-NEPS-NTB }\end{array}$ & $4.8^{\circ} \mathrm{C}$ & $10.5^{\circ} \mathrm{C}$ & $462 \mathrm{~mm}$ & $4.8^{\circ} \mathrm{C}$ & $11.3^{\circ} \mathrm{C}$ \\
\hline $\mathbf{6}$ & KSD-EPS-NTB & $9.6^{\circ} \mathrm{C}$ & $10.8^{\circ} \mathrm{C}$ & $420 \mathrm{~mm}$ & $9.5^{\circ} \mathrm{C}$ & $11.6^{\circ} \mathrm{C}$ \\
\hline $\mathbf{7}$ & KSD-NEPS-TBSI & $7.1^{\circ} \mathrm{C}$ & $15.0^{\circ} \mathrm{C}$ & $339 \mathrm{~mm}$ & $7.0^{\circ} \mathrm{C}$ & $16.7^{\circ} \mathrm{C}$ \\
\hline $\mathbf{8}$ & KSD-EPS-TBSI & $12.1^{\circ} \mathrm{C}$ & $15.0^{\circ} \mathrm{C}$ & $315 \mathrm{~mm}$ & $11.0^{\circ} \mathrm{C}$ & $16.7^{\circ} \mathrm{C}$ \\
\hline
\end{tabular}




\subsection{Interior Surface Temperatures Results Analysis}

The surface temperature results illustrated in Table 14 for above and below slab indicated the following:

For conventional concrete balcony scenarios 1 and 2, which had a lower U-value framed spandrel panel above and below slab along with the benefit of adding the insulated curb condition of $12.7 \mathrm{~mm}$ thick EPS, the interior surface temperature above slab has a slight increase from $9.2^{\circ} \mathrm{C}$ to $10^{\circ} \mathrm{C}$ and an $8 \mathrm{~mm}$ decrease in length until $20^{\circ} \mathrm{C}$. Similar effect is shown on scenarios 3 and 4 that had a proprietary thermal break along with and without the benefit of adding the insulated curb condition of $12.7 \mathrm{~mm}$ thick EPS where interior surface temperature has a slight increase from $12.5^{\circ} \mathrm{C}$ to $13.2^{\circ} \mathrm{C}$ and a $17 \mathrm{~mm}$ decrease in length until $20^{\circ} \mathrm{C}$.

However, significant increase in interior surface temperature is noticed from $4.8^{\circ} \mathrm{C}$ to $9.6^{\circ} \mathrm{C}$ for conventional scenarios 5 and 6 , which had a lower U-value sliding door above and spandrel panel below slab along with the benefit of adding the insulated curb condition of 12.7 $\mathrm{mm}$ thick EPS, and $42 \mathrm{~mm}$ decrease in length until $20^{\circ} \mathrm{C}$. Similar significant increase is noticed in interior surface temperature from $7.1^{\circ} \mathrm{C}$ to $12.1^{\circ} \mathrm{C}$ for scenarios 7 and 8 that had a proprietary thermal break along with and without the benefit of adding the insulated curb condition of 12.7 $\mathrm{mm}$ thick EPS and $24 \mathrm{~mm}$ decrease in length until $20^{\circ} \mathrm{C}$.

It should be noted that the interior surface temperatures resulted from simulating the same scenarios ( 1 to 8 ) with the inclusion of $77.8 \mathrm{~mm}$ of glass wool insulation in the stud cavity had an average insignificant increase in temperature from $0.3^{\circ} \mathrm{C}$ to $1.8^{\circ} \mathrm{C}$ applicable on both above and below slab interior surface temperature. This indicates that increasing façade insulation had insignificant effect on the interior concrete surface temperature. 


\subsection{Condensation Resistance Results Analysis}

Upon the review of isotherm lines of equal temperature lines of each scenario (see Appendix D), the dewpoint of $\left(+3^{\circ} \mathrm{C}\right)$ is occurring within the low U-value framed glazing system (sliding door section and spandrel panel section) and in concrete slab and in the stud cavity with and without insulation and it appeared that the risk of condensation is unlikely to occur at any of the (1 to 8) modeled scenarios.

\subsection{Interior Concrete Surface Temperatures Results Comparative Analysis}

Sections 2.4 and 2.5 of this report summarized and presented the previous key studies and illustrated the modeled scenarios and the interior concrete surface temperatures for each modeled scenario. As discussed previously that each study had its own assumptions, boundary conditions, different material thermal conductivity, and different methods of simulation.

Of particular interest to this study, and for the purpose of comparative analysis, it appeared that $\mathrm{Ge}, \mathrm{H}$ et al (2013) [14] is the only appropriate study that used 2D THERM method of simulation, scenarios and models that had similarity to this study and found interior surface temperatures at slab/frame intersections above and below balcony slab and even measured the length of concrete surface temperature until it reaches $20^{\circ} \mathrm{C}$.

Table 15 illustrates scenarios (I and II) from Ge, $\mathrm{H}$ et al (2013) that are similar to the scenarios of this report in terms of glazing system configuration, with and without the addition of a proprietary thermal break. Scenarios $(1,3,5$, and 7$)$ from this study were chosen in such a manner that these scenarios only include a low U-value framed glazing system without the inclusion of the insulated curb condition, so that any significant difference could be distinguished because of the use of a low U-value framed glazing system. 
Table 15: Interior Surface Temperature and Length until $20^{\circ} \mathrm{C}$ for Scenarios from Ge, H, et, all (2013) [14] and this MRP Study

\begin{tabular}{|c|c|c|c|c|c|c|}
\hline \multirow[b]{2}{*}{ STUDY } & \multirow{2}{*}{\multicolumn{3}{|c|}{ BALCONY SLAB SCEANRIO }} & \multicolumn{2}{|c|}{ ABOVE BALCONY } & \multirow{3}{*}{$\begin{array}{c}\begin{array}{c}\text { BELOW } \\
\text { BALCONY }\end{array} \\
\begin{array}{c}\text { Surface } \\
\text { Temperature } \\
\left({ }^{\circ} \mathrm{C}\right)\end{array} \\
11.5\end{array}$} \\
\hline & & & & & Length Until & \\
\hline \multirow{8}{*}{$\begin{array}{l}\text { Ge, H, } \\
\text { et, all } \\
(2013)\end{array}$} & \multirow{2}{*}{$\mathbf{I}$} & \multirow{2}{*}{$\begin{array}{l}\text { Above: Sliding doors } \\
\text { Below: Spandrel Panel }\end{array}$} & $\begin{array}{c}\text { No } \\
\text { Break }\end{array}$ & 7.0 & 440 & \\
\hline & & & Break & 12.8 & 270 & 16.1 \\
\hline & \multirow{2}{*}{ II } & \multirow{2}{*}{$\begin{array}{l}\text { Above: Spandrel Panel } \\
\text { Below: Spandrel Panel }\end{array}$} & $\begin{array}{c}\text { No } \\
\text { Break }\end{array}$ & 9.3 & 370 & 9.8 \\
\hline & & & Break & 13.4 & 250 & 14.9 \\
\hline & \multirow{2}{*}{ III } & \multirow{2}{*}{$\begin{array}{l}\text { Above: Clear DGU-RSI } \\
0.35\left(\mathrm{U}=2.86 \mathrm{~W} / \mathrm{m}^{2} . \mathrm{K}\right) \\
\text { Below: Spandrel RSI } \\
2.50\left(\mathrm{U}=0.4 \mathrm{~W} / \mathrm{m}^{2} . \mathrm{K}\right)\end{array}$} & $\begin{array}{c}\text { No } \\
\text { Break }\end{array}$ & 6.2 & 390 & 6.7 \\
\hline & & & Break & 11.5 & 280 & 16.2 \\
\hline & \multirow{2}{*}{ IV } & \multirow{2}{*}{$\begin{array}{l}\text { Above: Clear DGU-RSI } \\
0.73\left(\mathrm{U}=1.369 \mathrm{~W} / \mathrm{m}^{2} . \mathrm{K}\right) \\
\text { Below: Spandrel RSI } \\
2.50\left(\mathrm{U}=0.4 \mathrm{~W} / \mathrm{m}^{2} . K\right)\end{array}$} & $\begin{array}{c}\text { No } \\
\text { Break }\end{array}$ & 6.3 & 390 & 6.7 \\
\hline & & & Break & 12.3 & 280 & 16.3 \\
\hline \multirow{8}{*}{$\begin{array}{l}\text { MRP } \\
\text { Study }\end{array}$} & 1 & $\begin{array}{c}\text { Conventional } \\
\text { KSP-NEPS-NTB }\end{array}$ & $\begin{array}{l}\text { No } \\
\text { Break }\end{array}$ & 9.2 & 346 & 9.4 \\
\hline & 3 & KSP-NEPS-TBSI & Break & 12.5 & 260 & 14.2 \\
\hline & 5 & $\begin{array}{c}\text { Conventional } \\
\text { KSD-NEPS-NTB } \\
\end{array}$ & $\begin{array}{l}\text { No } \\
\text { Break }\end{array}$ & 4.8 & 462 & 10.5 \\
\hline & 7 & KSD-NEPS-TBSI & Break & 7.1 & 339 & 15.0 \\
\hline & 2 & KSP-EPS-NTB & Curb & 10.0 & 339 & 9.5 \\
\hline & 4 & KSP-EPS-TBSI & $\begin{array}{l}\text { Curb } \\
+ \\
\text { Break } \\
\end{array}$ & 13.2 & 260 & 14.2 \\
\hline & 6 & KSD-EPS-NTB & Curb & 9.6 & 420 & 10.8 \\
\hline & 8 & KSD-EPS-TBSI & $\begin{array}{l}\text { Curb } \\
+ \\
\text { Break } \\
\end{array}$ & 12.1 & 315 & 15.0 \\
\hline
\end{tabular}

The following could be derived from the comparative analysis of the figures listed in Table 15:

For conventional balcony scenario (II) from Ge, H, et, all (2013) and conventional balcony scenarios (1) from this MRP report which have spandrel/spandrel above and below balcony slab with no thermal break, the interior surface temperature values are $9.3^{\circ} \mathrm{C}$ versus 
$9.2^{\circ} \mathrm{C}$ above slab and $9.8^{\circ} \mathrm{C}$ versus $9.4^{\circ} \mathrm{C}$ below slab and the length measured until the temperature reaches $20^{\circ} \mathrm{C}$ is $370 \mathrm{~mm}$ versus $346 \mathrm{~mm}$.

Also, for same balcony scenario (II) and balcony scenarios (3) which have spandrel/spandrel above and below balcony slab with thermal break installed, the interior surface temperature values are $13.4^{\circ} \mathrm{C}$ versus $12.5^{\circ} \mathrm{C}$ above slab and $14.9^{\circ} \mathrm{C}$ versus $12.5^{\circ} \mathrm{C}$ below slab and the length measured until the temperature reaches $20^{\circ} \mathrm{C}$ is $250 \mathrm{~mm}$ versus $260 \mathrm{~mm}$.

The differences among the results are insignificant and appeared consistent with the conventional status. On the other hand, for the thermal break status, the interior surface temperature results from $\mathrm{Ge}, \mathrm{H}$, et, all (2013) appeared higher from the temperature results of this MRP.

For conventional balcony scenario (I) from Ge, H, et, all (2013) and conventional balcony scenarios (5) from this MRP report which have sliding/spandrel above and below balcony slab with no thermal break, the interior surface temperature values are $7.0^{\circ} \mathrm{C}$ versus $4.8^{\circ} \mathrm{C}$ above slab and $11.5^{\circ} \mathrm{C}$ versus $10.5^{\circ} \mathrm{C}$ below slab and the length measured until the temperature reaches $20^{\circ} \mathrm{C}$ is $440 \mathrm{~mm}$ versus $462 \mathrm{~mm}$.

Also, for same balcony scenario (I) and balcony scenarios (7) which have sliding/spandrel above and below balcony slab with thermal break installed, the interior surface temperature values are $12.8^{\circ} \mathrm{C}$ versus $7.1^{\circ} \mathrm{C}$ above slab and $16.1^{\circ} \mathrm{C}$ versus $15.0^{\circ} \mathrm{C}$ below slab and the length measured until the temperature reaches $20^{\circ} \mathrm{C}$ is $270 \mathrm{~mm}$ versus $339 \mathrm{~mm}$.

The differences among the results for the conventional and for the thermal break status for above slab temperatures appeared significant. On the contrary, for below slab appeared insignificant. 
In both cases, temperature difference appeared high when thermal break was installed, this could be related to the positioning of the thermal break in the balcony slab. In $\mathrm{Ge}, \mathrm{H}$, et, all (2013), the proprietary thermal break was positioned in the concrete slab right below the sliding door frame, whereas the proprietary thermal break in this MRP report was positioned as per the manufacturer installation requirements a $100 \mathrm{~mm}$ off the sliding door frame to the inside of the floor slab (See Appendix D and E) and that could be the reason why the interior surface temperature appeared higher. In addition to that, no R-value was mentioned in $\mathrm{Ge}, \mathrm{H}$, et, all (2013) for scenarios (I) and (II) and therefore, it could be higher or lower than the ones used by this MRP.

For scenarios (III) and (IV) from Ge, H, et, all (2013) that have no proprietary thermal break, the interior surface temperature results of that study appeared similar despite the difference in $\mathrm{U}$-value used for glass component above slab $\left(2.85 \mathrm{~W} / \mathrm{m}^{2} . \mathrm{K}\right.$ versus $\left.1.369 \mathrm{~W} / \mathrm{m}^{2} . \mathrm{K}\right)$.

When comparing those results with the interior surface temperatures of scenarios (2) and (6) from this MRP report that have lower U-value framed condition of $\left(1.324 \mathrm{~W} / \mathrm{m}^{2} . \mathrm{K}\right.$ above slab and $0.378 \mathrm{~W} / \mathrm{m}^{2} . \mathrm{K}$ below slab) and incorporated the insulated curb condition, the interior surface temperatures above slab tend to increase from $6.2^{\circ} \mathrm{C}$ and $6.3{ }^{\circ} \mathrm{C}$ to $10.0{ }^{\circ} \mathrm{C}$ and $9.6{ }^{\circ} \mathrm{C}$ respectively, and below slab from $6.7^{\circ} \mathrm{C}$ to $9.5^{\circ} \mathrm{C}$ and $10.8^{\circ} \mathrm{C}$ respectively, which is significant. Also, the length measured until the temperature reaches $20^{\circ} \mathrm{C}$ for scenario (III) from $\mathrm{Ge}, \mathrm{H}$, et, all (2013) and (2) from this MRP is decreased $52 \mathrm{~mm}$.

Similar, for scenario (III) from Ge, H, et, all (2013) that have a proprietary thermal break when compared with similar scenario (4) from this MRP report that have lower U-value framed condition of $(1.324 \mathrm{~W} / \mathrm{m} 2 . \mathrm{K}$ above slab and $0.378 \mathrm{~W} / \mathrm{m} 2 . \mathrm{K}$ below slab) and incorporated the insulated curb condition and a proprietary thermal break, the interior surface temperatures are 
increased from $11.5^{\circ} \mathrm{C}$ to $13.2^{\circ} \mathrm{C}$ above slab and even the measured length until the temperature reaches $20^{\circ} \mathrm{C}$ for scenario (4) is decreased $20 \mathrm{~mm}$ (from $280 \mathrm{~mm}$ to $260 \mathrm{~mm}$ ) less than scenario (III) from Ge, H, et, all (2013).

In general terms, it appeared that from the relative comparison above, that when incorporating a lower U-value framed condition with or without the incorporation of the insulated curb condition of $12.7 \mathrm{~mm}$ EPS underneath the glazing frame, the interior concrete surface temperature tend to increase with or without the incorporation of a proprietary thermal break and that benefit the human thermal comfort.

\subsection{Thermal Transmittance U-value Modeling Results}

U-values and overall U-values are calculated for each component and for each proposed scenario (I to VIII) (See Appendix D) from interior boundary. This MRP report focused on the U-values of the upper surface of the concrete slab and on the overall U-value of a scenario with the inclusion of the insulated curb condition of $12.7 \mathrm{~mm}$ EPS to analyse if a significant decrease occurred in the U-value of that upper surface and in the overall U-value of a scenario because of that inclusion.

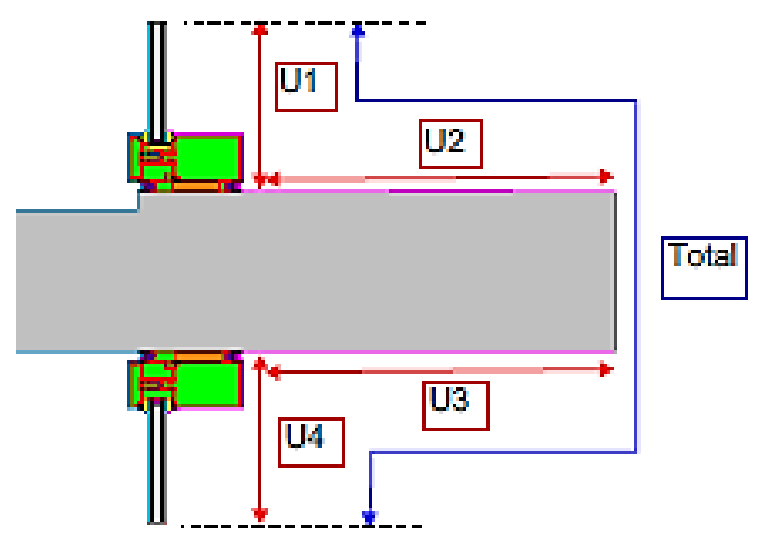

Figure 23: Concrete Balcony Slab Interior Boundaries Diagram showing Component U1, U2, U3, and U4 used in THERM to Calculate U-values and Overall U-values for Modeled Scenarios I to VIII 
Figure 21 showing a diagram of concrete balcony slab illustrating boundaries for each component used to calculate each U- value and overall U-value for each scenario. This diagram shows a simplified spandrel above and below slab with clear DGU with a U-value of 1.324 $\mathrm{W} / \mathrm{m}^{2} . \mathrm{K}$. The modeled height is $226 \mathrm{~mm}$ above and below slab and concrete surface measures $500 \mathrm{~mm}$ for upper and lower surface. It should be noted that for scenarios IV to VIII, the modeled height above slab is $300 \mathrm{~mm}$ and concrete surface measures $520 \mathrm{~mm}$ for the above surface only.

Table 16: U-value for components and Overall U-value for of each Scenario from I to VIII (See Appendix D)

\begin{tabular}{|c|c|c|c|c|c|c|c|c|c|}
\hline \multirow{2}{*}{\multicolumn{2}{|c|}{ SCENARIO }} & I & II & III & IV & $\mathbf{V}$ & VI & VII & VIII \\
\hline & & \multirow{2}{*}{$\begin{array}{l}\text { NO EPS } \\
\text { NO } \\
\text { BREAK }\end{array}$} & \multirow{2}{*}{$\begin{array}{l}\text { W/EPS } \\
\text { NO } \\
\text { BREAK }\end{array}$} & \multirow{2}{*}{$\begin{array}{l}\text { NO EPS } \\
\text { W/ } \\
\text { BREAK }\end{array}$} & \multirow{2}{*}{$\begin{array}{l}\text { W/EPS } \\
\text { W/ } \\
\text { BREAK }\end{array}$} & \multirow{2}{*}{$\begin{array}{l}\text { NO EPS } \\
\text { NO } \\
\text { BREAK }\end{array}$} & \multirow{2}{*}{$\begin{array}{l}\text { W/EPS } \\
\text { NO } \\
\text { BREAK }\end{array}$} & \multirow{2}{*}{$\begin{array}{l}\text { NO EPS } \\
\text { W/ } \\
\text { BREAK }\end{array}$} & \multirow{2}{*}{$\begin{array}{l}\text { W/EPS } \\
\text { W/ } \\
\text { BREAK }\end{array}$} \\
\hline Location & U-value & & & & & & & & \\
\hline $\begin{array}{l}\text { Above } \\
\text { Balcony/ } \\
\text { Slab }\end{array}$ & $\mathrm{W} / \mathrm{m}^{2} \cdot \mathrm{K}$ & 2.41 & 2.43 & 2.51 & 2.30 & 2.65 & 2.63 & 2.71 & 2.64 \\
\hline $\begin{array}{l}\text { Balcony/ } \\
\text { Slab } \\
\text { Upper } \\
\text { Surface }\end{array}$ & $\mathrm{W} / \mathrm{m}^{2} \cdot \mathrm{K}$ & 0.74 & 0.67 & 0.48 & 0.37 & 0.82 & 0.67 & 0.58 & 0.37 \\
\hline \multicolumn{2}{|c|}{ \% REDUCTION } & \multicolumn{2}{|c|}{$10 \%$} & \multicolumn{2}{|c|}{$23 \%$} & \multicolumn{2}{|c|}{$18 \%$} & \multicolumn{2}{|c|}{$36 \%$} \\
\hline $\begin{array}{l}\text { Balcony/ } \\
\text { Slab } \\
\text { Below } \\
\text { Surface } \\
\end{array}$ & $\mathrm{W} / \mathrm{m}^{2} . \mathrm{K}$ & 0.74 & 0.71 & 0.38 & 0.38 & 0.74 & 0.71 & 0.38 & 0.38 \\
\hline $\begin{array}{l}\text { Below } \\
\text { Balcony/ } \\
\text { Slab } \\
\end{array}$ & $\mathrm{W} / \mathrm{m}^{2} \cdot \mathrm{K}$ & 2.44 & 2.43 & 2.58 & 2.60 & 2.44 & 2.43 & 2.58 & 2.60 \\
\hline $\begin{array}{l}\text { Overall } \\
\text { U-value }\end{array}$ & $\mathrm{W} / \mathrm{m}^{2} . \mathrm{K}$ & 1.25 & 1.20 & 1.13 & 1.06 & 1.35 & 1.30 & 1.23 & 1.17 \\
\hline \multicolumn{2}{|c|}{ \% REDUCTION } & \multicolumn{2}{|c|}{$4 \%$} & \multicolumn{2}{|c|}{$6 \%$} & \multicolumn{2}{|c|}{$4 \%$} & \multicolumn{2}{|c|}{$5 \%$} \\
\hline
\end{tabular}

Table 16 illustrates the U-values for each component of each scenario from I to VIII (See Appendix D) per Figure 23. It also illustrates the overall U-value for each scenario and the \% reduction resulted in the $\mathrm{U}$-values of balcony slab upper surface and in the overall U-value from the inclusion of the insulated curb condition of $12.7 \mathrm{~mm}$ EPS. 


\subsection{Thermal Transmittance U-value Modeling Results Analysis}

Table 16 indicates that U-value tend to get lower in scenarios II and VI by $10 \%$ to $18 \%$ when the insulated curb condition of $12.7 \mathrm{~mm}$ EPS is added underneath the glazing frame. Even it get more reduced in scenarios VI and VIII by $23 \%$ to $36 \%$ when the insulated curb condition of $12.7 \mathrm{~mm}$ EPS is combined with a proprietary thermal break.

Overall U-values showed modest reduction of $4 \%$ in scenarios II and VI when the insulated curb condition of $12.7 \mathrm{~mm}$ is added and 5\% to $6 \%$ in scenarios VI and VIII when the insulated curb condition of $12.7 \mathrm{~mm}$ EPS is combined with a proprietary thermal break.

\subsection{Thermal Transmittance U-value Modeling Results Comparative Analysis}

For the purpose of comparative analysis with the previous key studies, and in order to get a meaningful outcome, similarity in scenarios must meet in terms of glazing system configuration above and below the balcony slab.

Sections 2.4 and 2.5 of this report summarized and presented the previous key studies and illustrated the modeled scenarios and the U-values and overall U-values for each modeled scenario. As discussed previously that each study had its own assumptions, boundary conditions, different material thermal conductivity, and different methods of simulation and most importantly is the simulated height of component that was used in the U-value and overall Uvalue calculations. All these factors could affect the U-value calculation and made it difficult to establish a common ground for comparison.

Of particular interest to this study, and for the purpose of comparative analysis, $\mathrm{Ge}, \mathrm{H}$ et al (2013) [14] is the only appropriate study that used 2D THERM method of simulation, and had couple of scenarios (III and IV) that had similarity to this MRP study (see Table 1). 
From this MRP study, Scenarios (I, III, V and VII) from this study (See Appendix D) were chosen in such a manner that these scenarios only include a low U-value framed glazing system without the inclusion of the insulated curb condition in order to distinguish any significant difference.

Table 17: Overall U-values for Scenarios (III and IV) from Ge, H, et, all (2013) and Scenarios (I, III, V, and VIII) from this MRP (Appendix D)

\begin{tabular}{|c|c|c|c|c|c|c|c|c|c|}
\hline \multicolumn{2}{|c|}{ STUDY } & \multicolumn{4}{|c|}{ MRP (Appendix D) } & \multicolumn{3}{c|}{ Ge, H, et, all (2013) } \\
\hline \multicolumn{2}{|c|}{ SCENARIO } & I & III & V & VII & \multicolumn{2}{c|}{ III } & \multicolumn{2}{c|}{ IV } \\
\cline { 3 - 10 } & No Break & Break & No Break & Break & No Break & Break & No Break & Break \\
\hline $\begin{array}{c}\text { Overall } \\
\text { U-value }\end{array}$ & $\mathrm{W} / \mathrm{m}^{2} . \mathrm{K}$ & 1.25 & 1.13 & 1.35 & 1.23 & 2.23 & 1.07 & 1.94 & 0.76 \\
\hline
\end{tabular}

Table 17 illustrates the overall U-values pertaining to the specific scenarios chosen from $\mathrm{Ge}, \mathrm{H}$ et al (2013) and specific scenarios from this MRP report (Appendix D).

Relative comparison is established between scenario (III) from Ge, H, et, all (2013) and scenario (I) from this MRP, the \% reduction in U-value found $43.9 \%$ and between (IV) from Ge, $\mathrm{H}$, et, all (2013) and scenario (V) from this MRP, the \% reduction in U-value found 30\%, both cases have no thermal break. These $\%$ reductions would have been realistically acceptable if the scenarios from both studies have been modeled and simulated using similar boundary conditions; however, this is not the case here for the following reasons:

- Both studies have used different concrete slab thickness (200 mm versus $210 \mathrm{~mm}$ ) and different balcony slab length on the interior $(0.5 \mathrm{~m}$ versus $1.0 \mathrm{~m})$ and this could have a great impact on the overall $\mathrm{U}$-value results.

- Both studies have used different components areas calculation and therefore, this could have an impact on the total area-weighted when calculating the overall U-value results. 
- Simulated models in both studies have used different height above and below balcony slab and that could have an impact on the overall U-value results. 


\subsection{CONCLUSION}

When using a lower U-value framed glazing door assembly along with the insulated curb condition of $12.7 \mathrm{~mm}$ thick EPS in conventional concrete balcony scenarios, the concrete surface temperatures had the tendency to increase, and even doubled in surface temperature values when compared to a traditional glazing door assembly with higher U-values. Concrete surface temperatures also had the tendency to increase in values when the insulated curb condition of $12.7 \mathrm{~mm}$ thick EPS is incorporated with a proprietary thermal break. Further, the incorporation of the insulated curb condition of $12.7 \mathrm{~mm}$ thick EPS contributed to benefit the human thermal comfort by decreasing the length of the concrete surface until the temperature reaches $20^{\circ} \mathrm{C}$.

The U-values generated from the scenarios in this MRP report, and specifically the scenarios that had an insulated curb condition showed relatively significant reduction in the Uvalues of the interior concrete upper surface. Also, the overall U-value showed modest \% reduction when the insulated curb condition was added. Nevertheless, using a lower U-value glazing system with better thermal characteristics had contributed to the overall reduction in results of the generated U-values and that should improve the energy efficiency and thermal performance of construction assemblies.

Having said that, it was difficult to establish a common ground to compare the U-value of this MRP with previous studies due to many differences in assumption, simulation approach and dimensions of components and many other factors.

Alternatively, this MRP study had shown that there is an alternative construction detail option that could provide similar benefits to heat loss reduction and human thermal comfort in lieu of increasing interior concrete surface temperatures and minimize the risk of condensation than the options of using a proprietary thermal break in the concrete balcony slab. That 
alternative construction detail option can be done by utilizing more efficient glazing frame assembly with a lower U-value than the traditional glazing assembly commonly used in the highrise MURB community and by utilizing an innovative construction details such as the insulated curb condition of 12.7 thick EPS installed beneath the glazing frame.

Thermal break research and development must not stop here and should move forward towards investigating more innovative and advanced construction assembly solutions or even put the proposed model of this MRP report into experimental testing by creating a mock-up and confirm that using a lower U-value framed glazing assembly and insulated curb condition could improve the overall thermal performance of an assembly.

It is suggested that further study could be implemented to establish the relationship between the results of this MRP and the results of increasing the thickness of the EPS of the insulated curb condition to $38.1 \mathrm{~mm}$ or higher using similar simulation approach. Because this increase in EPS thickness required creating $25.4 \mathrm{~mm}$ or higher depression in the cantilevered concrete slab, therefore, this suggestion must be verified by a structural engineer.

It is also suggested that further cost study analysis could be implemented to analyze the cost of using a lower U-value framed condition along with the inclusion of the insulated curb condition versus the incorporation of a proprietary thermal break.

Further, by providing innovative construction condition solution, construction and designer communities could provide the high-rise MURBs with economically viable energy efficiency solutions. 


\section{APPENDENICES}

\section{APPENDIX A}

Ge, H et al (2013):

As-designed section for scenarios I and II.
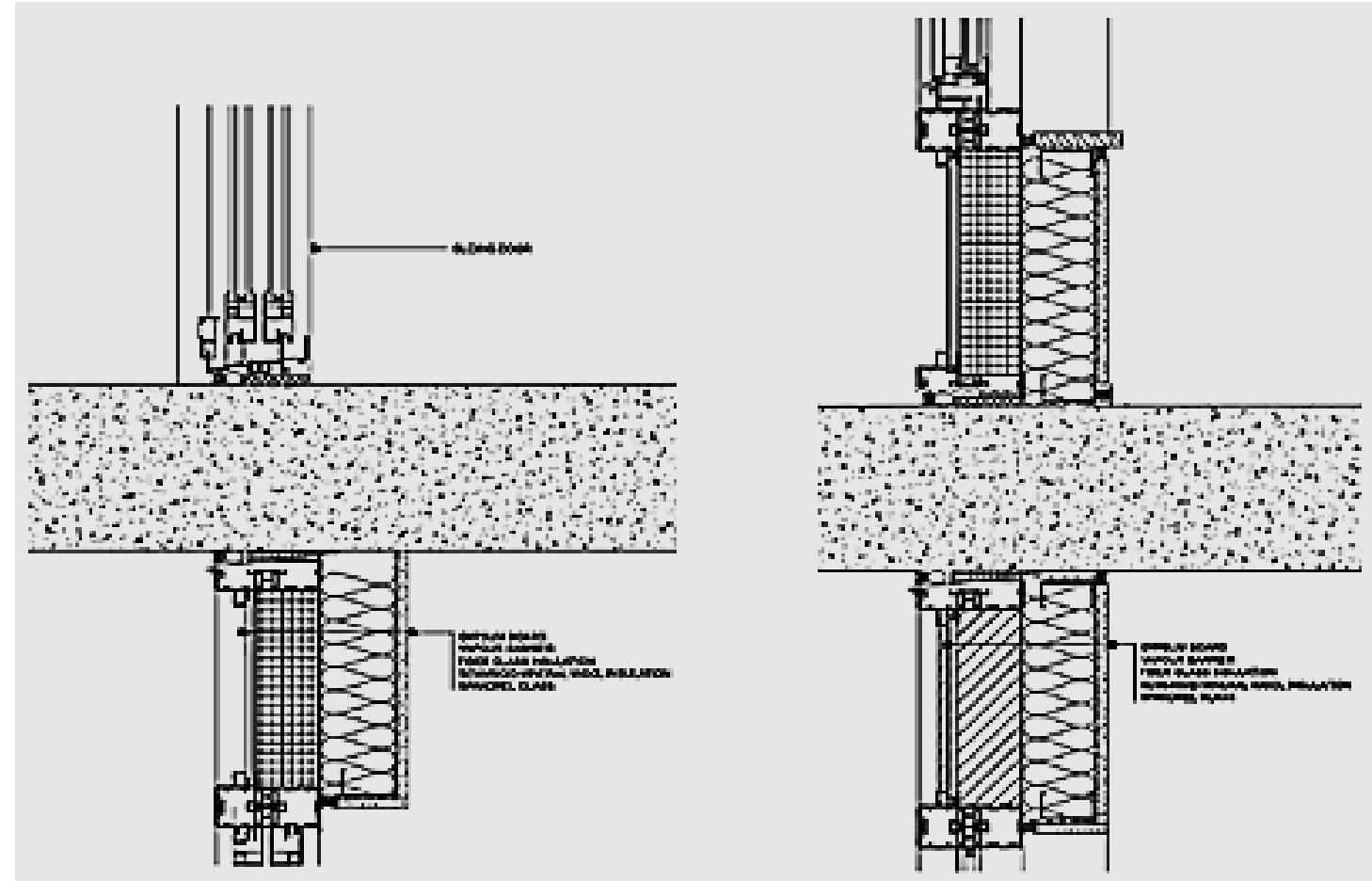
THERM models for each scenario - Section A illustrates models for each wall/slab scenario.

Section B illustrates temperature profiles for sliding door/spandrel panel section.
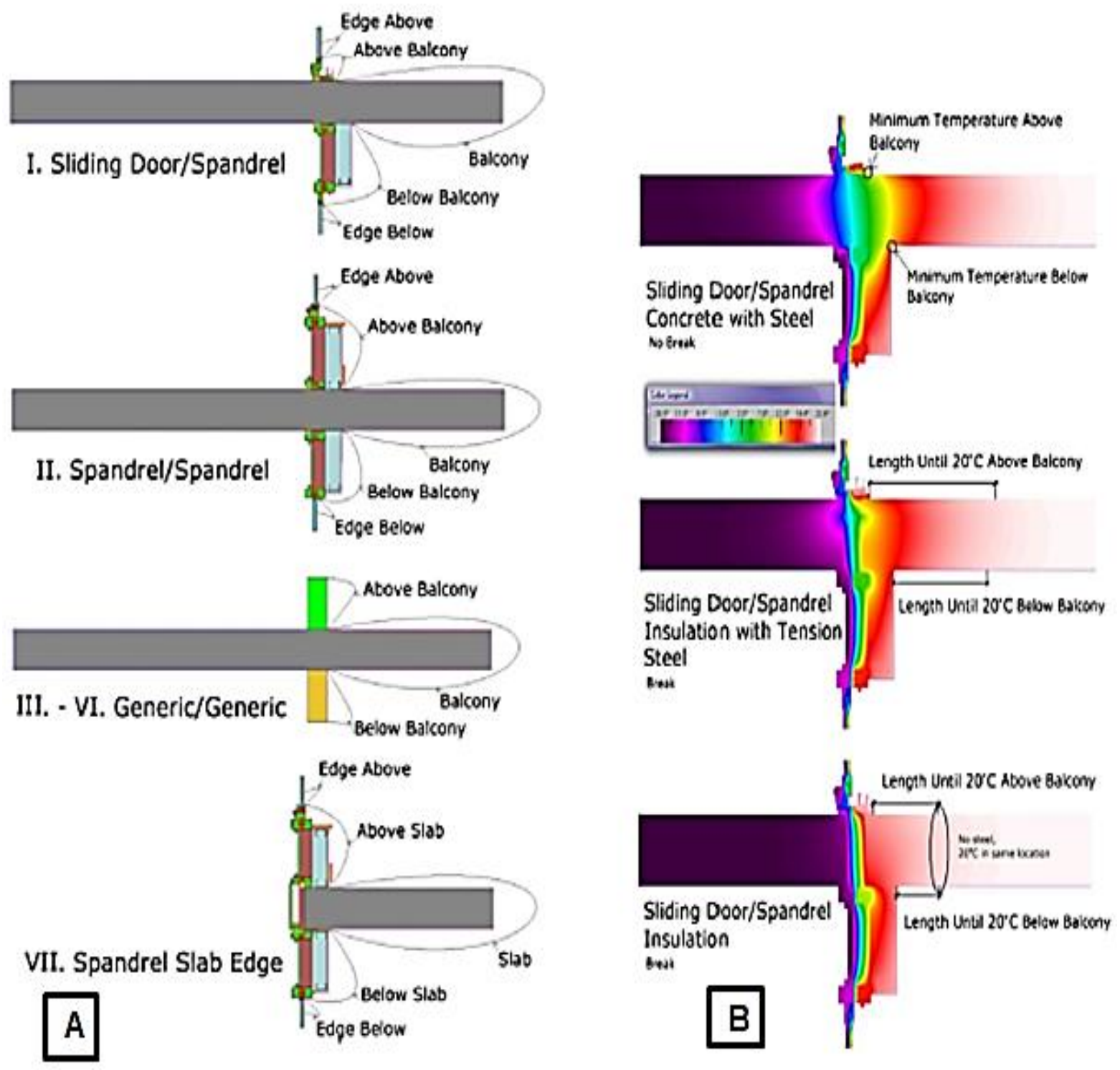


\section{APPENDIX B}

3D Heat Transfer Study:
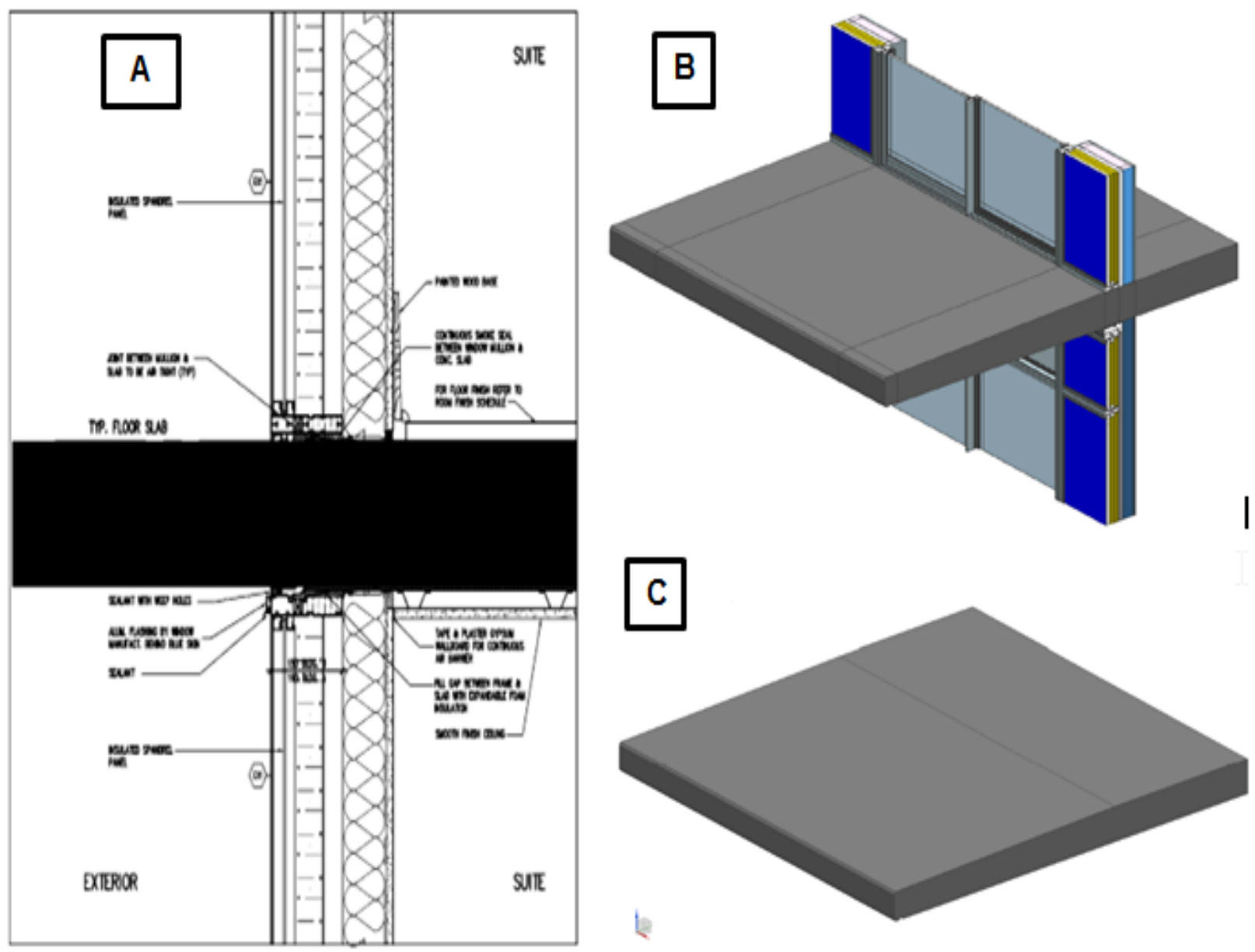

SCENARIO - 1: A)-Conventional Concrete Balcony Slab with Window-wall spandrel panel below and above B) - Modeled Continuous Slab. C) - Modeled Assembly for Continuous Slab 


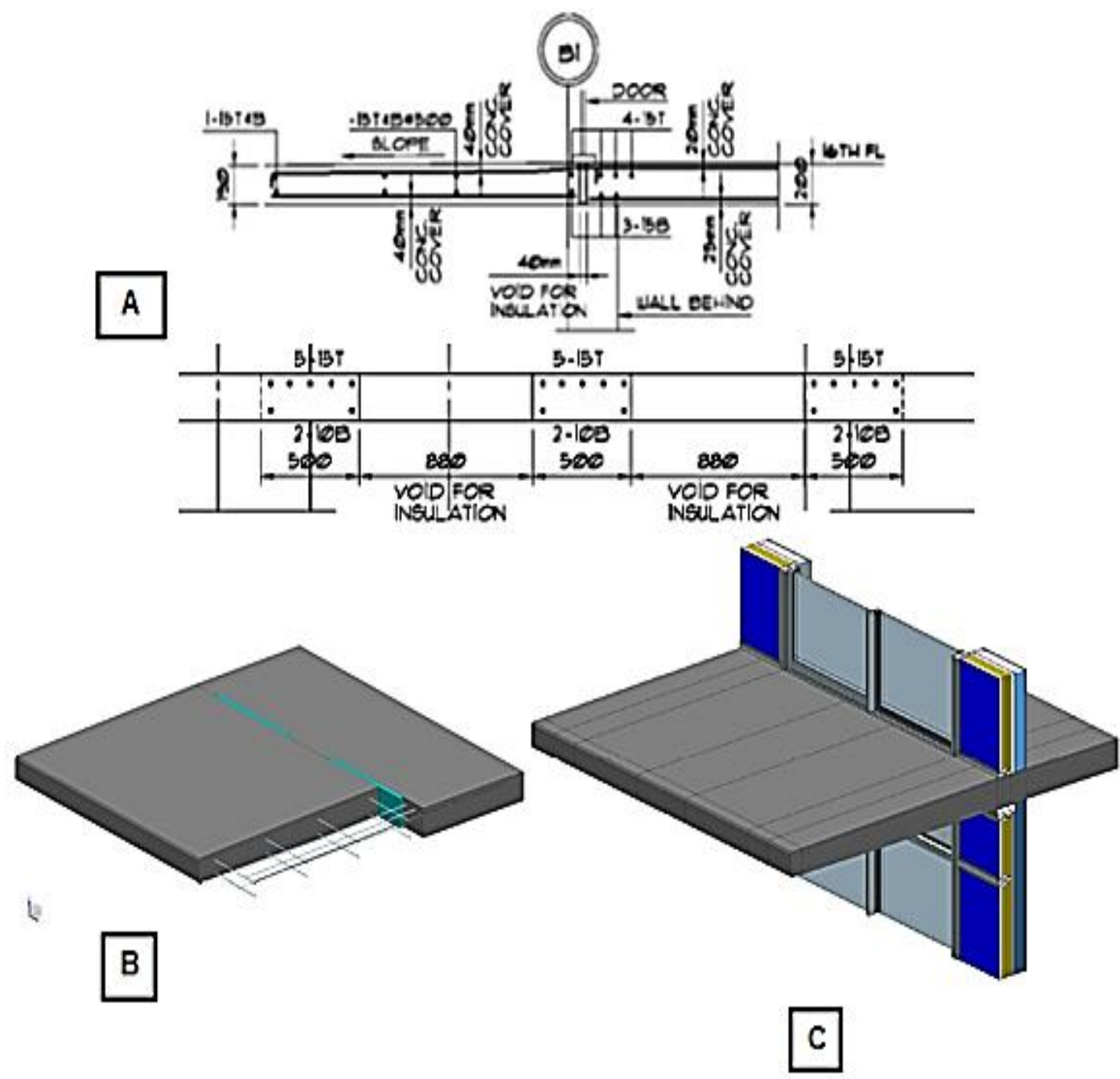

SCENARIO - 2: A): Cantilevered concrete balcony with interruptions consisting of reinforced concrete $(500 \mathrm{~mm})$ and rigid insulation $(800 \mathrm{~mm})$ of $40 \mathrm{~mm}$ thickness. B): Modeled Site solution with concrete partially removed to show insulation and rebar. C): Modeled Assembly for Site Solution. 


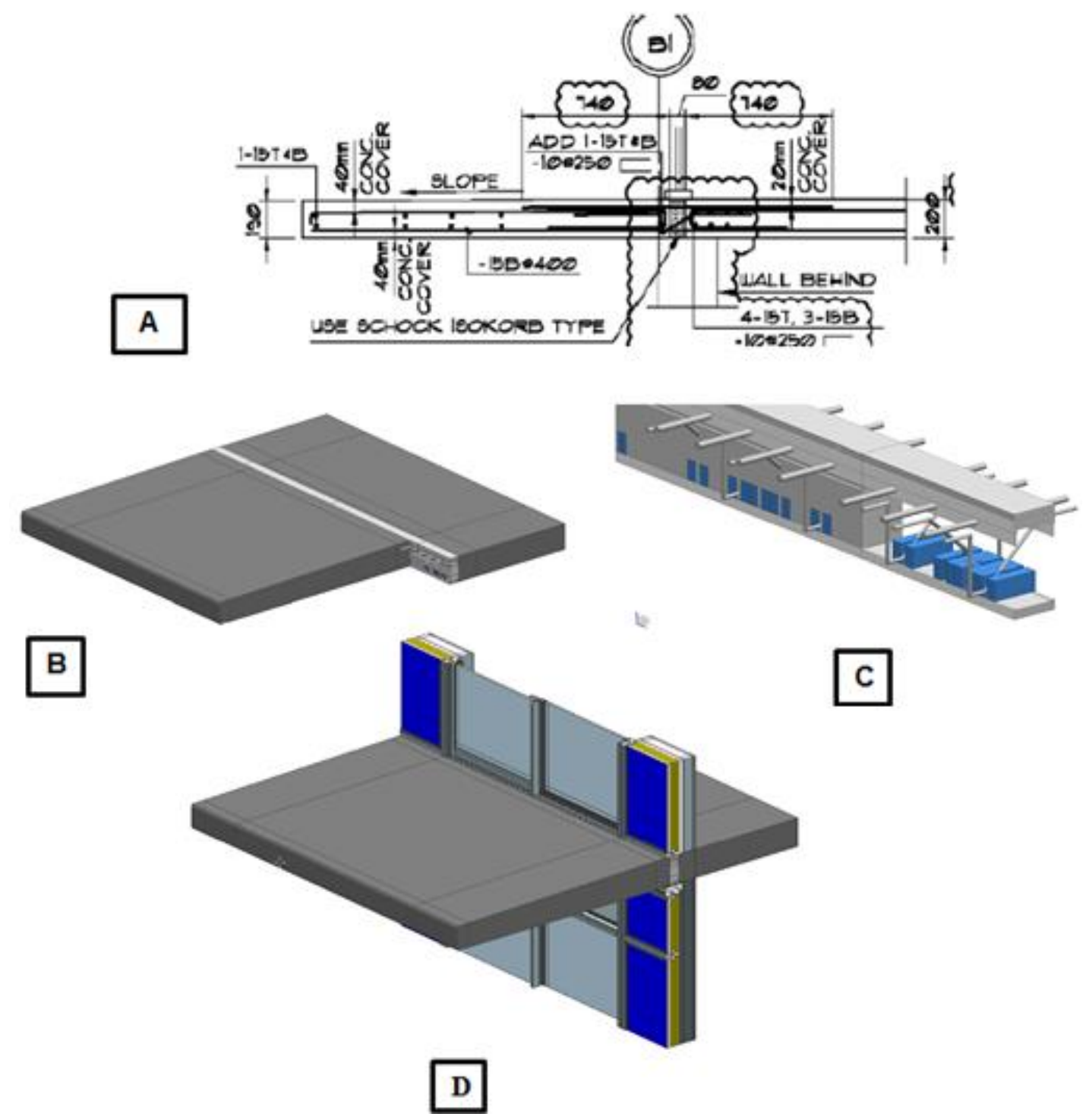

SCENARIO - 3: A): Cantilevered concrete balcony with a Schöck Isokorb CM20 thermal break.

B): Modeled Schöck Isokorb slab with concrete partially removed to show Isokorb system. C):

Modeled Schöck Isokorb Close-Up view with Insulation partially removed. D): Modeled Assembly for Schöck Isokorb Solution. 

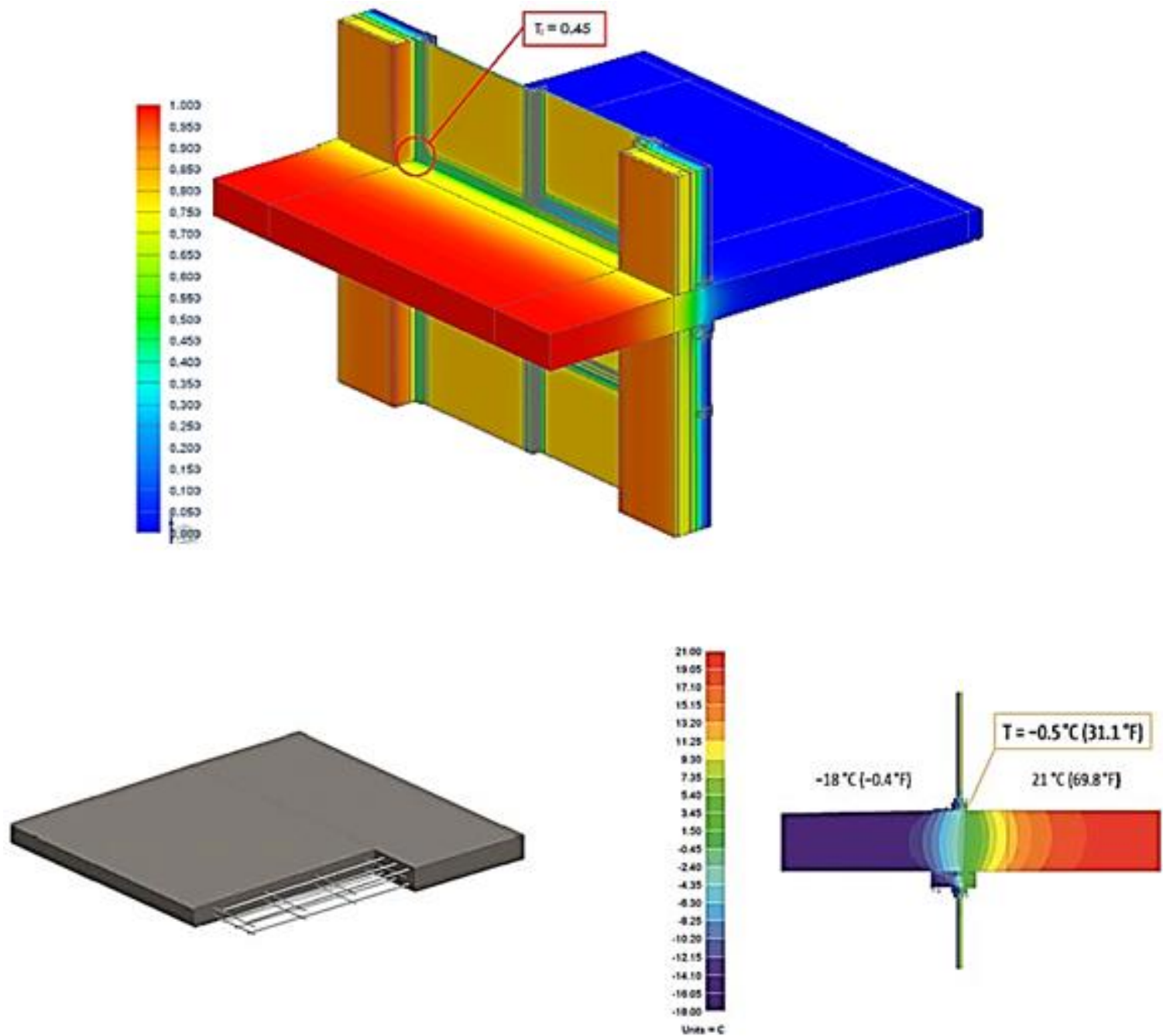

Interior Temperature Profile for Modeled (Conventional Solution) - Cantilevered Concrete Balcony with continuous Concrete Slab penetrating through the building envelope. Lowest temperature on Concrete Floor indicated with location 

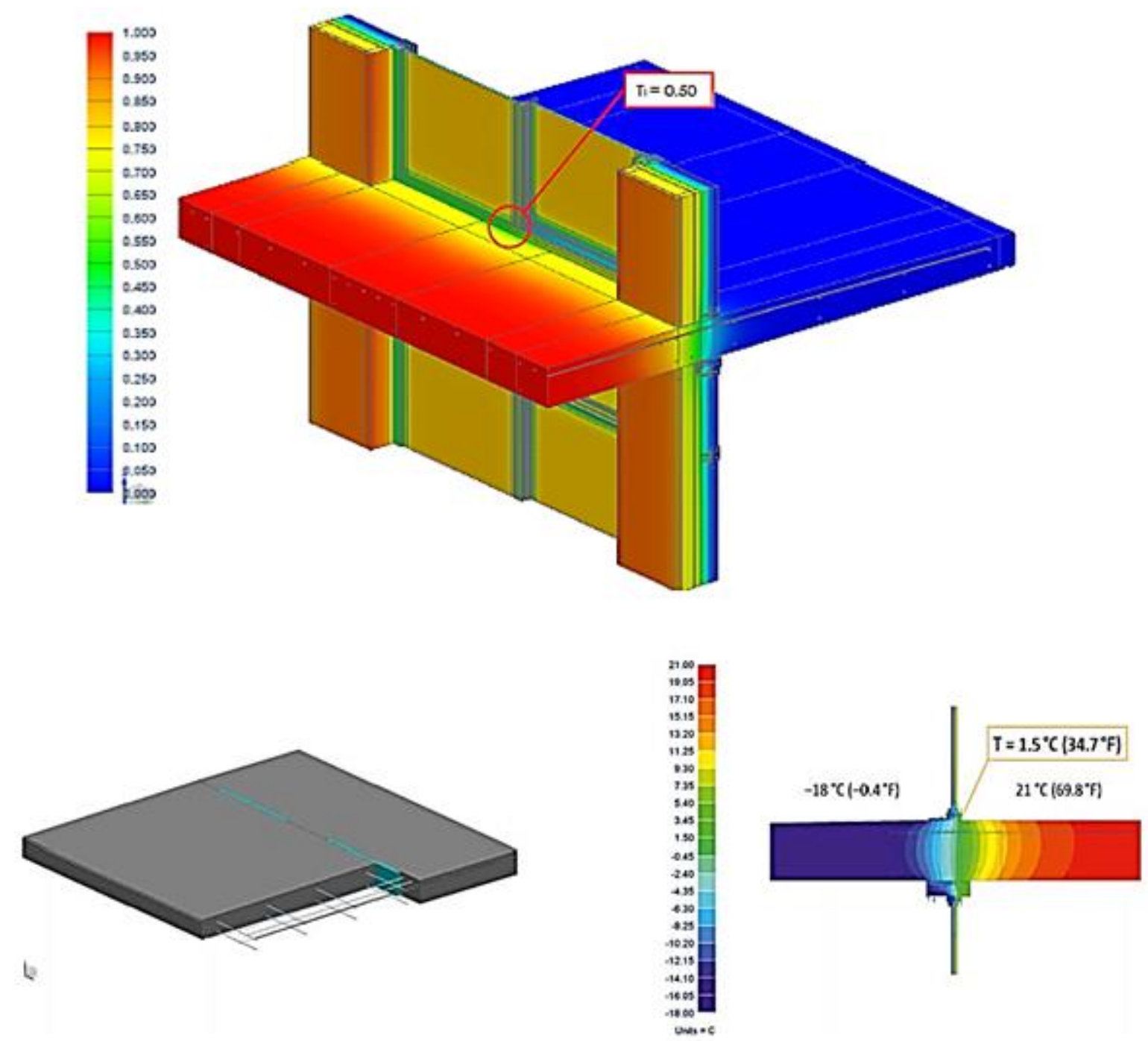

Interior Temperature Profile for Modeled (Site Solution) - Cantilevered Concrete Balcony Slab with Intermittent Insulation placed between continuous Concrete Beam connections. Lowest temperature on Concrete Floor indicated with location 

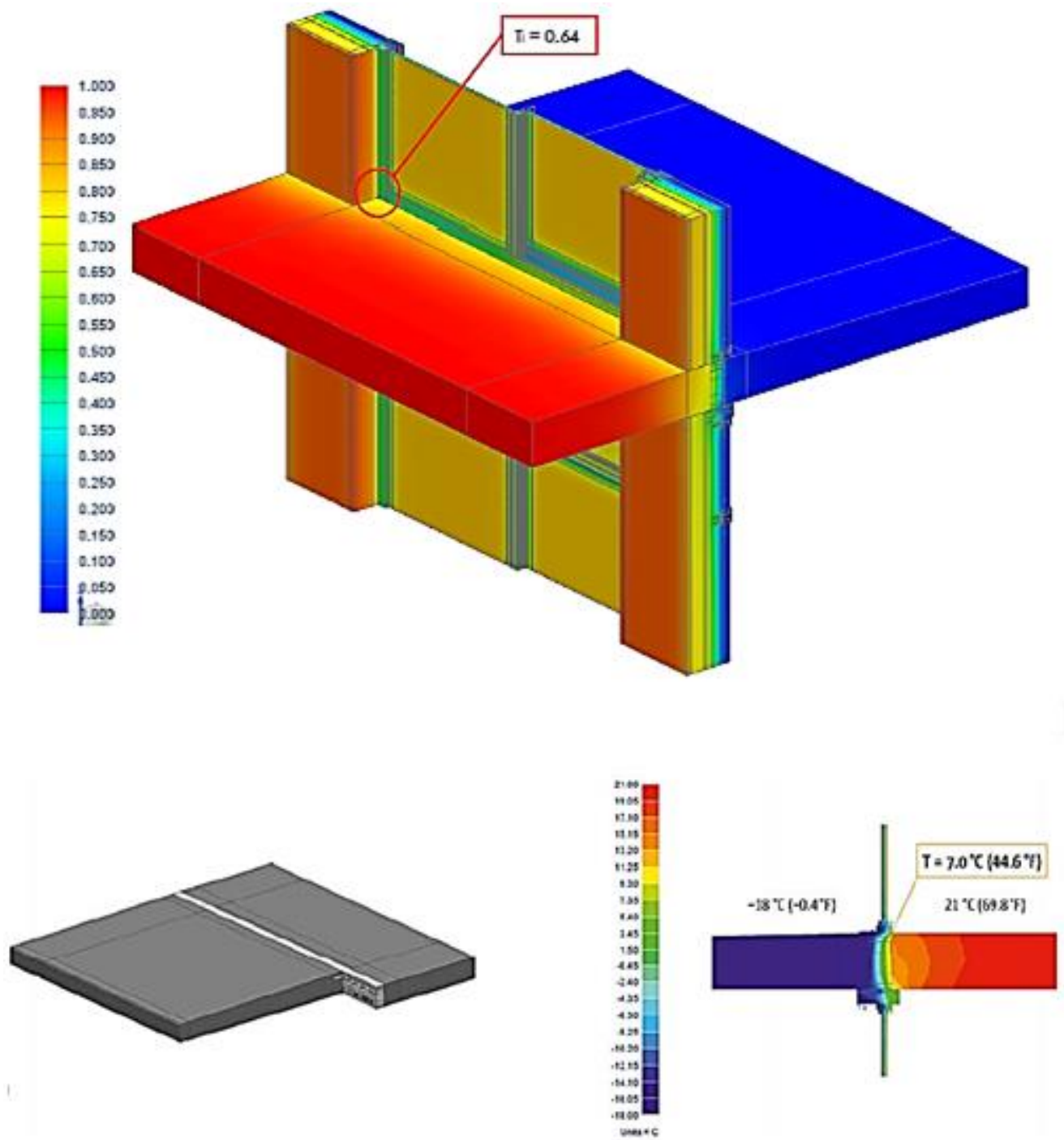

Interior Temperature Profile for Modeled (Schöck Isokorb Solution) - Cantilevered Concrete

Balcony Slab with Isokob CM20 thermal break Solution. Lowest temperature on Concrete Floor indicated with location 


\section{APPENDIX C}

3D Heat Transfer Study (RDH)
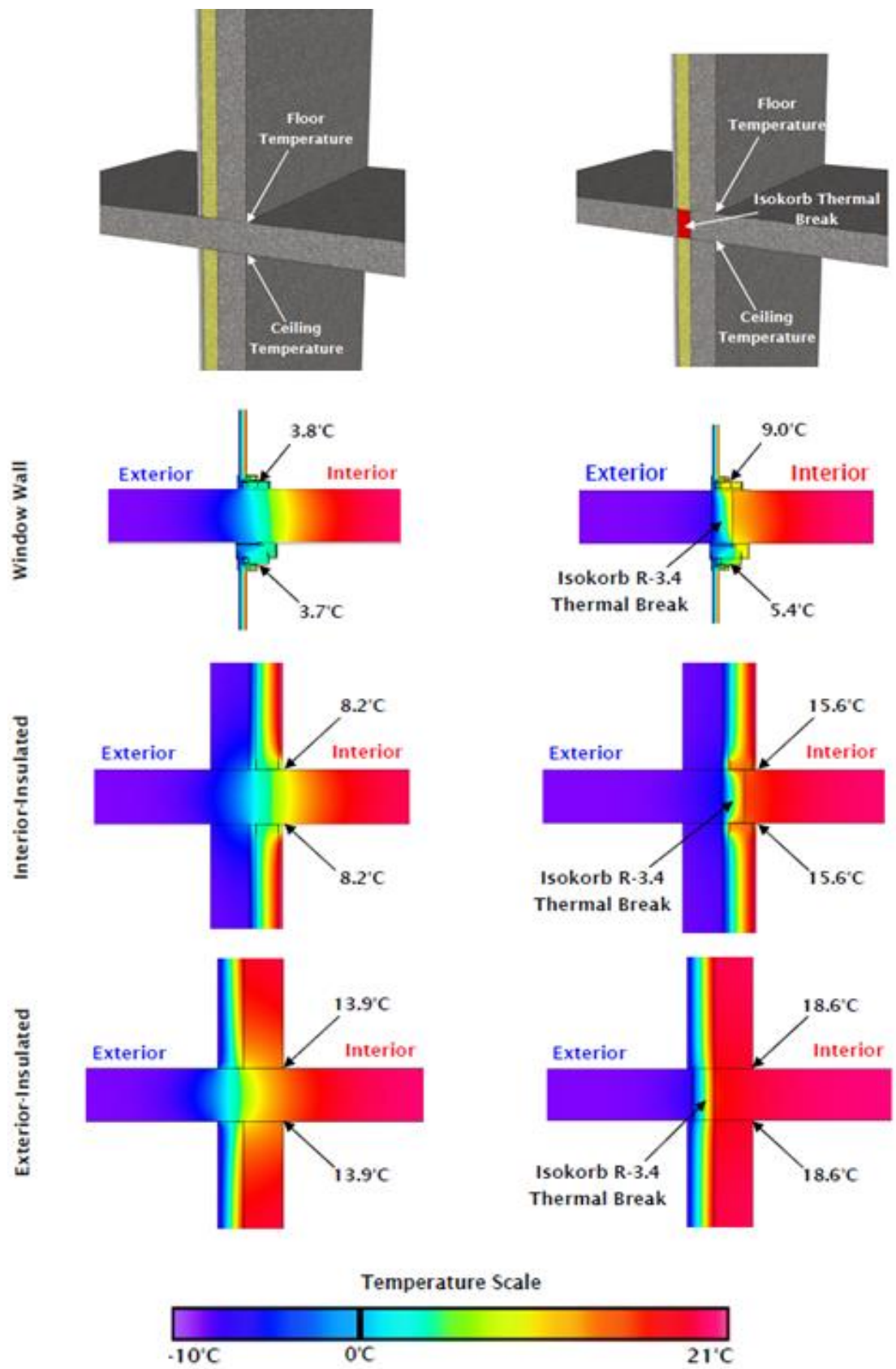

3D Thermal modelling for several wall assemblies with and without thermal breaks showing locations of the calculated surface temperature 


\section{APPENDIX D}

1 - Cantilevered Concrete Balcony Slab complete cross sections for Scenarios No. 1 to 8:

Group No.1: All scenarios of this group are with low U-value framed spandrel panel sill and head above and below balcony slab.

Scenario 1: Conventional Cantilevered Concrete Balcony Slab with KAWNEER Spandrel Panel

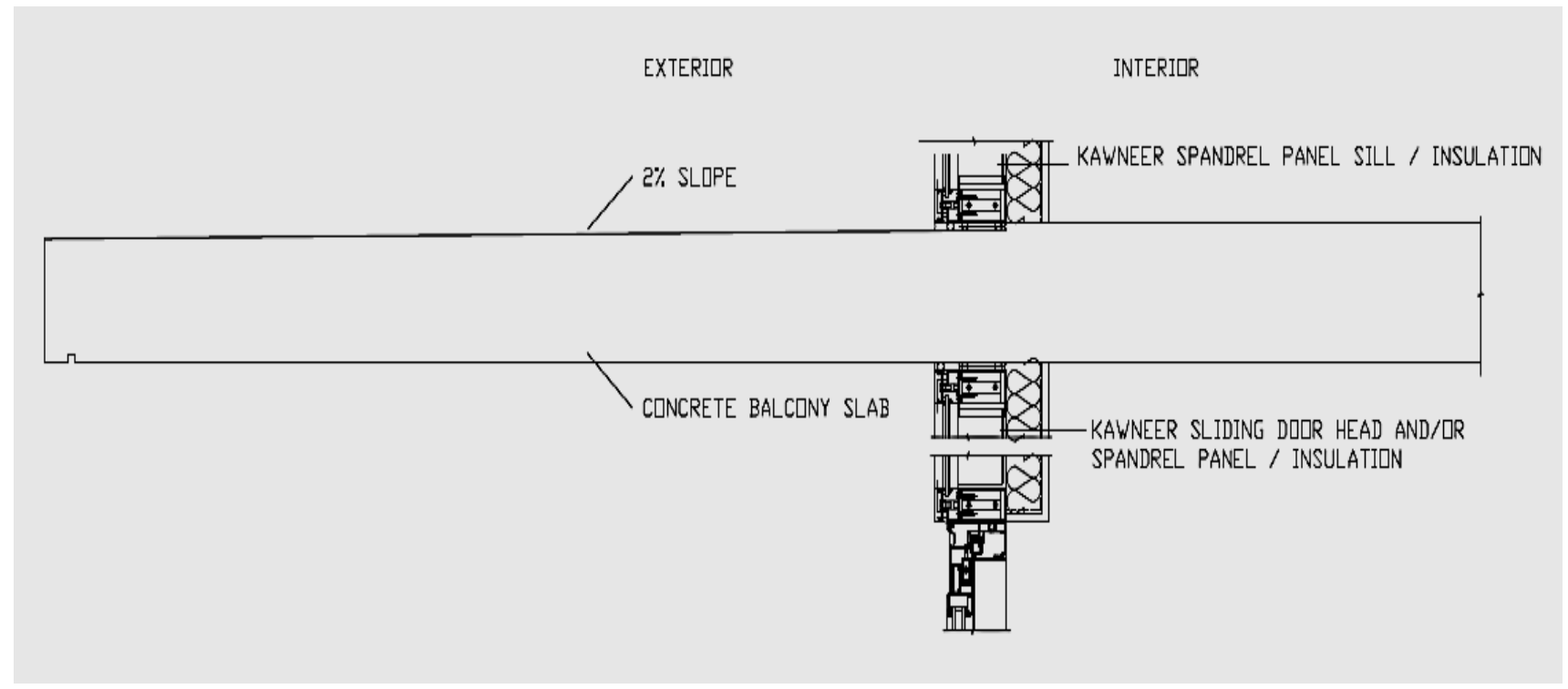

Scenario 2: Conventional Cantilevered Concrete Balcony Slab with KAWNEER Spandrel Panel +12.7 mm Concrete Curb with 25.4 mm EPS Insulation

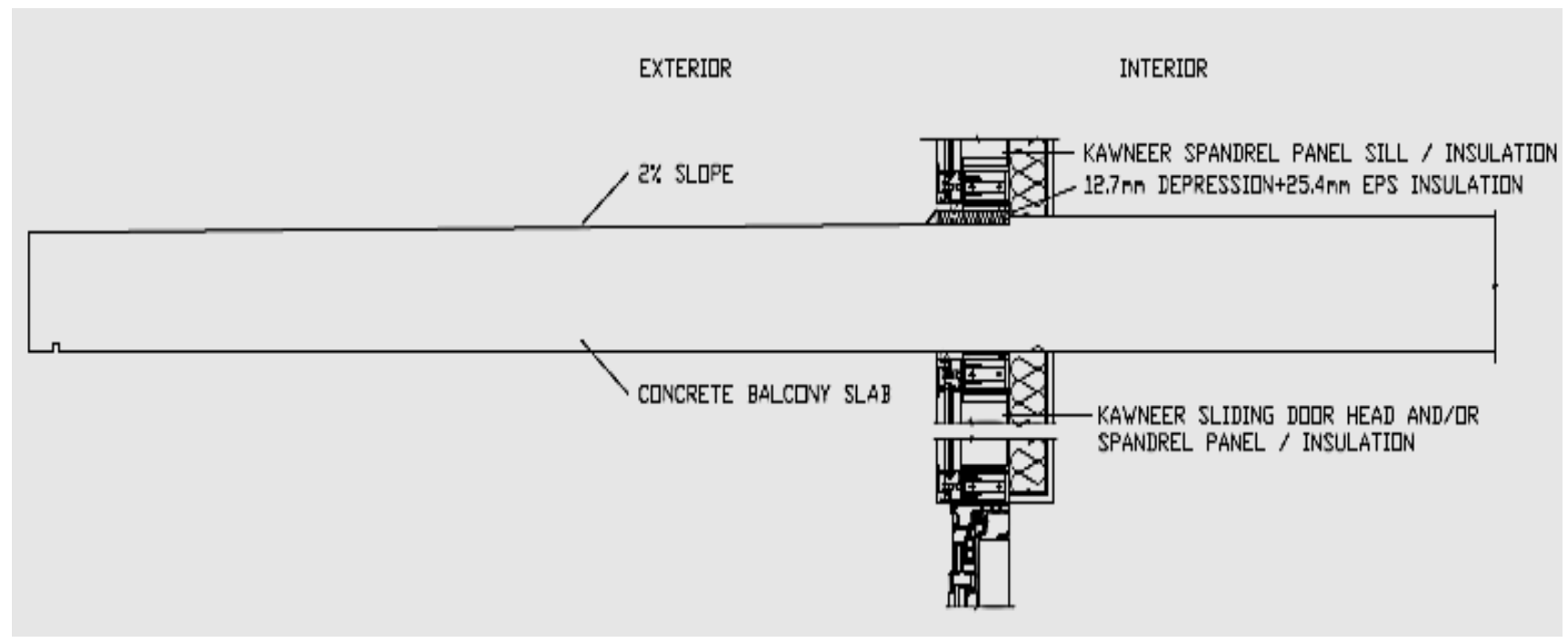


Scenario 3: Cantilevered Concrete Balcony Slab with KAWNEER Spandrel Panel + Schöck Isokorb $^{\circledR}$ Type CM20 Thermal Break

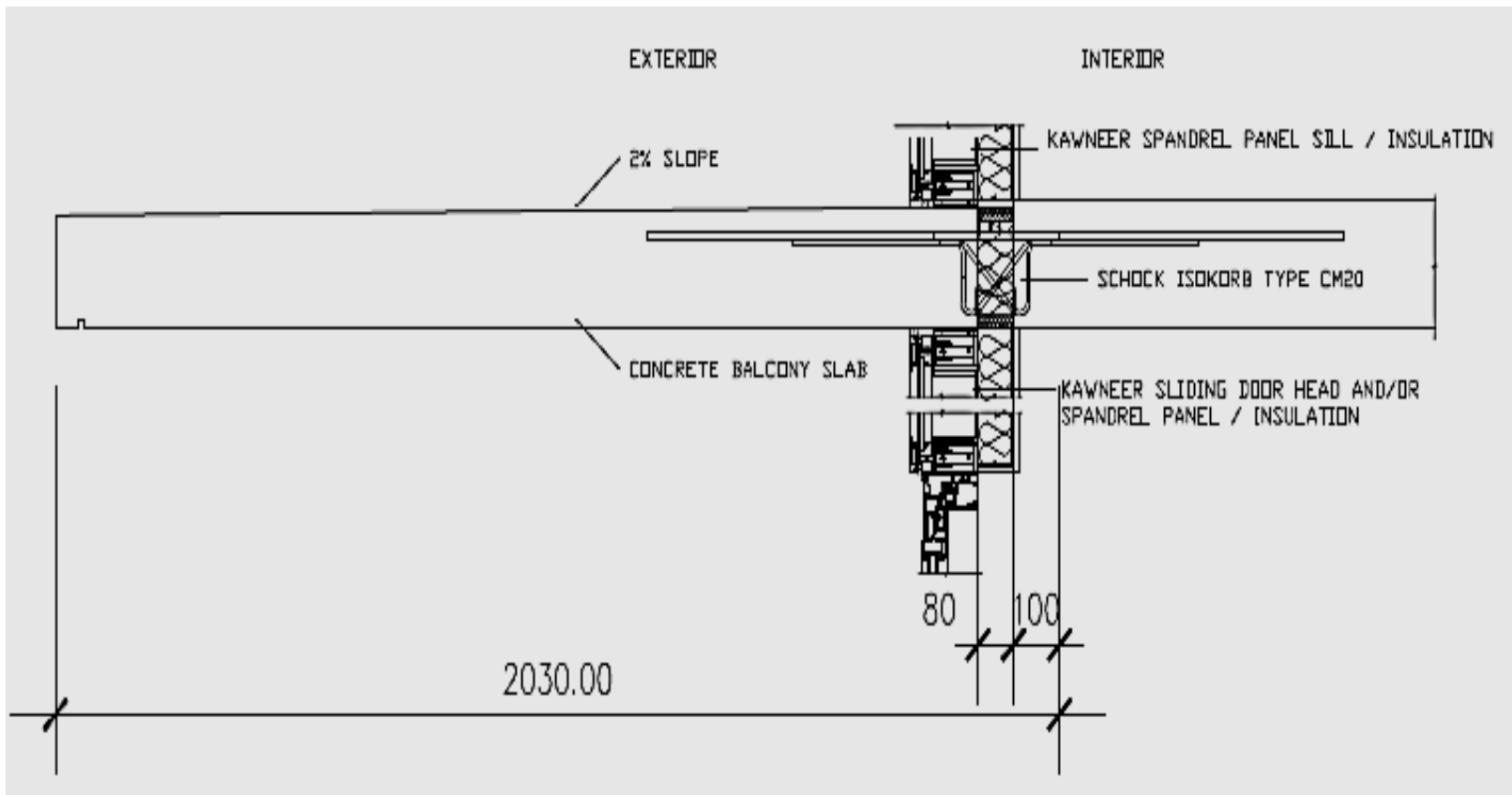

Scenario 4: Cantilevered Concrete Balcony Slab with KAWNEER Spandrel Panel $+12.7 \mathrm{~mm}$ Concrete Curb with 25.4 mm EPS Insulation + Schöck Isokorb ${ }^{\circledR}$ Type CM20 Thermal Break

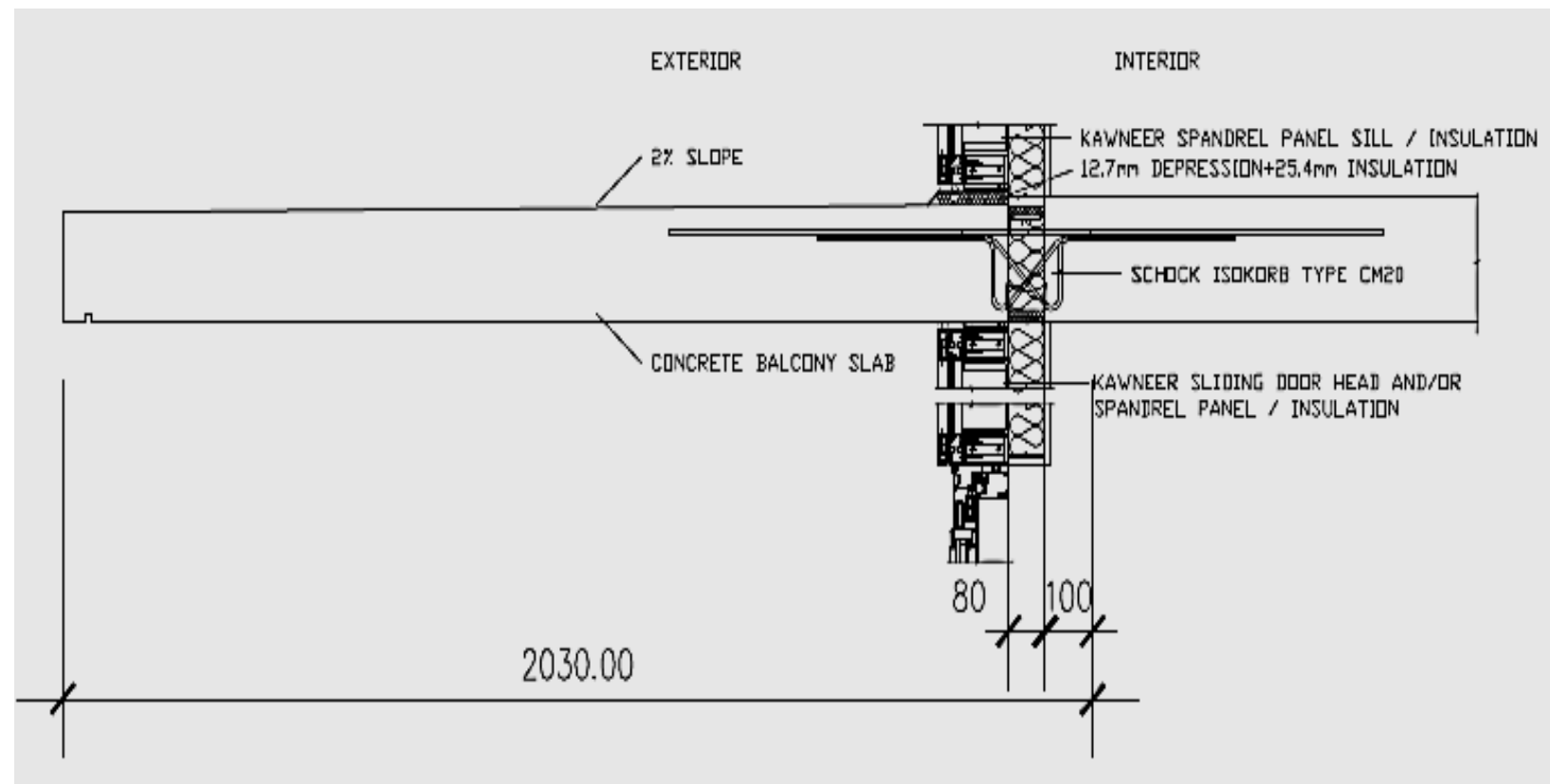


Group No. 2: All scenarios of this group are with low $U$-value framed sliding door sill and low U-value spandrel panel head above and below balcony slab.

Scenario 5: Conventional Cantilevered Concrete Balcony Slab with KAWNEER Sliding Door

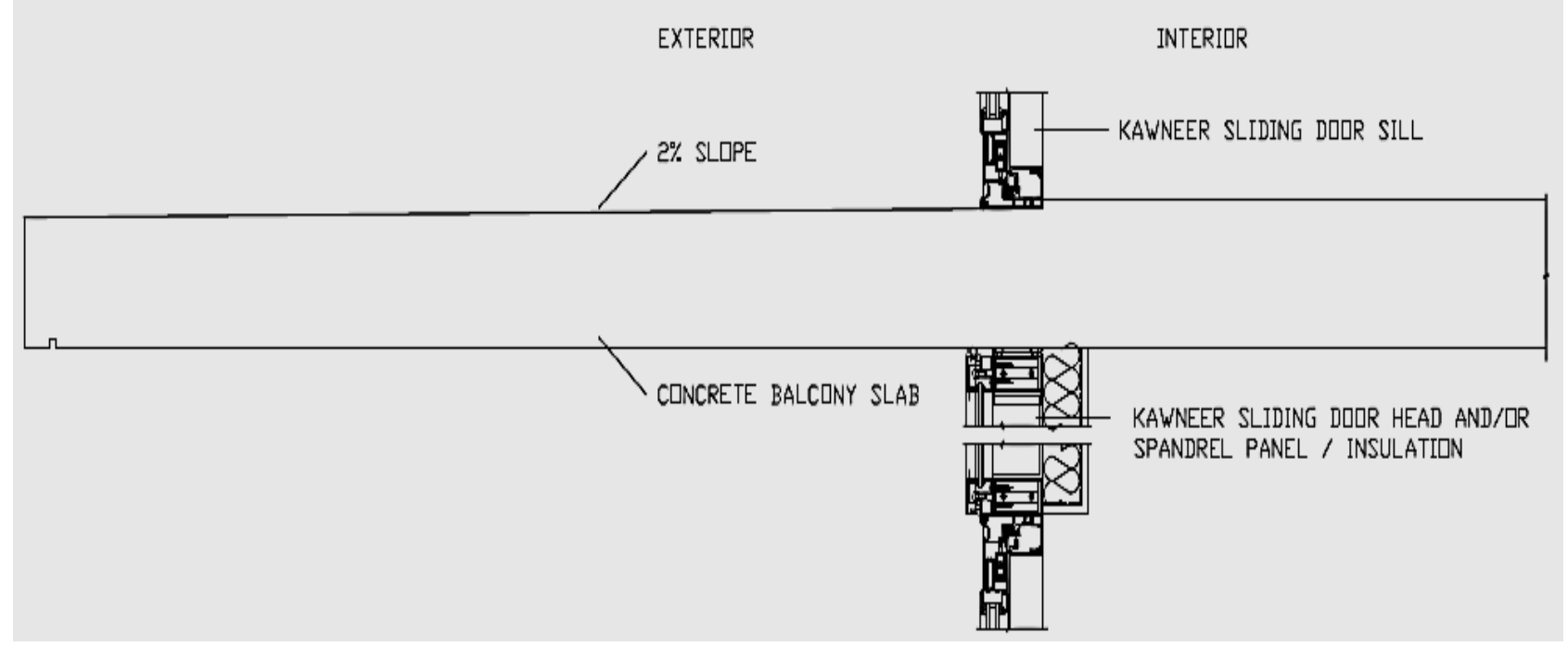

Scenario 6: Conventional Cantilevered Concrete Balcony Slab with KAWNEER Sliding Door + 12.7 mm Concrete Curb with 25.4 mm EPS Insulation

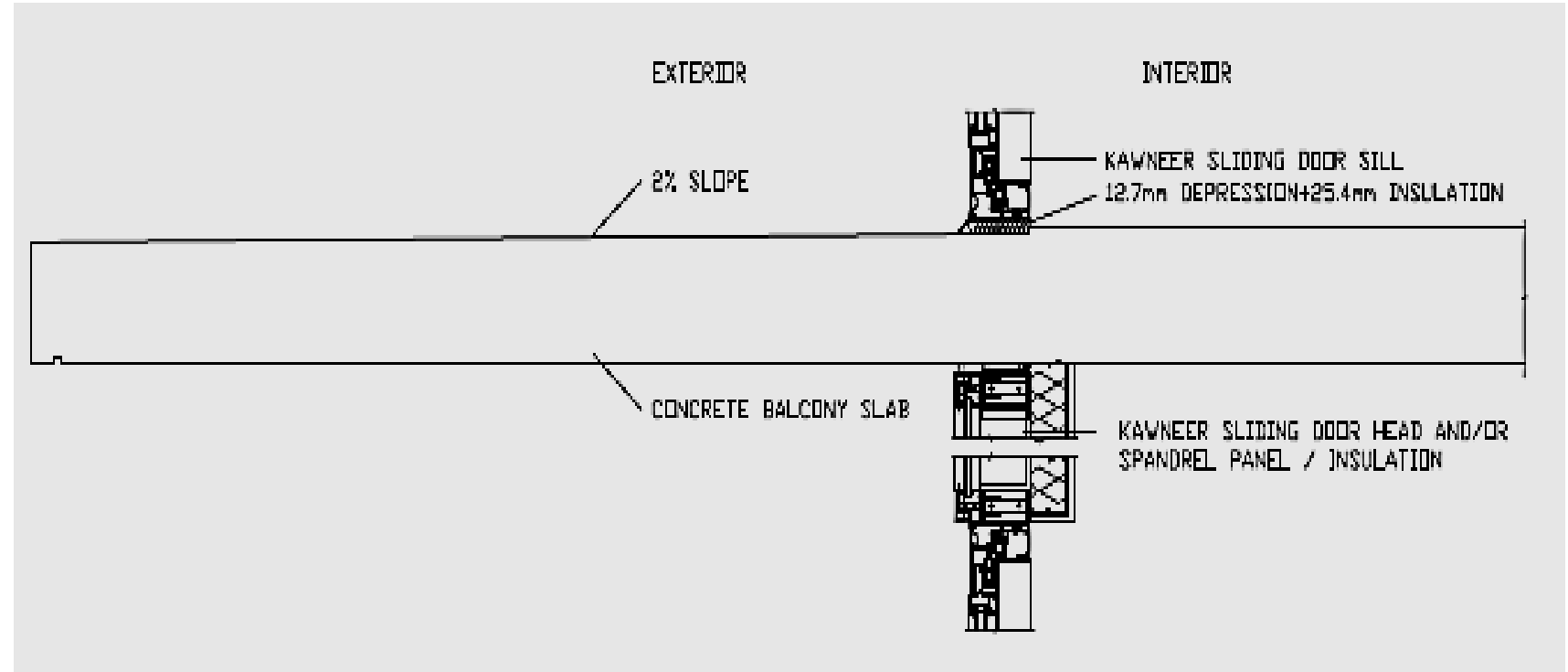


Scenario 7: Cantilevered Concrete Balcony Slab with KAWNEER Sliding Door + Schöck Isokorb $^{\circledR}$ Type CM20 Thermal Break

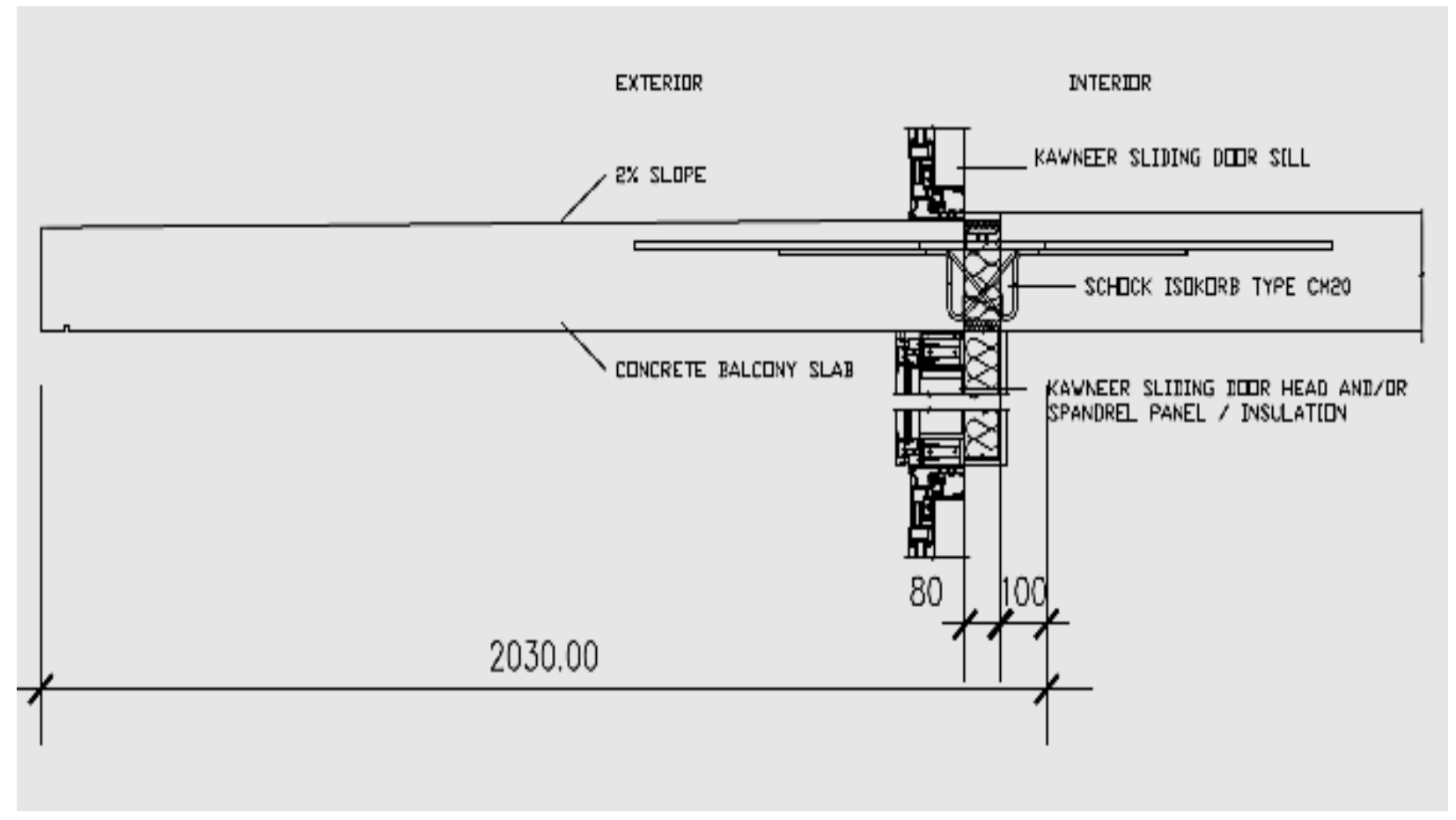

Scenario 8: Cantilevered Concrete Balcony Slab with KAWNEER Sliding Door + $12.7 \mathrm{~mm}$ Concrete Curb with 25.4 mm EPS Insulation + Schöck Isokorb ${ }^{\circledR}$ Type CM20 Thermal Break

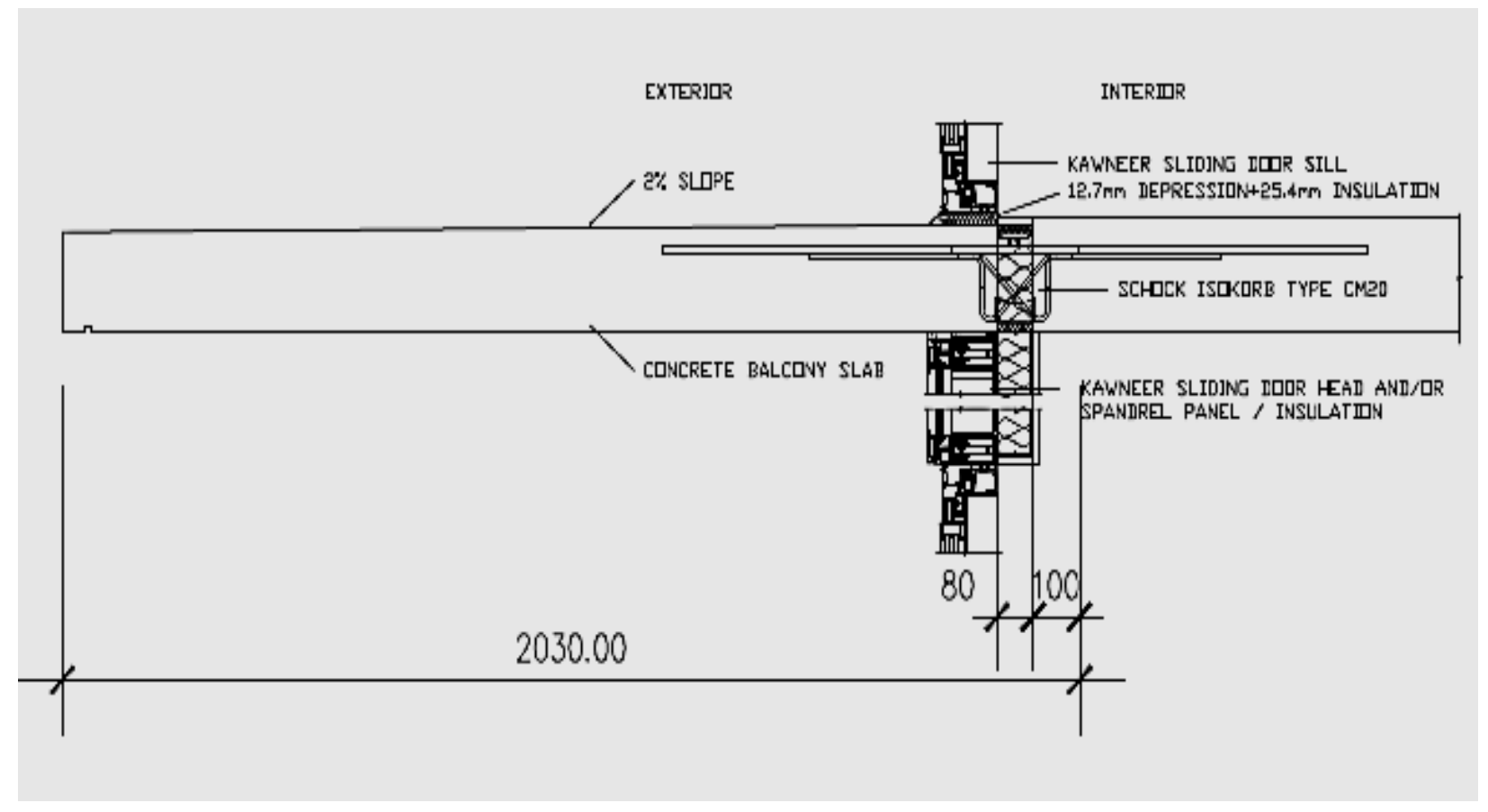


2 - MRP 2DTHERM lines of equal temperature (Isotherm) and thermal profile of each scenario from 1 to 8 showing interior surface temperature captured at slab/frame intersection above and below slab and the length of where the $20^{\circ} \mathrm{C}$ is reached.

Scenario 1: Conventional - KSP-NEPS-NTB
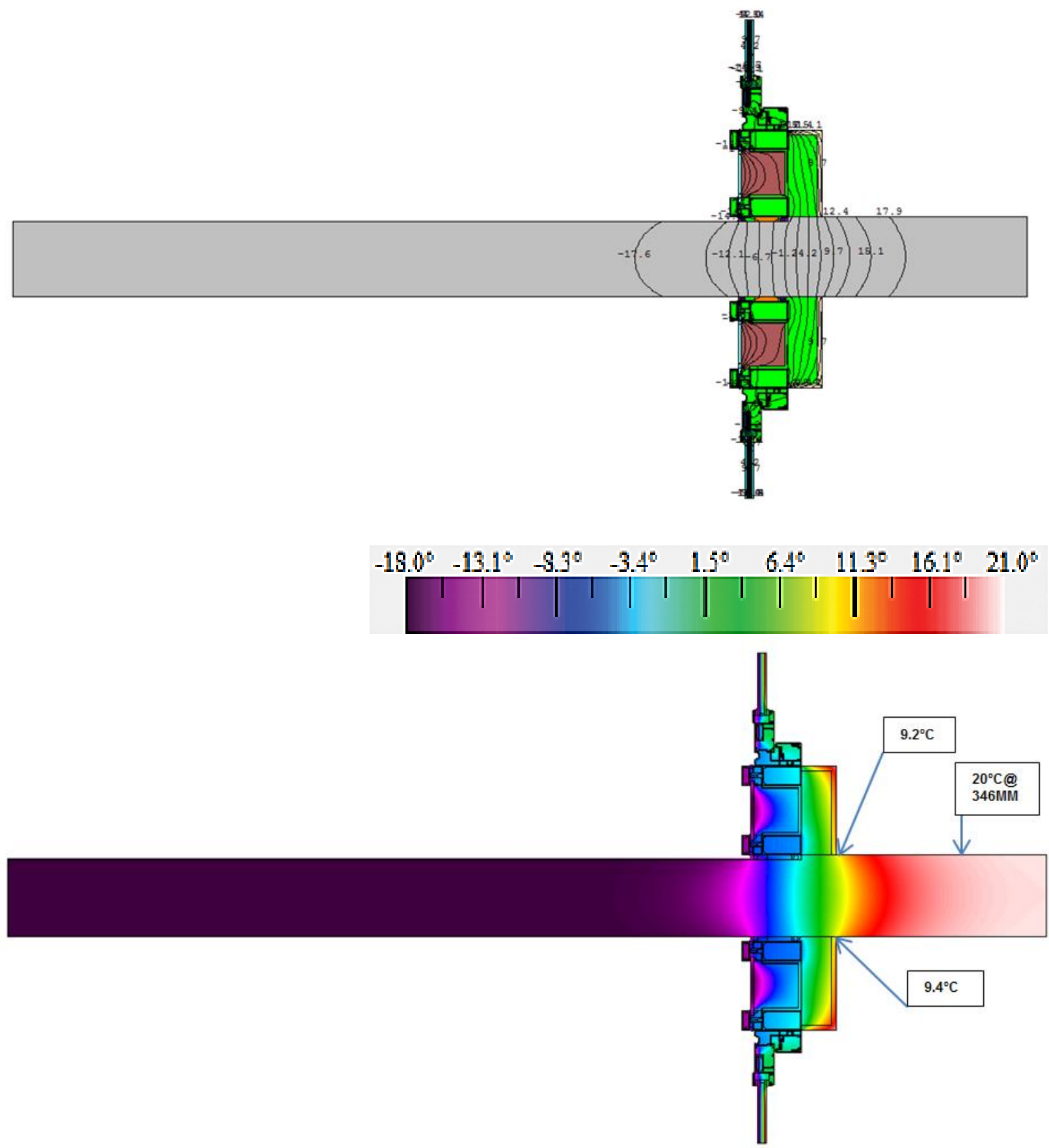
Scenario 2: Conventional - KSP-EPS-NTB
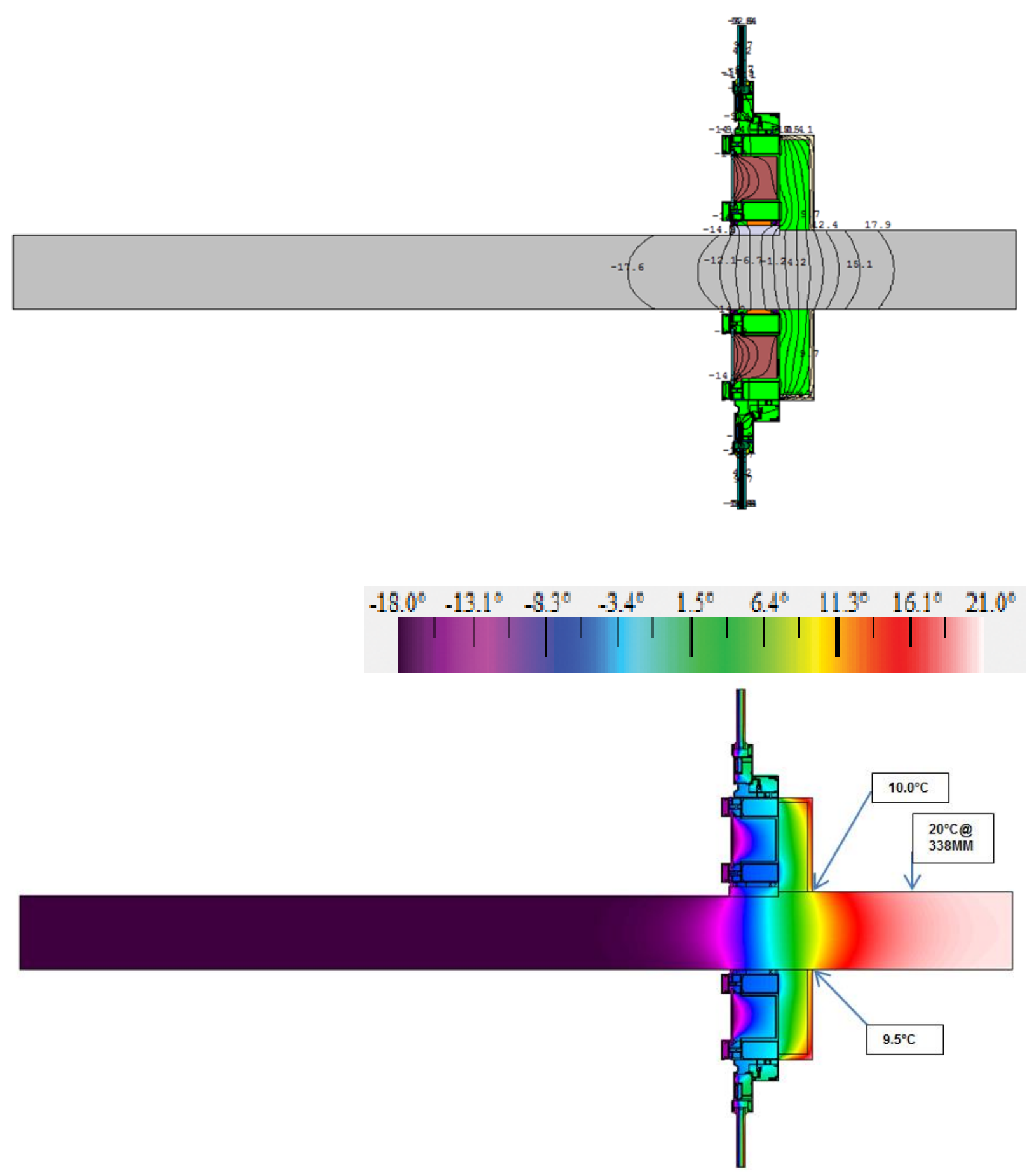
Scenario 3: KSP-NEPS-TBSI
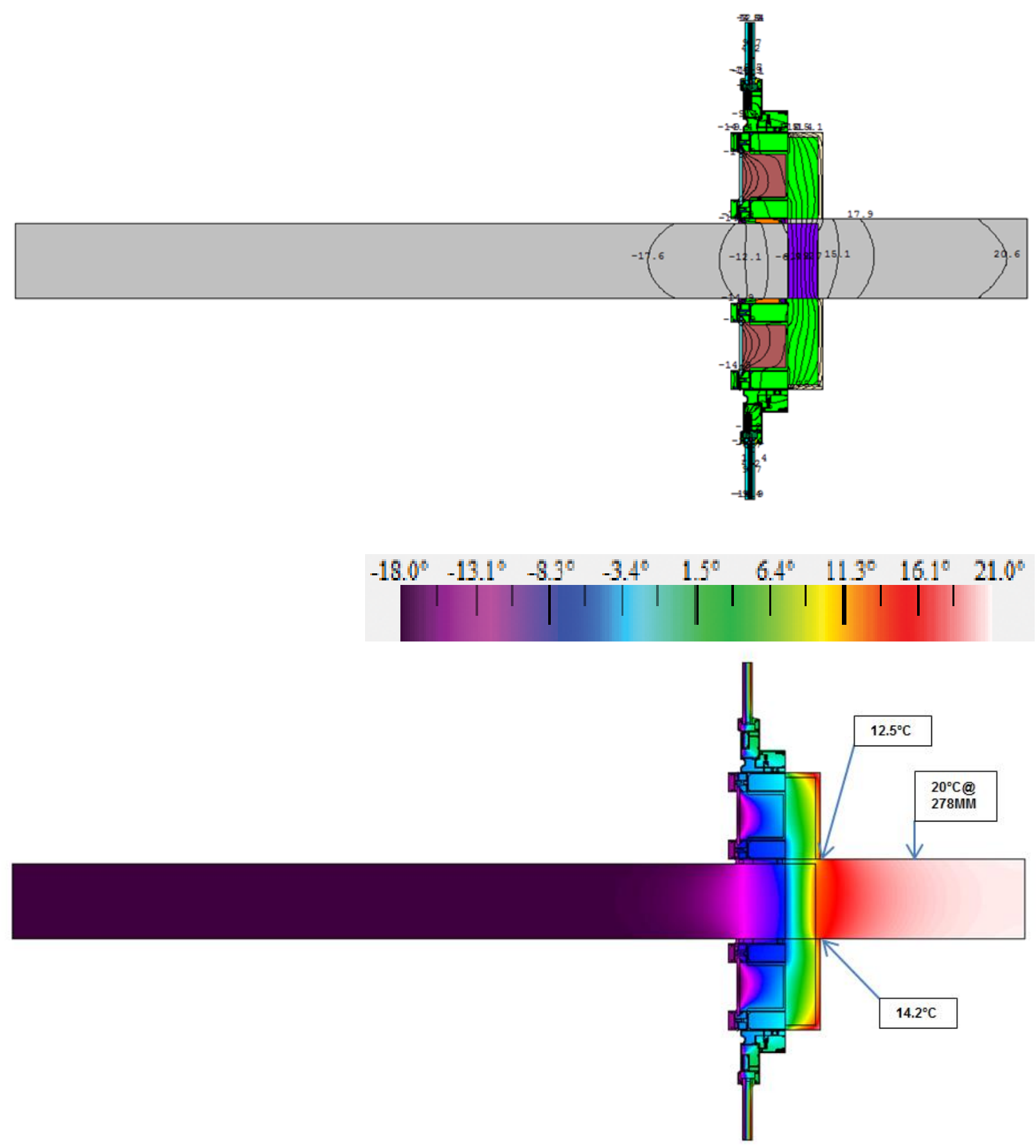
Scenario 4: KPS-EPS-TBSI

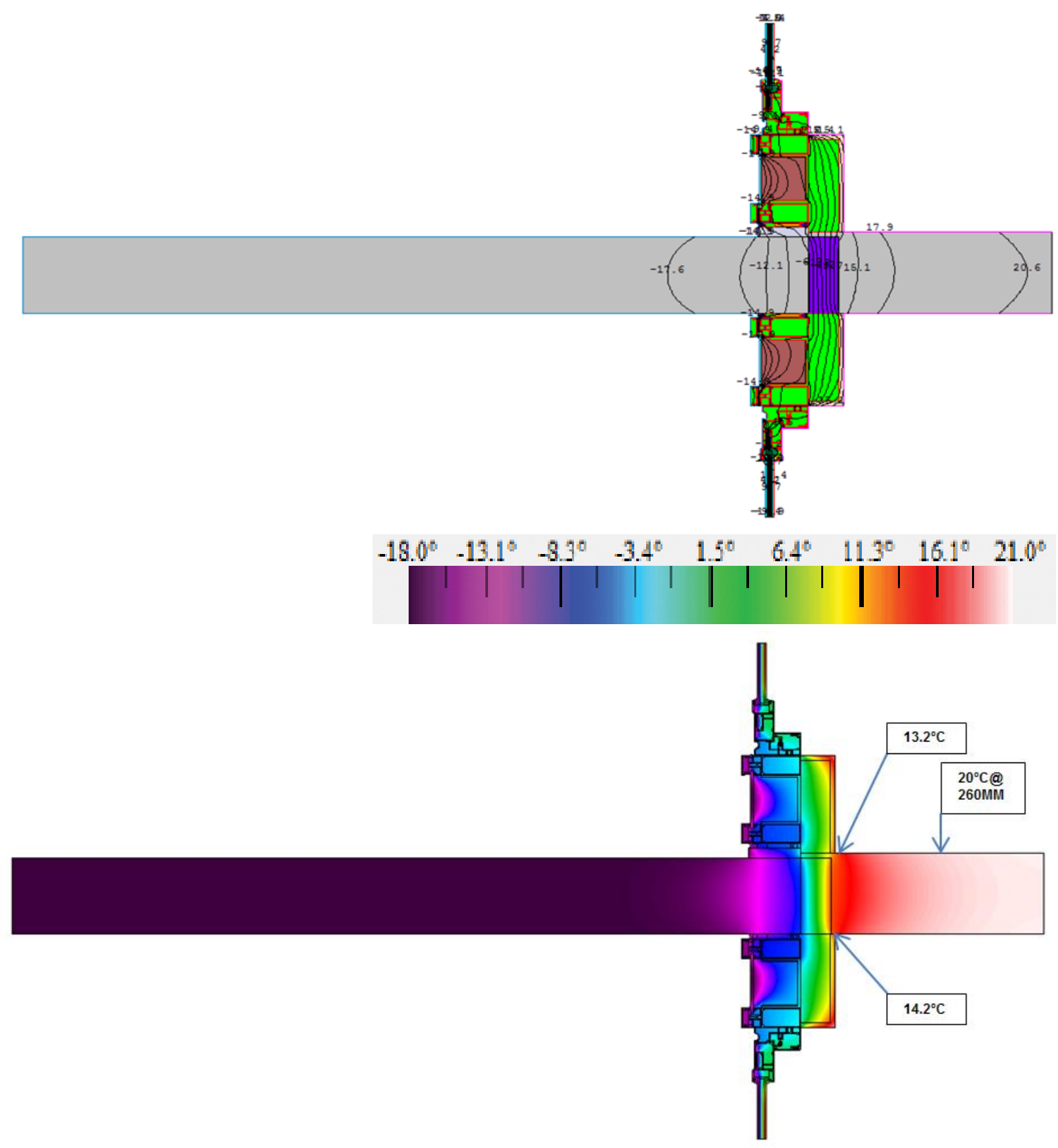


Scenario 5: Conventional - KSD-NEPS-NTB
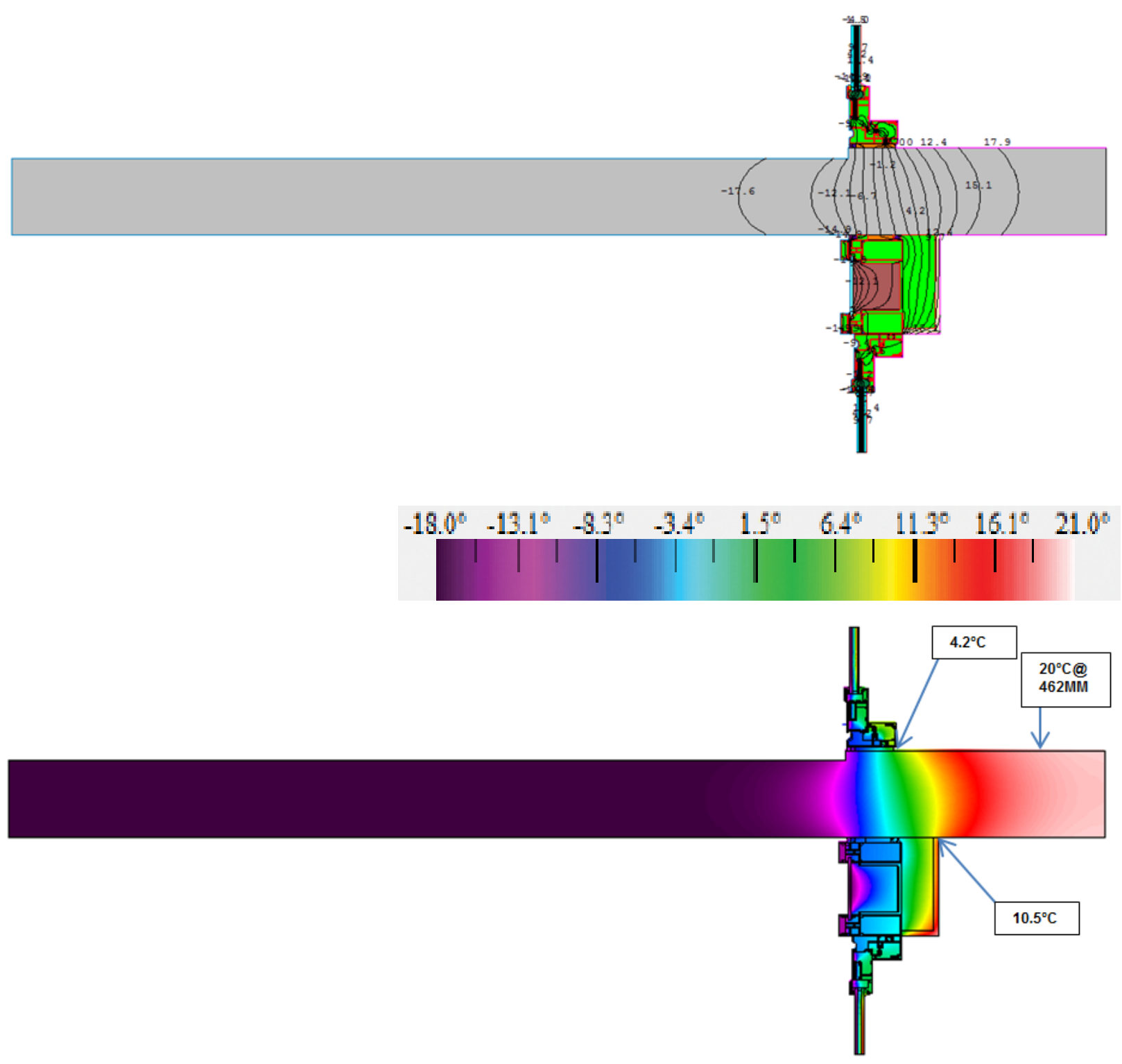
Scenario 6: KSD-EPS-NTB
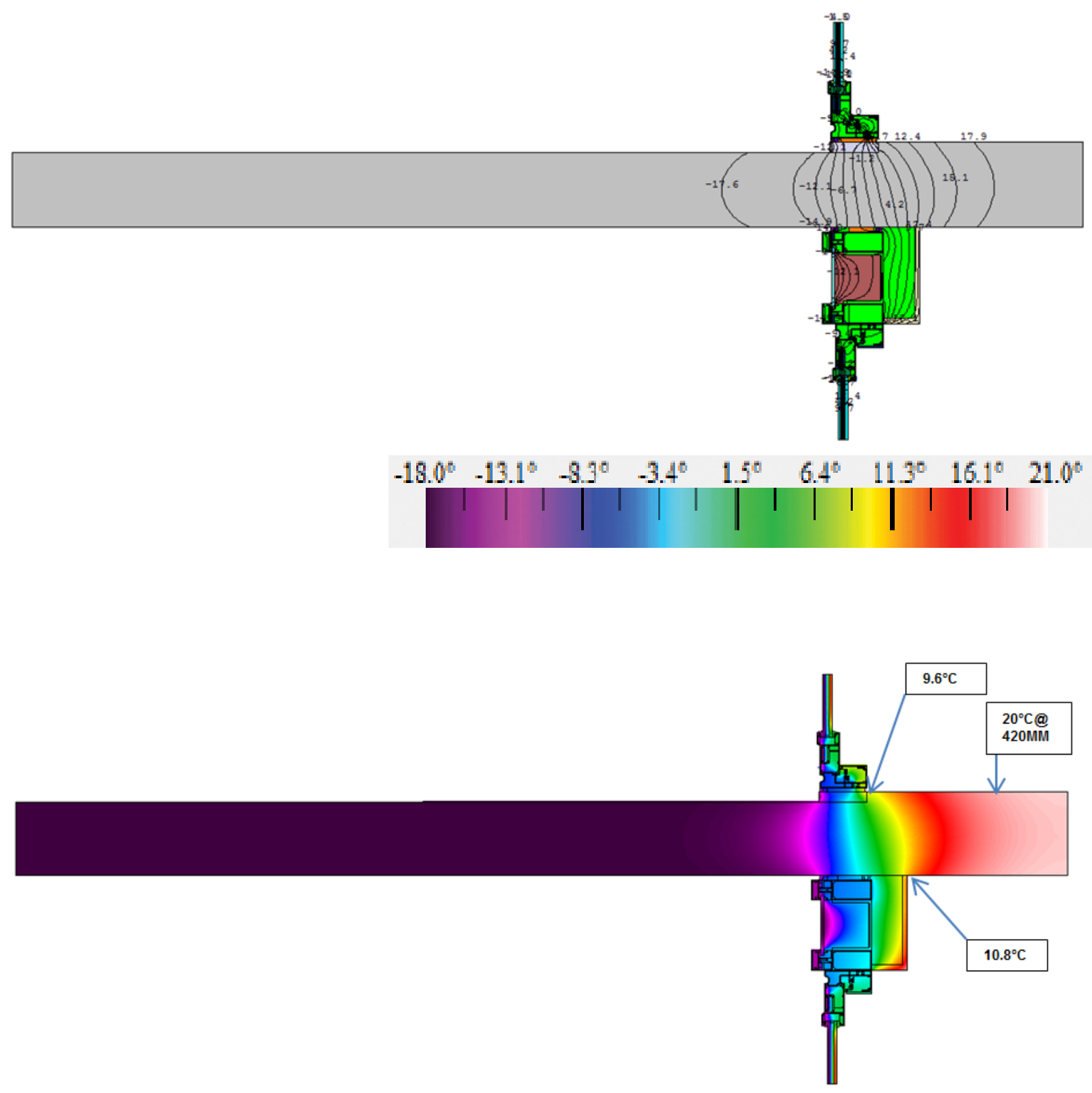
Scenario 7: KSD-NEPS-TBSI
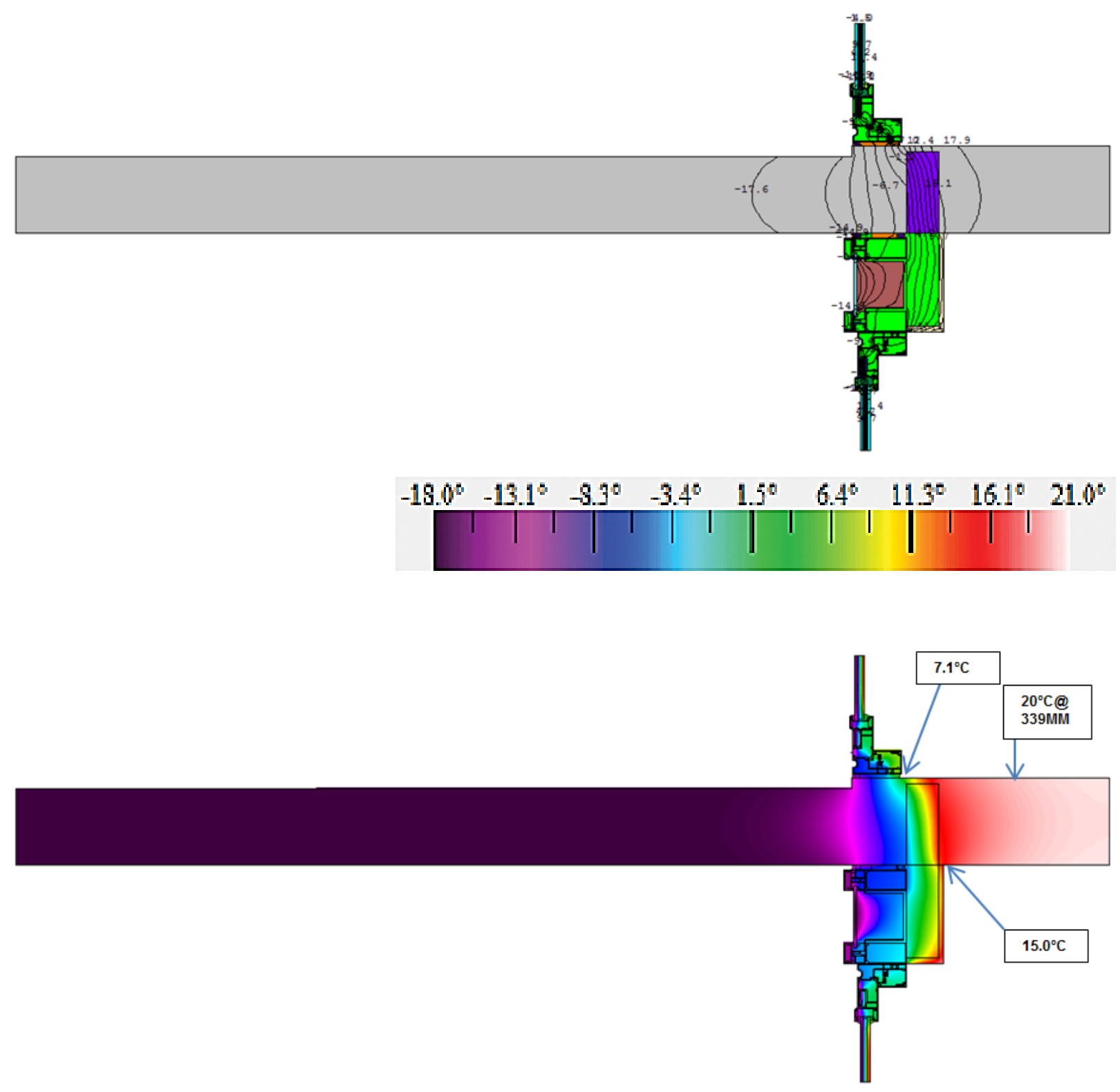
Scenario 8: KSD-EPS-TBSI
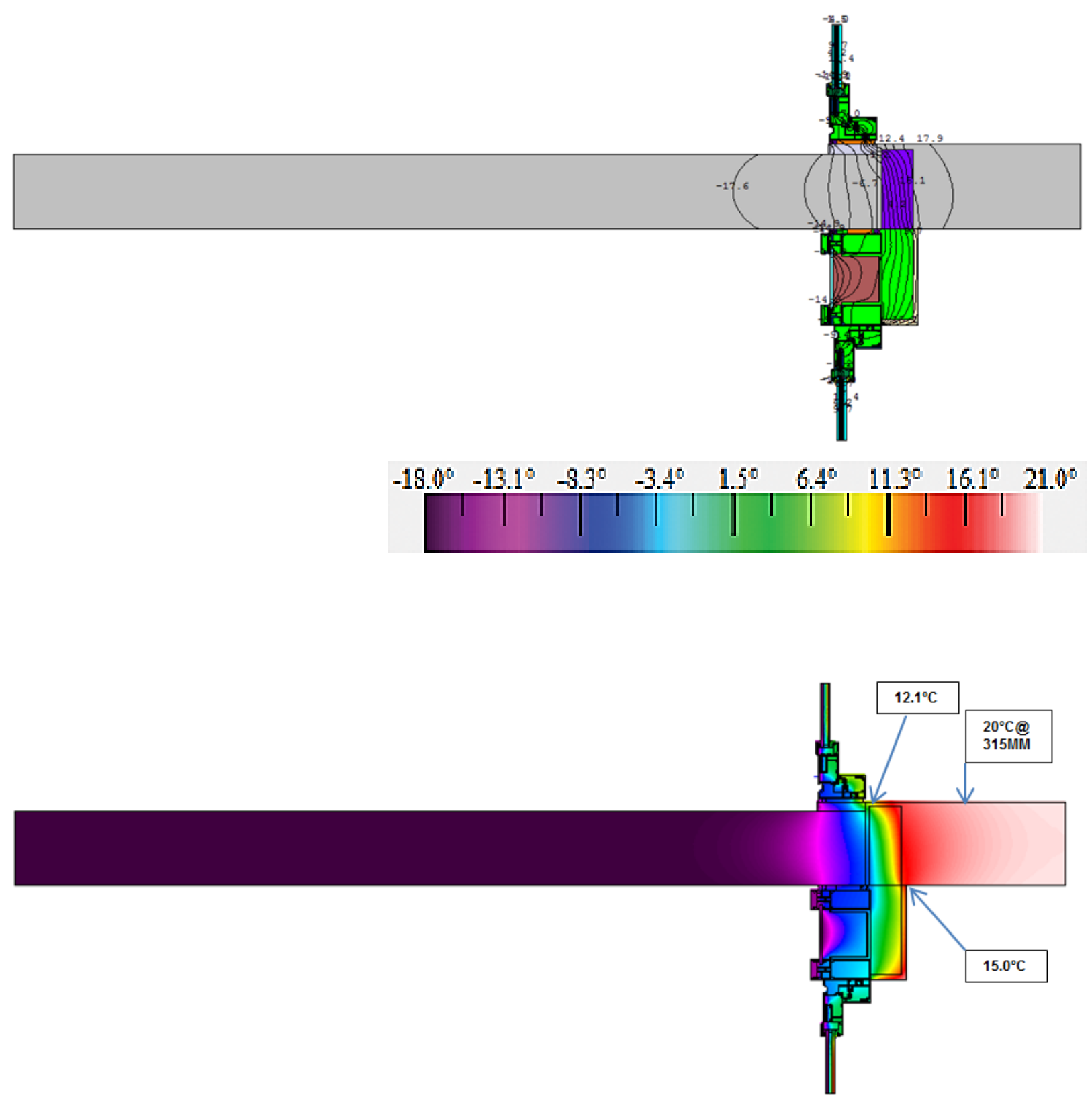
3 - MRP 2D THERM Modeled Scenarios No. I to VIII:

Scenario I: Conventional - KSP-NEPS-NTB

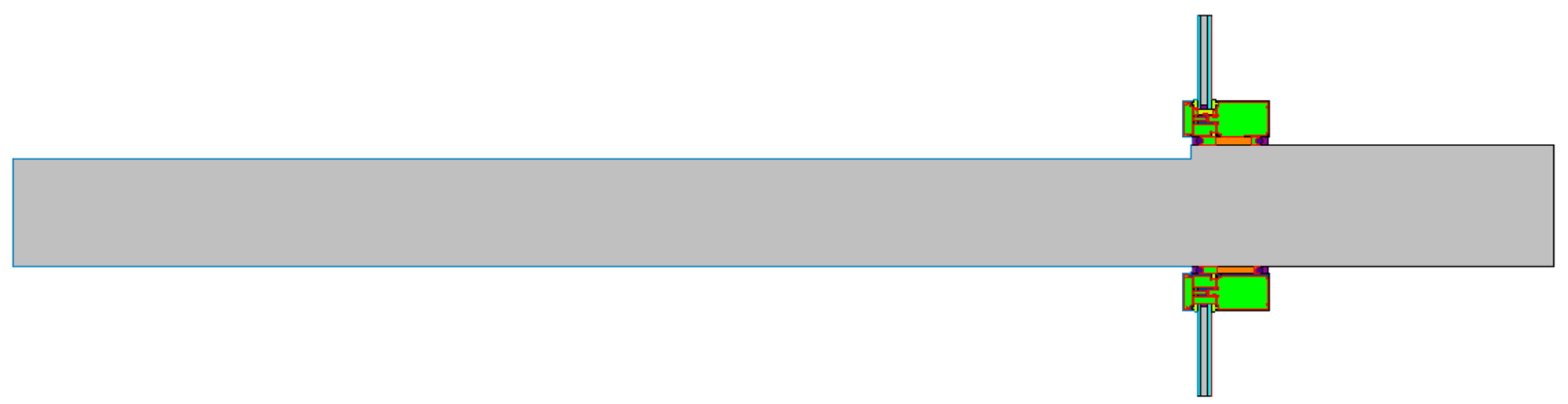

Scenario II: KSP-EPS-NTB

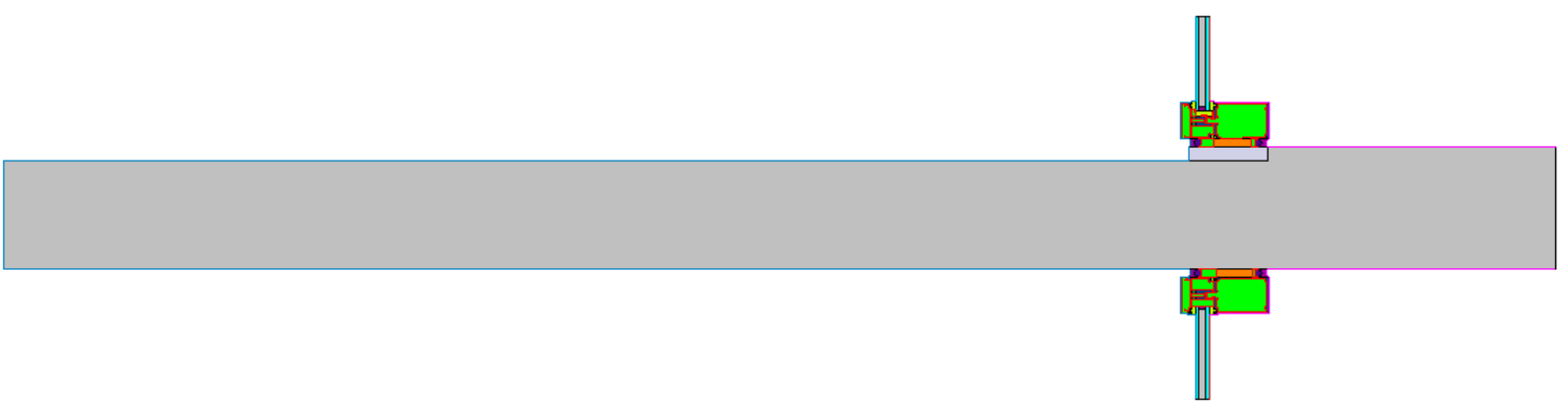

Scenario III: KSP-NEPS-TBSI

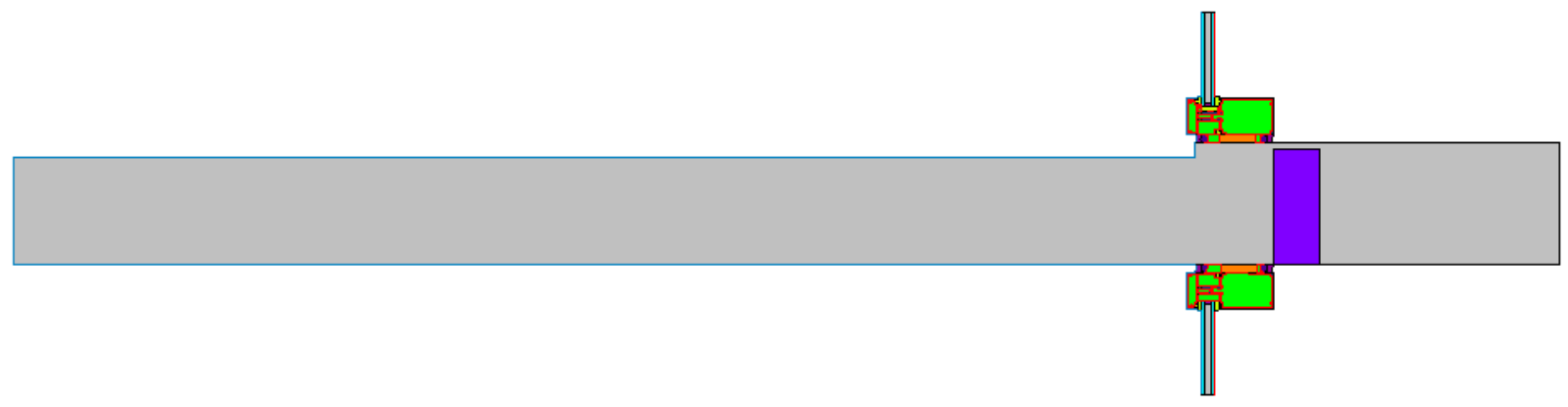

Scenario IV: KPS-EPS-TBSI

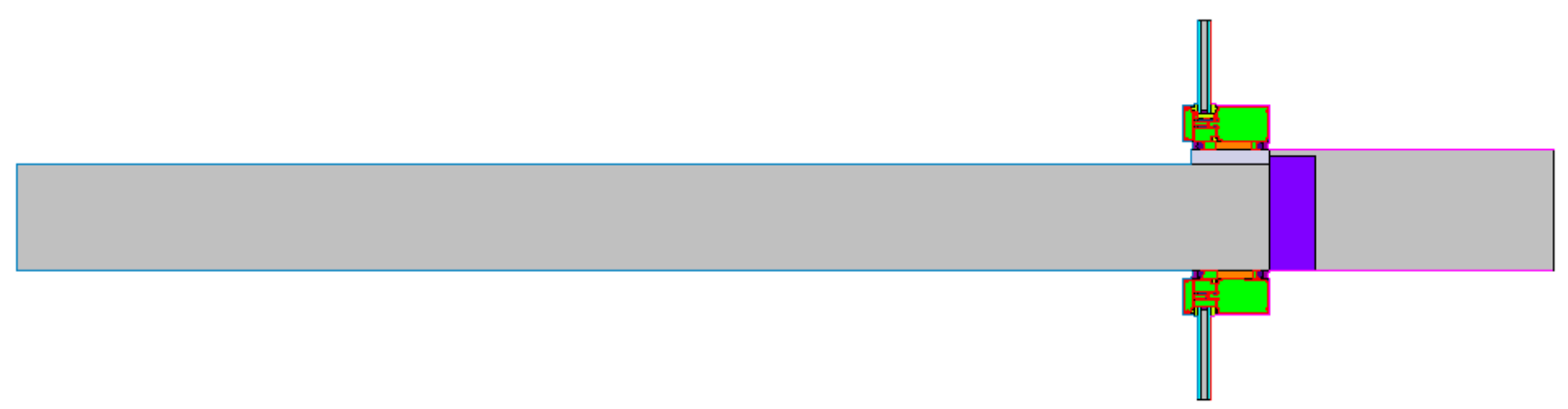


Scenario V: Conventional - KSD-NEPS-NTB

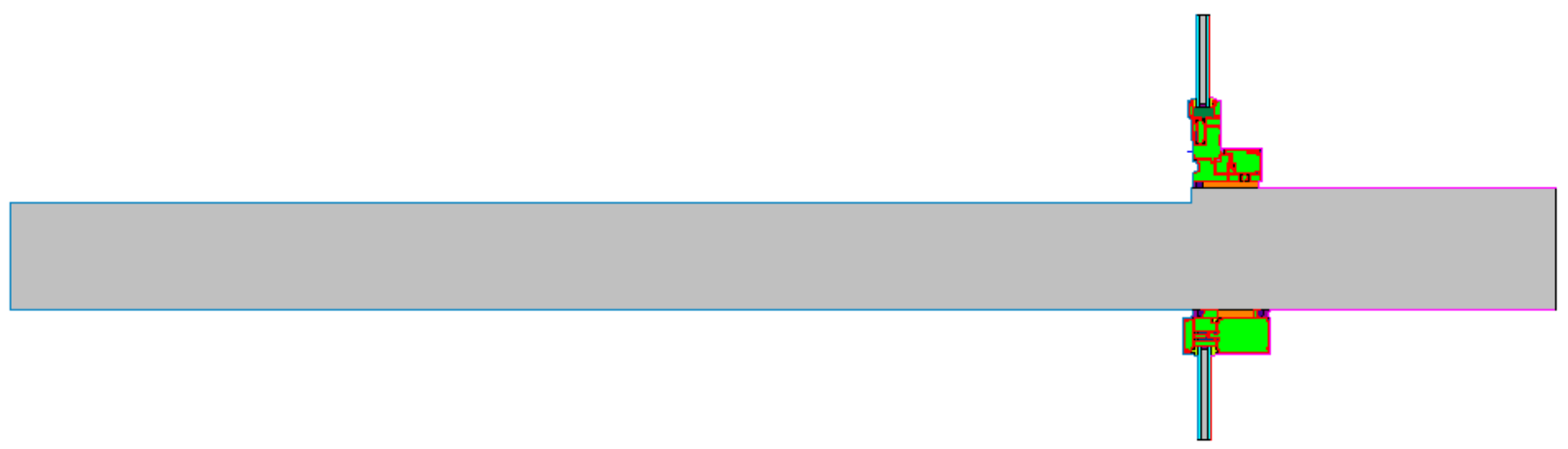

Scenario VI: KSD-EPS-NTB

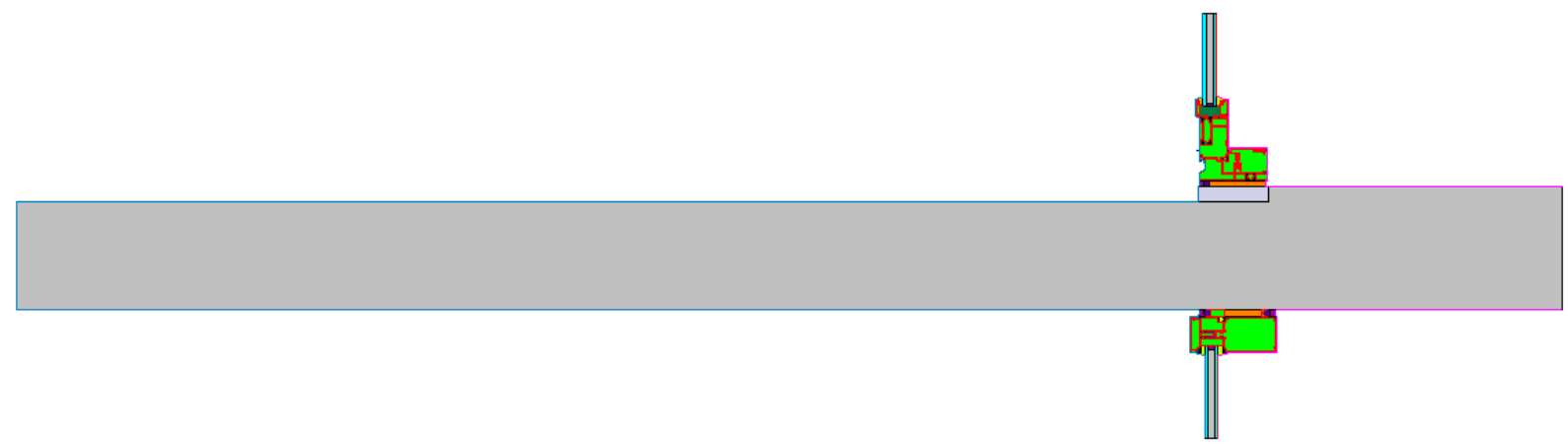

Scenario VII: KSD-NEPS-TBSI

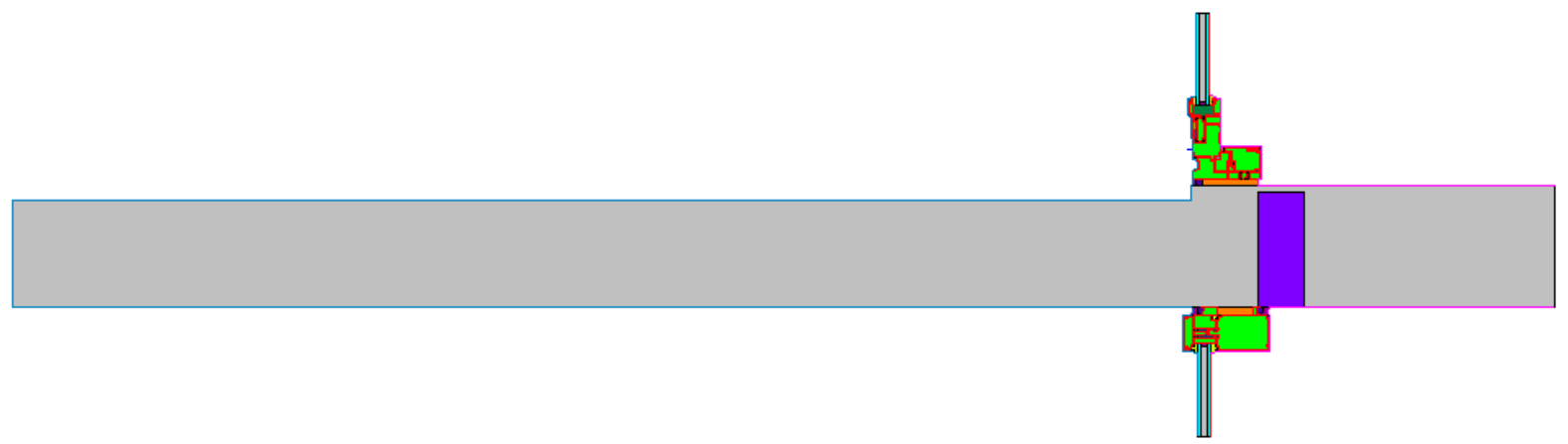

Scenario VIII: KSD-EPS-TBSI

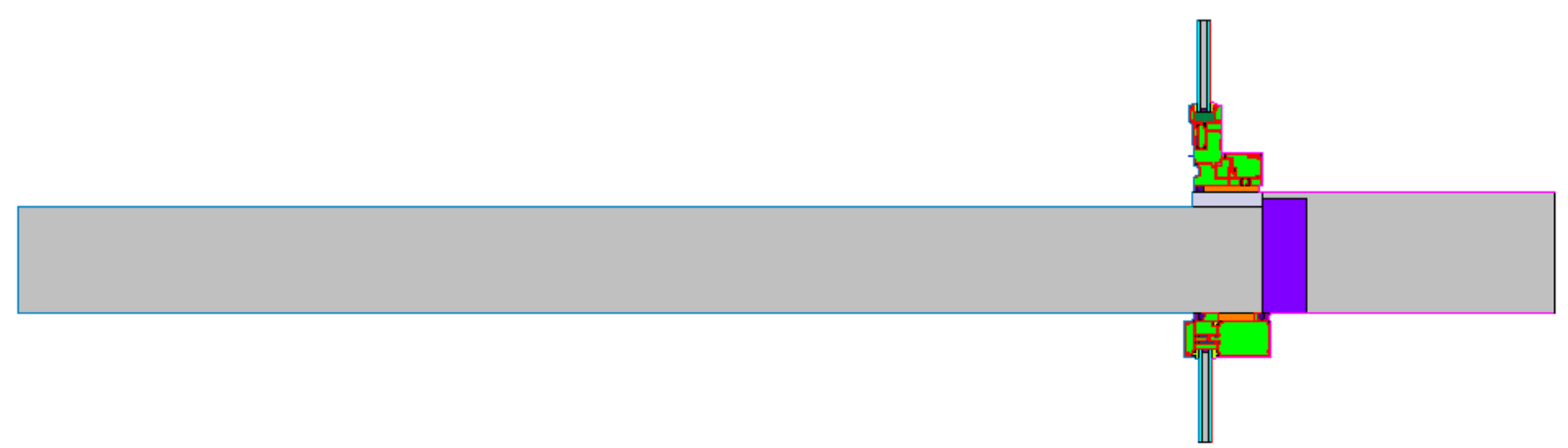


4 - MRP. U-value and Overall U-values calculated for scenarios I to VIII from interior boundary to account for asymmetric geometry (refer to Diagram below):

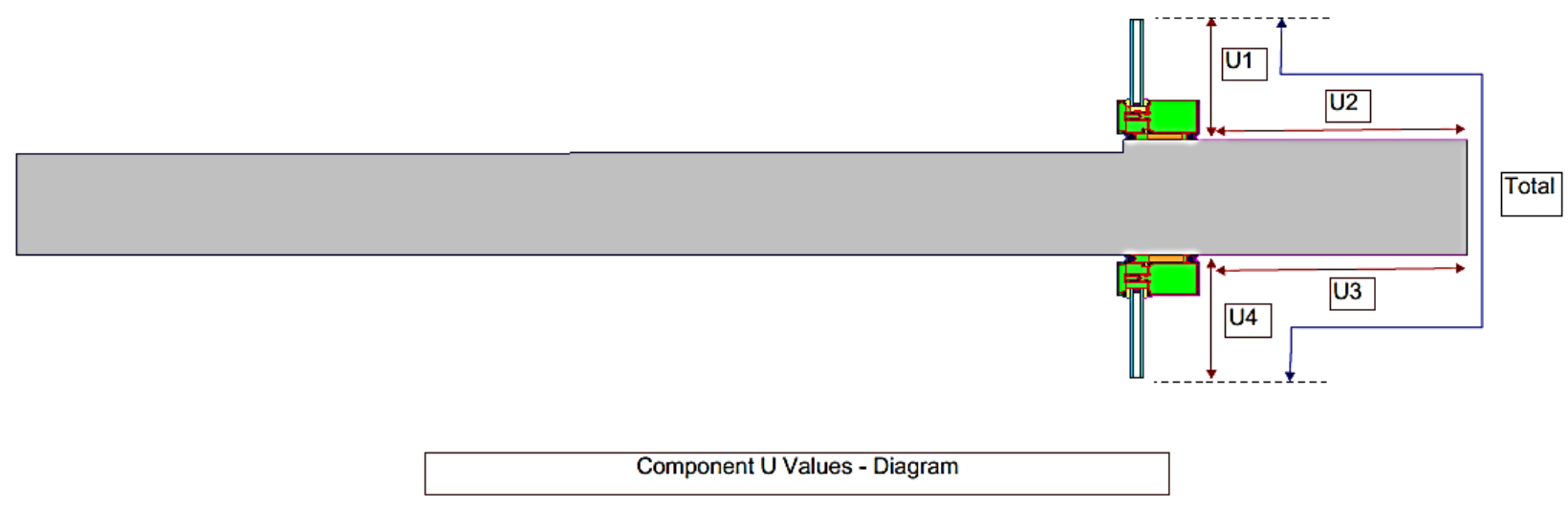

Scenario I: Conventional - KSP-NEPS-NTB

$\mathrm{U} 1: 2.41 \mathrm{~W} / \mathrm{m}^{2} . \mathrm{K}$

$\mathrm{U} 2: 0.74 \mathrm{~W} / \mathrm{m}^{2} . \mathrm{K}$

$\mathrm{U} 3: 0.74 \mathrm{~W} / \mathrm{m}^{2} . \mathrm{K}$

$\mathrm{U} 4: 2.44 \mathrm{~W} / \mathrm{m}^{2} . \mathrm{K}$

Overall U-value: $1.25 \mathrm{~W} / \mathrm{m}^{2} \mathrm{~K}$

Scenario II: KSP-EPS-NTB

$\mathrm{U} 1: 2.43 \mathrm{~W} / \mathrm{m}^{2} . \mathrm{K}$

$\mathrm{U} 2: 0.67 \mathrm{~W} / \mathrm{m}^{2} . \mathrm{K}$

$\mathrm{U} 3: 0.71 \mathrm{~W} / \mathrm{m}^{2} . \mathrm{K}$

$\mathrm{U} 4: 2.43 \mathrm{~W} / \mathrm{m}^{2} . \mathrm{K}$

Overall U-value: $1.20 \mathrm{~W} / \mathrm{m}^{2} \cdot \mathrm{K}$

\section{Scenario III: KSP-NEPS-TBSI}

$\mathrm{U} 1: 2.51 \mathrm{~W} / \mathrm{m}^{2} . \mathrm{K}$

$\mathrm{U} 2: 0.48 \mathrm{~W} / \mathrm{m}^{2} . \mathrm{K}$

$\mathrm{U} 3: 0.38 \mathrm{~W} / \mathrm{m}^{2} . \mathrm{K}$

$\mathrm{U} 4: 2.58 \mathrm{~W} / \mathrm{m}^{2} . \mathrm{K}$

Overall U-value: $1.13 \mathrm{~W} / \mathrm{m}^{2} . \mathrm{K}$

Scenario IV: KPS-EPS-TBSI

$\mathrm{U} 1: 2.30 \mathrm{~W} / \mathrm{m}^{2} . \mathrm{K}$

$\mathrm{U} 2: 0.37 \mathrm{~W} / \mathrm{m}^{2} . \mathrm{K}$

$\mathrm{U} 3: 0.38 \mathrm{~W} / \mathrm{m}^{2} . \mathrm{K}$

$\mathrm{U} 4: 2.60 \mathrm{~W} / \mathrm{m}^{2} . \mathrm{K}$

Overall U-value: $1.06 \mathrm{~W} / \mathrm{m}^{2} . \mathrm{K}$ 
Scenario V: Conventional - KSD-NEPS-NTB

$\mathrm{U} 1: 2.65 \mathrm{~W} / \mathrm{m}^{2} . \mathrm{K}$

$\mathrm{U} 2: 0.82 \mathrm{~W} / \mathrm{m}^{2} . \mathrm{K}$

$\mathrm{U} 3: 0.74 \mathrm{~W} / \mathrm{m}^{2} . \mathrm{K}$

$\mathrm{U} 4: 2.44 \mathrm{~W} / \mathrm{m}^{2} . \mathrm{K}$

Overall U-value: $1.35 \mathrm{~W} / \mathrm{m}^{2} . \mathrm{K}$

\title{
Scenario VI: KSD-EPS-NTB
}
$\mathrm{U} 1: 2.63 \mathrm{~W} / \mathrm{m}^{2} . \mathrm{K}$
$\mathrm{U} 2: 0.67 \mathrm{~W} / \mathrm{m}^{2} . \mathrm{K}$
$\mathrm{U} 3: 0.71 \mathrm{~W} / \mathrm{m}^{2} . \mathrm{K}$
$\mathrm{U} 4: 2.43 \mathrm{~W} / \mathrm{m}^{2} . \mathrm{K}$
Overall U-value: $1.30 \mathrm{~W} / \mathrm{m}^{2} . \mathrm{K}$

\section{Scenario VII: KSD-NEPS-TBSI}

\author{
$\mathrm{U} 1: 2.71 \mathrm{~W} / \mathrm{m}^{2} . \mathrm{K}$ \\ $\mathrm{U} 2: 0.58 \mathrm{~W} / \mathrm{m}^{2} . \mathrm{K}$ \\ $\mathrm{U} 3: 0.38 \mathrm{~W} / \mathrm{m}^{2} . \mathrm{K}$ \\ $\mathrm{U} 4: 2.58 \mathrm{~W} / \mathrm{m}^{2} . \mathrm{K}$ \\ Overall U-value: $1.23 \mathrm{~W} / \mathrm{m}^{2} . \mathrm{K}$
}

\section{Scenario VIII: KSD-EPS-TBSI}

$\mathrm{U} 1: 2.64 \mathrm{~W} / \mathrm{m}^{2} . \mathrm{K}$

$\mathrm{U} 2: 0.37 \mathrm{~W} / \mathrm{m}^{2} . \mathrm{K}$

$\mathrm{U} 3: 0.38 \mathrm{~W} / \mathrm{m}^{2} . \mathrm{K}$

$\mathrm{U} 4: 2.60 \mathrm{~W} / \mathrm{m}^{2} . \mathrm{K}$

Overall U-value: $1.17 \mathrm{~W} / \mathrm{m}^{2} . \mathrm{K}$ 


\section{APPENDIX E}

Schöck Isokorb CM20 Thermal Break Insulating Element:

\section{Schöck Isokorb ${ }^{\circledR}$ type CM}

Concrete cover/type designation

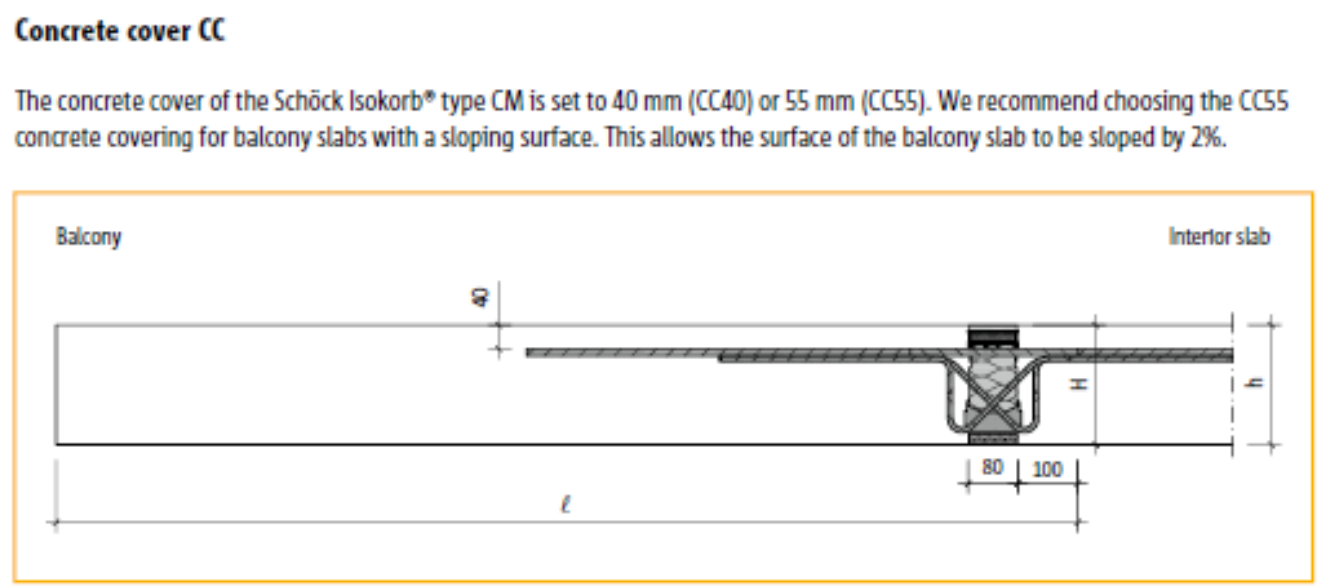

Canate cover with level bolcany slab

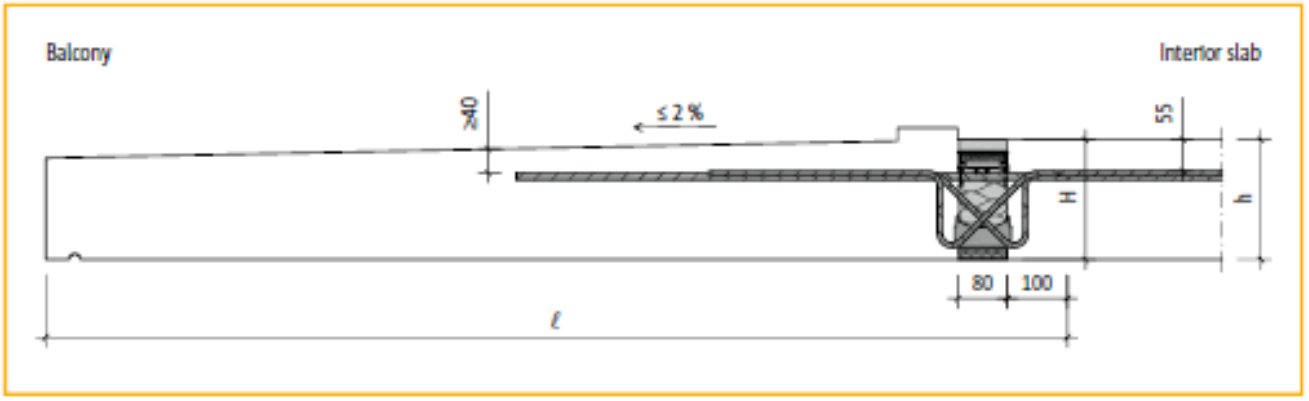

Concrete cover with sloped baicony slat

The concrete cover recommend for our proposed model is CC55 as shown in the figure

below. This allows the surface of the balcony slab to be sloped by $2 \%$ which is the case for the majority of cantilevered balcony slabs in high-rise MURBs. Also it shows how to position the Schöck Isokorb ${ }^{\circledR}$ type $\mathrm{CM}$ thermal break insulating element in the concrete balcony slab and the support of the balcony is assumed to be $100 \mathrm{~mm}$ from the interior slab side, " $\ell$ "is the cantilever length, and $\mathrm{CC}$ is the concrete cover for tension bars. These entire requirements were considered when completing the proposed model. 


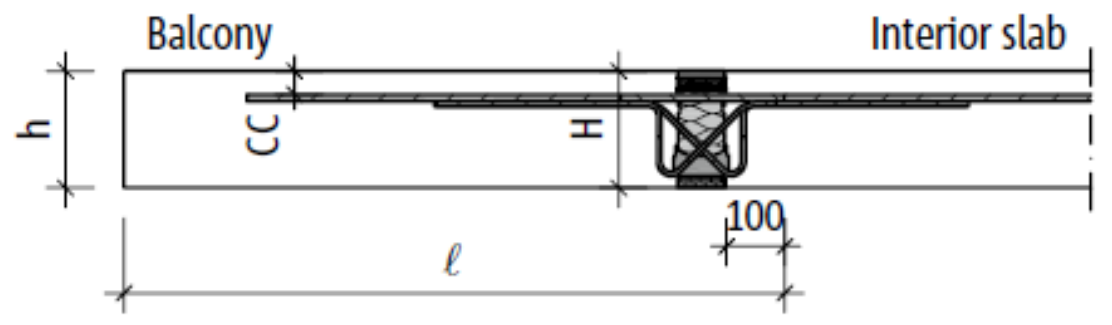

\section{Schöck Isokorb ${ }^{\circledR}$ Insulating Element Positioning in the Cantilevered balcony slab}

The table below shows the maximum cantilever lengths " $l$ " associated with Schöck Isokorb ${ }^{\circledR}$ height $\mathrm{H}$ recommended with for each concrete cover thickness in order to avoid excessive vibration in the balcony slab. For the proposed model, a sloped cantilevered concrete balcony slab with a Schöck Isokorb ${ }^{\circledR}$ thermal break CM20 height of $200 \mathrm{~mm}$, the maximum " $"$ " recommended is $2.03 \mathrm{~m}$.

\section{Max cantilever length with Schöck Isokorb ${ }^{\circledR}$ height $\mathbf{H}$ for each concrete cover thickness}

\begin{tabular}{|c|c|c|c|c|c|c|c|c|}
\hline Schöck Isokorb ${ }^{\circledR}$ height H [mm] & 180 & 190 & $\mathbf{2 0 0}$ & 210 & 220 & 230 & 240 & 250 \\
\hline Concrete Cover for Tension Bars & \multicolumn{7}{|c|}{ Max “l” [m] } \\
\hline CC $=40 \mathrm{~mm}$ & 1.95 & 2.10 & 2.25 & 2.39 & 2.54 & 2.68 & 2.83 & 2.98 \\
\hline CC $=\mathbf{5 5} \mathbf{~ m m}$ & & 1.88 & $\mathbf{2 . 0 3}$ & 2.17 & 2.32 & 2.46 & 2.61 & 2.76 \\
\hline
\end{tabular}

The Figure below illustrates Schöck Isokorb ${ }^{\circledR}$ type CM cross section and overhead view which is identical for the type CM 4 load capacities and for the respective concrete cover. However, the load capacities of Schöck Isokorb ${ }^{\circledR}$ type CM vary in the number of tension bars, shear force bars and pressure bearings. 

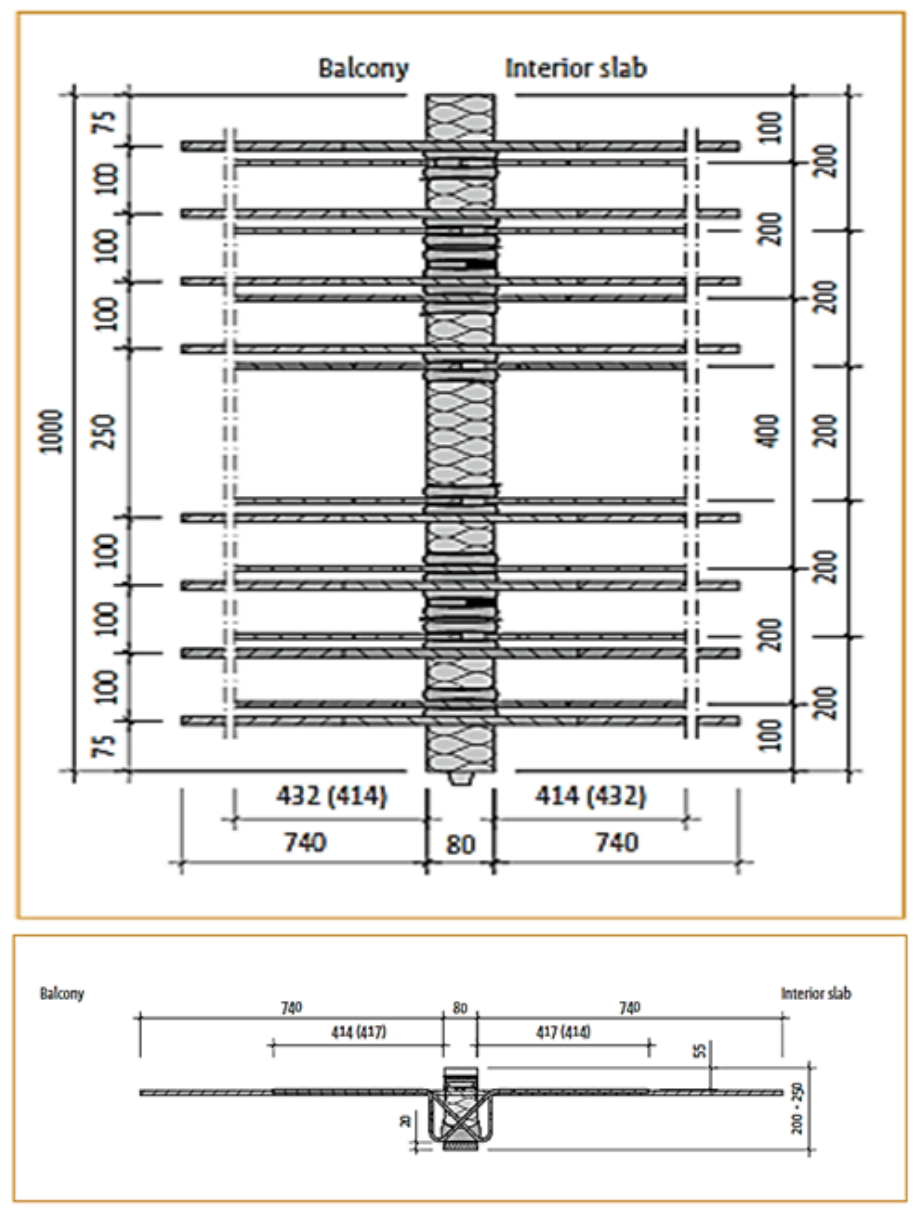

\section{Product cross-section and overhead view of Schöck Isokorb ${ }^{\circledR}$ Type CM}

Schöck Isokorb ${ }^{\circledast}$

Equivalent Thermal Conductivity $k_{\text {eq }}$

\begin{tabular}{|c|c|c|c|c|c|c|c|c|c|c|c|c|c|c|c|c|c|c|}
\hline \multicolumn{19}{|c|}{$\mathrm{k}_{\mathrm{eq}}$-value $[\mathrm{W} /(\mathrm{mk})]$} \\
\hline \multirow{3}{*}{$\begin{array}{l}\text { Isokorb } \\
\text { type }\end{array}$} & \multicolumn{16}{|c|}{ Isokorb ${ }^{8}$ height $\mathrm{H}[\mathrm{mm}]$} & \multirow{3}{*}{$\begin{array}{l}\text { Isokorb } \\
\text { length }[\mathrm{m}]\end{array}$} & \multirow{3}{*}{\begin{tabular}{|c} 
Fire \\
protection
\end{tabular}} \\
\hline & \multicolumn{2}{|c|}{180} & \multicolumn{2}{|c|}{190} & \multicolumn{2}{|c|}{200} & \multicolumn{2}{|c|}{210} & \multicolumn{2}{|c|}{220} & \multicolumn{2}{|c|}{230} & \multicolumn{2}{|c|}{240} & \multicolumn{2}{|c|}{250} & & \\
\hline & Ro & R90/R120 & RO & R90/R120 & RO & R90/R120 & RO & R90/R120 & Ro & R90/R120 & RO & R90/R120 & RO & R90/R120 & RO & R90/R120 & & \\
\hline CM10 & 0.157 & 0.176 & 0.151 & 0.168 & 0.145 & 0.161 & 0.140 & 0.155 & 0.135 & 0.150 & 0.131 & 0.145 & 0.127 & 0.140 & 0.123 & 0.136 & 1.00 & $\mathrm{R} 120$ \\
\hline CM20 & 0.185 & 0.203 & 0.177 & 0.194 & 0.170 & 0.186 & 0.163 & 0.179 & 0.157 & 0.172 & 0.152 & 0.166 & 0.147 & 0.161 & 0.142 & 0.156 & 1.00 & R120 \\
\hline CM30 & 0.212 & 0.230 & 0.202 & 0.220 & 0.194 & 0.210 & 0.186 & 0.202 & 0.179 & 0.194 & 0.173 & 0.187 & 0.167 & 0.181 & 0.162 & 0.175 & 1.00 & R120 \\
\hline CM40 & 0.239 & 0.257 & 0.228 & 0.245 & 0.218 & 0.235 & 0.210 & 0.225 & 0.202 & 0.217 & 0.194 & 0.209 & 0.188 & 0.201 & 0.182 & 0.195 & 1.00 & R120 \\
\hline CMD10 & 0.180 & 0.198 & 0.173 & 0.190 & 0.166 & 0.182 & 0.159 & 0.175 & 0.154 & 0.169 & 0.148 & 0.163 & 0.144 & 0.157 & 0.139 & 0.152 & 1.00 & R90 \\
\hline CMD20 & 0.218 & 0.236 & 0.208 & 0.225 & 0.200 & 0.216 & 0.192 & 0.207 & 0.184 & 0.199 & 0.178 & 0.192 & 0.172 & 0.186 & 0.166 & 0.179 & 1.00 & R90 \\
\hline CMD30 & 0.256 & 0.274 & 0.244 & 0.261 & 0.233 & 0.250 & 0.224 & 0.239 & 0.215 & 0.230 & 0.207 & 0.222 & 0.200 & 0.214 & 0.193 & 0.207 & 1.00 & R90 \\
\hline CMD40 & 0.293 & 0.311 & 0.279 & 0.297 & 0.267 & 0.284 & 0.256 & 0.272 & 0.246 & 0.261 & 0.237 & 0.251 & 0.228 & 0.242 & 0.221 & 0.234 & 1.00 & R90 \\
\hline CV10 & 0.079 & 0.097 & 0.077 & 0.094 & 0.074 & 0.091 & 0.073 & 0.088 & 0.071 & 0.086 & 0.069 & 0.083 & 0.068 & 0.081 & 0.066 & 0.079 & 1.00 & R120 \\
\hline CV2O & 0.088 & 0.107 & 0.086 & 0.103 & 0.083 & 0.099 & 0.081 & 0.096 & 0.078 & 0.093 & 0.077 & 0.091 & 0.075 & 0.088 & 0.073 & 0.086 & 1.00 & R120 \\
\hline CV 30 & 0.101 & 0.119 & 0.097 & 0.115 & 0.094 & 0.111 & 0.091 & 0.107 & 0.089 & 0.104 & 0.086 & 0.101 & 0.084 & 0.098 & 0.082 & 0.095 & 1.00 & R120 \\
\hline CVB10 & . & - & - & 1. & 0.141 & 0.157 & 0.135 & 0.151 & 0.131 & 0.146 & 0.127 & 0.141 & 0.123 & 0.136 & 0.119 & 0.132 & 0.30 & R90 \\
\hline CVB20 & - & - & - & - & - & - & 0.179 & 0.194 & 0.172 & 0.187 & 0.166 & 0.180 & 0.161 & 0.174 & 0.156 & 0.169 & 0.30 & R90 \\
\hline CVB30 & - & - & - & - & - & - & - & - & 0.225 & 0.240 & 0.217 & 0.231 & 0.209 & 0.223 & 0.202 & 0.215 & 0.30 & R90 \\
\hline CEQ1 & 0.118 & 0.136 & 0.113 & 0.130 & 0.109 & 0.126 & 0.106 & 0.121 & 0.102 & 0.117 & 0.099 & 0.114 & 0.097 & 0.110 & 0.094 & 0.107 & 0.10 & R90 \\
\hline CEQ2 & 0.410 & 0.428 & 0.390 & 0.408 & 0.373 & 0.389 & 0.356 & 0.372 & 0.342 & 0.357 & 0.328 & 0.343 & 0.316 & 0.330 & 0.305 & 0.318 & 0.10 & R90 \\
\hline $\begin{array}{c}\text { Isokorb } \\
\text { type }\end{array}$ & $\begin{array}{l}\text { Isokorb } \\
\text { height } \\
\text { Himml }\end{array}$ & & & & & & & & & & & & & & & & & \\
\hline S22 & 1.90 & & & & & & & & & & & & & & & & & \\
\hline
\end{tabular}




\section{REFERENCES}

[1] THERM. Two-Dimensional Building Heat-Transfer Modeling. Retrieved August 19, 2014 from http://windows.lbl.gov/software/therm/therm.html

[2] Thermal Break Definition. Retrieved August 19, 2014 from http://en.wikipedia.org/wiki/Thermal_break

[3] Ge, H., McClung, V. R., \& Zhang, S. (May, 2013). Impact of balcony thermal bridges on the overall thermal performance of multi-unit residential buildings: A case study. Energy \& Buildings, 60, 163. doi:10.1016/j.enbuild.2013.01.004. Retrieved from Ryerson Library

[4] Roppel, P., Cianfrone, C. (June 19, 2013). Thermal and Whole building Energy Performance of Thermal Break Technology for Concrete Balconies in High-Rise Multi-unit Residential Buildings. Last visited August 20, 2014, retrieved from http://www.schockus.com/upload/documents/flashbook/en_us/isokorb_/report_thermal_and_whole_building_e nergy_performan_13-06-

27_5353/files/assets/common/downloads/MH_Balcony_final_report_19June2013[5353].pdf

[5] Hens, H. (2007). Building physics - heat, air and moisture: Fundamentals and Engineering Methods with Examples and Exercises. Berlin: Ernst \& Sohn.

[6] Thermal Bridging Solutions. Schöck Isokorb ${ }^{\circledR}$ Specifiers Handbook (November 2012). Retrieved August 20, 2014 from http://www.bpindex.co.uk/res/pdfs/b5326f0a0bbb48.pdf [7] RDH Building Engineering Limited. Research + Forensics Publications. Balcony and Slab Edge Study. Research Report - 1 - R-values and energy Code Canada (September 24, 2013). Last visited June 11, 2014, retrieved from http://rdh.com/wp-content/uploads/2014/04/TheImportance-of-Slab-Edge-Balcony-Thermal-Bridges.pdf 
[8] RDH Building Engineering Limited. Research + Forensics Publications. Balcony and Slab Edge Study. Research Report - 2 - Thermal Comfort (September 24, 2013). Last visited June 11, 2014, retrieved from http://rdh.com/wp-content/uploads/2014/04/Thermal-Comfort.pdf [9] RDH Building Engineering Limited. Research + Forensics Publications. Balcony and Slab Edge Study. Research Report - 3 - Energy Saving (September 24, 2013). Last visited June 11, 2014, retrieved from http://rdh.com/wp-content/uploads/2014/04/Energy-Savings.pdf [10] RDH Building Engineering Limited. Research + Forensics Publications. Balcony and Slab Edge Study. Research Report - 4 - Other Considerations (September 24, 2013). Last visited June 11, 2014, retrieved from http://rdh.com/wp-content/uploads/2014/04/OtherConsiderations.pdf

[11] ASIEPI. Schild, P., Blom, P., P188, 26-03-2010, Good Practice guidance on thermal bridges \& construction details, Part 1: Principles. Retrieved May 28, 2013 from http://www.asiepi.eu/wp-4-thermal-bridges/information-papers.html

[12] Schöck Isokorb: Design Guide. Solution to Prevent Thermal Bridging (June 2014), retrieved August 20, 2014 from http://www.schoeck.ca/upload/documents/flashbook/en_us/isokorb_/design_guide_schoeck_ isokorb_solutions_to_prevent_14-07-07_5752/files/assets/basic-html/index.html\#1

[13] Schöck Isokorb: The extension of the energy efficiency of buildings. Last visited June 30, 2014, retrieved from http://www.ahkbalt.org/fileadmin/ahk_baltikum/Projekte/Energieeffizienz/Energieeffizienz_2013/06_Tati ana_Egorova_Schoeck_26022013_Riga.pdf 
[14] Begoc, M., \& Currier, M. (2004). Cutting out thermal bridging. Concrete, 38(5), 26-26. Retrieved January 6, 2013 from http://search.proquest.com.ezproxy.lib.ryerson.ca/docview/204052487

[15] Fin (extended surface) - Wikipedia, the free encyclopedia. Last visited June 14, 2014 retrieved from http://en.wikipedia.org/wiki/Fin_(extended_surface)

[16] Building Science Information: BSI-062: Insight Thermal Bridge Redux. By Joseph Lstiburek, created: 2012/07/11 in ASHRAE Journal. Last visited August 21, 2014 from http://www.buildingscience.com/documents/insights/bsi062-thermal-bridges-redux

[17] Pete E. (January 2014). 130 High-Rise Building Projects in Toronto lead North America. CBC NEWS. Retrieved August 21, 2014 from http://www.cbc.ca/news/business/130-highrise-building-projects-in-toronto-lead-northamerica-1.2504776

[18] Schöck Isokorb ${ }^{\circledR}$ Type CM. Technical Manual Schöck Isokorb ${ }^{\circledR}$ Type CM. Last visited August 21, 2014, retrieved from http://www.schoeck.ca/upload/documents/flashbook/en_ca/isokorb_/technical_manual_sch oeck_isokorb_type_cm_12-03-23_4824/files/assets/basic-html/toc.html

[19] Morrison Hershfield Ltd. 2011. ASHRAE RP-1365, Thermal Performance of Building Envelope Construction Details for Mid- and High-Rise Buildings, American Society of Heating, Refrigeration and Air conditioning Engineers, Inc., Atlanta, GA.

[20] Lstiburek, Joseph W,PhD., P.Eng. (2009). High-rise igloos. ASHRAE Journal, 51(4), 6264,66. Retrieved from http://ezproxy.lib.ryerson.ca/login?url=http://search.proquest.com/docview/220449228?acco untid=13631 
[21] Lstiburek, Joseph W,PhD., P.Eng. (2007). A bridge too far. ASHRAE Journal, 49(10), 6464,66,68. Retrieved from http://ezproxy.lib.ryerson.ca/login?url=http://search.proquest.com/docview/220453051?acco untid $=13631$

[22] Thermal Break Technology References in Canada. Last visited August 22, 2014, retrieved from http://www.schoeck.ca/upload/files/download/References_Schoeck_Isokorb_\%5B5249\%5 D.pdf

[23] Cianfrone C., Noris N., Roppel P., Marceau M., (2012). Thermal Performance of Three Dimensional Building Envelop Assemblies and Details for Improving the Accuracy of Whole Building Performance Simulation. Last visited August 22, 2014, retrieved from http://www.ibpsa.us/simbuild2012/Papers/SB12_TS02a_3_Cianfrone.pdf

[24] Roppel, P., P.Eng, Lawton, M., P.Eng, \& Norris, N. (2012). Thermal performance of building envelope details for mid- and high-rise buildings. ASHRAE Transactions, 118, 569-584. Retrieved from http://ezproxy.lib.ryerson.ca/login?url=http://search.proquest.com/docview/1239093531?acc ountid=13631

[25] Schöck - Press Release (June 20, 2013) - Morrison Hershfield release results of a Collaborative Study on Thermal \& Energy Performance of Thermal Break Technology in Concrete Balconies. Last visited June 22, 2014, retrieved from http://www.morrisonhershfield.com/newsroom/Documents/Sch\%C3\%B6ckMorrison\%20Hershfield\%20Study_Press\%20Release.pdf 
[26] CAN/SA A440.2-09, Fenestration energy performance, Canadian Standard Association, 2009.

[27] General Specification: 9000 Series Double Glazed Window Wall. Starline Architectural Windows Limited. Retrieved July 15, 2014 from http://www.mah.gov.on.ca/AssetFactory.aspx?did=9227

[28] Supplementary Standard SB-10, Energy Efficiency Supplement (July 1, 2011 update). 2006 Building Code - Supplementary Standards. Retrieved July 15, 2014 from http://www.mah.gov.on.ca/AssetFactory.aspx?did=9227

[29] KAWNEER Curtain Wall Systems, 1600 UT System ${ }^{\mathrm{TM}} 2$ - Architectural Detail Manual. Last visited July 18, 2014, retrieved from http://www.kawneer.com/kawneer/north_america/catalog/pdf/Curtain_wall/Arch_1600UT _System2(Eng).pdf

[30] KAWNEER Doors - Sliding, $\mathrm{AA}^{\mathrm{TM}} 3900$ Thermal Sliding Door - Last visited July 18, 2014, Retrieved from http://www.kawneer.com/kawneer/north_america/catalog/pdf/AA3900_Slider_E--A.pdf

[31] Expanded Polystyrene Insulation: Below Grade Testing Confirms R-Value Retention (August 2008)-Technical Bulletin. Retrieved July 19, 2014 from http://www.truefoam.com/site/media/Truefoam/EPS\%20Below\%20Grade101.pdf

[32] McBride, S. (June, 2009). Insulation: EPS and XPS. BUILDINGS.

Retrieved July 19, 2014 from http://www.buildings.com/article-details/articleid/8498/title/insulation-eps-and-xps.aspx 
[33] THERM 6.3 / WINDOW 6.3 NFRC Simulation Manual - Last visited September 19, 2014, retrieved from http://windows.lbl.gov/software/NFRC/SimMan/NFRCSim6.3-2013-07Manual.pdf 